Metáforas visuais alternativas para layouts gerados por projeções multidimensionais: um estudo de caso na visualização de músicas 

SERVIÇO DE PÓS-GRADUAÇÃO DO ICMC-USP

Data de Depósito:

Assinatura:

\title{
Metáforas visuais alternativas para layouts gerados por projeções multidimensionais: um estudo de caso na visualização de músicas
}

\author{
Aurea Rossy Soriano Vargas
}

Orientadora: Profa. Dra. Maria Cristina Ferreira de Oliveira

Dissertação apresentada ao Instituto de Ciências Matemáticas e de Computação - ICMC-USP, como parte dos requisitos para obtenção do título de Mestre em Ciências - Ciências de Computação e Matemática Computacional. VERSÃO REVISADA 
Ficha catalográfica elaborada pela Biblioteca Prof. Achille Bassi e Seção Técnica de Informática, ICMC/USP, com os dados fornecidos pelo(a) autor(a)

\begin{tabular}{|c|c|}
\hline \multirow[t]{3}{*}{$\mathrm{S} 714 \mathrm{~m}$} & $\begin{array}{l}\text { Soriano Vargas, Aurea Rossy } \\
\text { Metáforas visuais alternativas para layouts } \\
\text { gerados por projeções multidimensionais: um estudo } \\
\text { de caso na visualização de músicas / Aurea Rossy } \\
\text { Soriano Vargas; orientador Maria Cristina Ferreira } \\
\text { de oliveira. -- São Carlos, } 2013 \text {. } \\
\quad 85 \text { p. }\end{array}$ \\
\hline & $\begin{array}{l}\text { Tese (Doutorado - Programa de Pós-Graduação em } \\
\text { Ciências de Computação e Matemática Computacional) -- } \\
\text { Instituto de Ciências Matemáticas e de Computação, } \\
\text { Universidade de São Paulo, } 2013 \text {. }\end{array}$ \\
\hline & $\begin{array}{l}\text { 1. Visualização Computacional. 2. Projeção } \\
\text { Multidimensional. 3. Visualização de Música. } 4 . \\
\text { Estrutura Musical. I. Ferreira de Oliveira, Maria } \\
\text { Cristina, orient. II. Título. }\end{array}$ \\
\hline
\end{tabular}


A Deus por todas as bênçãos.

A Nossa Senhora Auxiliadora, a minha eterna mãe protetora. 



\section{Agradecimentos}

A Deus e a Virgem Maria por me dar a saúde e a força para a realização deste objetivo, e encher minha vida de alegria e bênçãos.

A minha orientadora, professora Dra. Maria Cristina Ferreira de Oliveira pela orientação com paciência e carinho, pela ajuda e amizade, pela confiança em mim depositada, por não ter desesperado pelos meus excessos de espanhol, pelas suas críticas construtivas, indispensáveis na elaboração deste projeto. ¡Muchas gracias!

Aos professores Dr. Gustavo Nonato e Dr. Fernando Paulovich pelas ideias, conselhos e apoio, fundamentais para a redação do artigo e a conclusão deste trabalho.

Aos professores Dr. Ricardo da Silva Torres (UNICAMP), Dr. Fernando Paulovich e Dr. Haim Levkowitz (UMass) pelas ideias e revisões na qualificação e defesa.

Aos meus pais, Dora Cristina Vargas Núñez de Soriano e Raúl Soriano Filinich, meus tesouros, a quem eu amo profundamente, sendo os pilares em tudo na minha vida, sempre acreditaram em mim, por me estimular aos estudos desde os primeiros anos de vida, por seu apoio incondicional, e por me ensinar a lutar por meus objetivos.

A minha irmã Laura Andrea Soriano Vargas, pelo apoio e estar comigo em todos os momentos, por sempre estar atenta a qualquer coisa que aconteça comigo, apesar da distância e as lutas de irmãs, é a melhor irmã do mundo.

As minhas avózinhas, mamãe Nelly Núñez, mamãe Marlene Núñez (Pipito) e mamãe Salomé Alfaro (Salo), pelos ensinamentos, histórias, por sempre orar por mim e pelo amor; e aos meus queridos papai Jorge Vargas (Coquito), mamãe Francisca Filinich (Panchita), papai Raúl Soriano Barco, papai Marcelino Núñez, mamãe Trinidad Mendoza (Trini) e ao meu irmão, todos meus anjos, que sempre cuidam de mim desde o céu.

A meu amigo, meu colega, meu noivo Oscar Alonso Cuadros Linares, obrigada pelas ideias, pelas suas valiosas revisões, seu apoio, paciência e compreensão nos momentos mais difíceis.

À Mariela Zea Pinto, minha amiga querida, minha irmã da alma, obrigada pelas suas palavras de apoio, obrigada por estar sempre ai para mim e pela sua amizade. Ter amigas como você torna a vida mais fácil e divertida.

A minha grande e nova amiga Laura Florian Cruz, obrigada pelo seu apoio e confiança.

Ao Renato Rodrigues, obrigada pelas suas explicações do Vispipeline e revisões da dissertação, obrigada pela sua ajuda indispensável.

Aos meus familiares e amigos, que compartilharam muitos momentos alegres, obrigada por seu apoio apesar da distância. 
Ao Instituto de Ciências Matemáticas e de Computação ICMC-USP, pela oportunidade de realização do curso de mestrado. Aos professores pelos ensinamentos e aos funcionários por sempre estar dispostos na prestação dos seus serviços.

Ao Conselho Nacional de Desenvolvimento Científico e Tecnológico (CNPq) e a Fundação de Amparo à Pesquisa do Estado de São Paulo (FAPESP) pelo apoio financeiro (processos 131085/2011-5, 155367/2011-0 e 11/14165-6).

A todas as pessoas que, direta ou indiretamente, contribuíram para que este trabalho se realizasse. 
"Por vezes sentimos que aquilo que fazemos não é senão uma gota de água no mar. Mas o mar seria menor se lhe faltasse uma gota."

Madre Teresa de Calcuta 



\section{Resumo}

SORIANO VARGAS, Aurea. Metáforas visuais alternativas para layouts gerados por projeções multidimensionais: Um estudo de caso na Visualização de Músicas, 2013. Dissertação (Mestrado) - Instituto de Ciências Matemáticas e de Computação, Universidade de São Paulo, São Carlos, 2013.

Os layouts gerados por técnicas de projeção multidimensional podem ser a base para diferentes metáforas de visualização que são aplicáveis a diversos tipos de dados. Existe muito interesse em investigar metáforas alternativas à comumente usada, nuvem de pontos usada para exibir layouts gerados por projeções multidimensionais. Neste trabalho, foi estudado este problema, com foco no domínio da visualização de músicas. Existem muitas dimensões envolvidas na percepção e manipulação de músicas e portanto é difícil encontrar um modelo computacional intuitivo para representá-las. Nosso objetivo neste trabalho foi investigar as representações visuais capazes de transmitir a estrutura de uma música, assim como exibir uma coleção de músicas de modo a ressaltar as similaridades. A solução proposta consiste em uma representação icônica de músicas individuais, que é associada ao posicionamento espacial dos grupos ou coleções de músicas gerado por uma técnica de projeção multidimensional que reflete suas similaridades estruturais. Tanto a projeção quanto o ícone requerem um vetor de características para representar a música. As características são extraídas a partir de arquivos MIDI, já que a própria natureza das descrições MIDI permite a identificação das estruturas musicais relevantes. Estas características proporcionam a entrada tanto para a comparação de dissimilaridades quanto para a construção do ícone da música. Os posicionamentos espaciais são obtidos usando a técnica de projeção multidimensional Least Square Projection (LSP), e as similaridades são calculadas usando a distância Dynamic Time Warping (DTW). O ícone fornece um resumo visual das repetições de acordes em uma música em particular. Nessa dissertação são descritos os processos de geração destas representações visuais, além de descrever um sistema que implementa esses recursos e ilustrar como eles podem apoiar algumas tarefas exploratórias das coleções de músicas, identificando possíveis cenários de uso. 



\title{
Abstract
}

\author{
SORIANO VARGAS, Aurea. Alternative visual metaphors for layouts \\ generated by multidimensional projections: A case study in Visualiza- \\ tion of Music, 2013. Dissertation (Master) - Institute of Mathematics and \\ Computer Science, University of São Paulo, São Carlos, 2013.
}

The layouts generated by multidimensional projection techniques can be the basis for different visualization metaphors that are applicable to various data types. There is much interest in investigating alternatives to the point cloud metaphor commonly used to present projection layouts. In this work, we investigated this problem, targeting the domain of music visualization. There are many dimensions involved in the perception and manipulation of music and therefore it is difficult to find an intuitive computer model to represent music. Our goal in this work was to investigate visual representations capable of conveying the musical structure of a song, as well as displaying a collection of songs so as to highlight their similarities. The proposed solution consists of an iconic representation for individual songs, that is associated with the spatial positioning of groups or collections of songs generated by a multidimensional projection technique that reflects their structural similarity. Both the projection and the icon require a feature vector representation of the music. The features are extracted from MIDI files, as the nature of the MIDI descriptions allows the identification of the relevant musical structures. These features provide the input for both the dissimilarity comparison and for constructing the music icon. The spatial layout is computed with the Least Square Projection (LSP) technique, and similarities are computed using the Dynamic Time Warping (DTW) distance. The icon provides a visual summary of the chord repetitions in a particular song. We describe the process of generating these visual representations, describe a system that implements such funcionalities and illustrate how they can support some exploratory tasks on music collections, identifying possible usage scenarios. 



\section{Sumário}

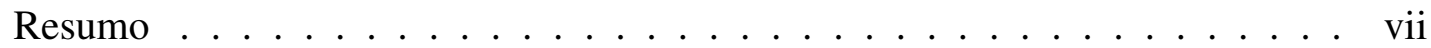

Abstract .................... ix

Sumário .............................. xi

Lista de Figuras . . . . . . . . . . . . . . . . . . xiii

Lista de Tabelas . . . . . . . . . . . . . . . . . . xvii

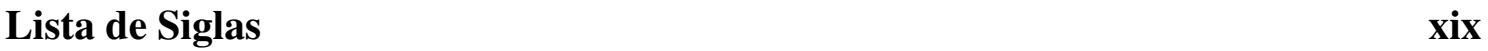

1 Introdução 1

2 Técnicas de posicionamento de pontos por similaridade 5

2.1 Considerações Iniciais . . . . . . . . . . . . . . . . 5

2.2 Projeção Multidimensional: Least Square Projection (LSP) . . . . . . . 6

2.3 Árvore Filogenética: Neighbor-Joining (NJ) . . . . . . . . . . . . . . . . 9

2.4 Considerações finais . . . . . . . . . . . . . . . . . . . 12

3 Visualização por agregação $\quad 13$

3.1 Considerações Iniciais . . . . . . . . . . . . . . . . . . . 13

3.2 Abordagens baseadas no conceito de Splatting . . . . . . . . . . . . . . 13

3.2.1 GraphSplatting . . . . . . . . . . . . . . . . . 14

3.2.2 Splatting de linhas em Coordenadas Paralelas . . . . . . . . . . 17

3.3 Abordagens baseadas na representação e exibição de uma hierarquia . . . 20

3.3.1 Agregação Hierárquica em Visualização de Informação . . . . . . 20

3.3.2 HiPP: Projeção por Posicionamento Hierárquico . . . . . . . . . 21

3.4 Considerações finais . . . . . . . . . . . . . . . . . 23

4 Visualização de música

4.1 Considerações Iniciais . . . . . . . . . . . . . . . . . 25

4.2 Visualizações de uma coleção de músicas . . . . . . . . . . . . . . . 25

4.2.1 Visualizações usando tags . . . . . . . . . . . . . . 26

4.2.2 Visualizações usando características extraídas do sinal . . . . . . 28

4.3 Visualizações de músicas individuais . . . . . . . . . . . . . . . . . 32 
5 Processo de Visualização de Músicas $\quad 35$

5.1 Considerações Iniciais . . . . . . . . . . . . . . . . . . . . . . . . . . . 35

5.2 Conceitos básicos sobre teoria musical . . . . . . . . . . . . 35

5.3 Musical Instrument Digital Interface (MIDI) . . . . . . . . . . . . . 40

5.4 Extração de características . . . . . . . . . . . . . . . . . . 41

5.4.1 Estrutura musical . . . . . . . . . . . . . . . . 42

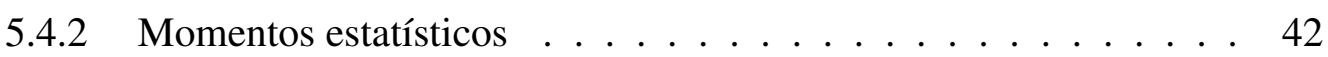

5.4 .3 Histograma de notas ... . . . . . . . . . . . . . . . 44

5.4.4 Características extraídas usando JSymbolic . . . . . . . . . . . . 44

5.5 Representação icônica da música . . . . . . . . . . . . . . . . . . . . 44

5.6 Mapas de similaridade . . . . . . . . . . . . . . . . . 47

5.7 Representações por densidade . . . . . . . . . . . . . . . . 52

5.8 Representação por distribuição espacial . . . . . . . . . . . . . . 53

6 Resultados

6.1 Considerações Iniciais . . . . . . . . . . . . . . . . . . . . . 59

6.2 Sistema de Visualização . . . . . . . . . . . . . . . . . . . 60

6.3 Experimento 1: Comparação das técnicas de representação por densidade 66

6.4 Experimento 2: Comparação das técnicas de extração de características . 69

6.5 Experimento 3: Estrutura versus gênero . . . . . . . . . . . . . . . 70

6.6 Experimento 4: Identificando versões das músicas . . . . . . . . . . . . 74

6.7 Experimento 5: Variações temporais de uma banda . . . . . . . . . . . 75

7 Conclusões $\quad \mathbf{7 7}$

7.1 Discussões, limitações e trabalhos futuros . . . . . . . . . . . . . . . 78

Referências $\quad 85$ 


\section{Lista de Figuras}

1.1 Mapa de similaridade de uma coleção de 6.174 músicas projetada com a técnica LSP. As cores indicam diferentes categorias musicais. . . . . . . 3

2.1 Uma coleção de 1.396 músicas projetada com a técnica LSP, a cor de cada círculo indica o agrupamento à qual a música pertence: azul para música clássica, cinza para jazz, vermelho para rock e verde para sertanejo. Notar que a maioria dos círculos cinzas estão sobrepostos aos azuis. . . . . . . . 8

2.2 Exemplo de exibições mais usadas para exibir árvores filogenéticas. (a) Cladograma. (b) Filograma. (c) Radial. Fonte: (Carrizo, 2004) . . . . . . 9

2.3 (a) Exemplo de árvore de similaridade de um conjunto de imagens utilizando a técnica NJ. (b) O mesmo exemplo exibindo as imagens associadas. Fonte: (Souza Paiva, 2011) . . . . . . . . . . . . . . 10

2.4 Promoção: Operação que substitui um nó por um nó folha quando existe uma certa configuração. Os círculos preenchidos representam objetos atuais e os triângulos representam subárvores. Fonte: (Paiva et al., 2011). . . 11

2.5 Exemplo de diferentes configurações para a árvore na visualização de 1.000 elementos do conjunto de dados Corel. Empregando a estratégia de promoção de nós, o espaço visual é melhor aproveitado (Figura b), dada a diminuição da quantidade de nós virtuais presentes na abordagem original (Figura a). Fonte: (Paiva et al., 2011). . . . . . . . . . . . . . 11

3.1 Contribuições de todos os pontos para o ponto atual. . . . . . . . . . . 15

3.2 A matriz Gaussiana é multiplicada pelo resultado da função $M$ para gerar o campo splat a ser visualizado na tela. . . . . . . . . . . . . . . 16

3.3 (a) Exemplo com 40 pontos. (b) Splatting com valor menor de $\sigma$. (c) Splatting com valor maior de $\sigma$. Fonte: (Van Liere e De Leeuw, 2003) . . 16

3.4 Grupos representados com cores diferentes. Fonte: (Zhou et al., 2009) . . 18

3.5 Exibição de um banco de dados sintético. (a) Coordenadas paralelas Originais (b) Com splatting depois de 800 iterações. (c) Com splatting depois de 2.000 iterações (d) Resultado do splatting com cores indicando diferentes agrupamentos. Fonte: (Zhou et al., 2009) . . . . . . . . . . . .

3.6 Trajetos de visualizações de agregação hierárquica. As setas indicam a altura atual da agregação. Nós brancos são renderizados enquanto os nós pretos são omitidos. Fonte: (Elmqvist e Fekete, 2010) . . . . . . . . . . . 
3.7 Coordenadas Paralelas de um conjunto de dados com 8 dimensões. Fonte: (Elmqvist e Fekete, 2010) . . . . . . . . . . . . . . . . . .

3.8 Mapa de 675 documentos de quatro áreas distintas gerado pela técnica HiPP. O primeiro nível representa os agrupamentos mais abstratos, e os níveis subsequentes representam sub-grupos mais detalhados até instâncias de dados individuais. Fonte: (Paulovich e Minghim, 2008) . . . . . .

4.1 Visualizações alternativas de uma coleção de músicas. Fonte: Torrens et al. (2004) . . . . . . . . . . . . . . . . . . . 26

4.2 Exemplo de uma coleção de músicas de tamanho médio (Os autores não especificaram o número de músicas). Fonte: Dalhuijsen e van Velthoven (2010) . . . . . . . . . . . . . . . . . . . 27

4.3 Islands of music apresentando 77 músicas. Fonte: Pampalk (2001) . . . . 28

4.4 Visualização de músicas em um iPaq PDA. Fonte: Neumayer et al. (2005) 29

4.5 Soundsieve obtido para a música Fur Elise, de Beethoven. Fonte: Lillie (2008) . . . . . . . . . . . . . . . . . . 30

4.6 Imagem da tela de MusicBox. Fonte: Lillie (2008) . . . . . . . . . . . . . 30

4.7 Exemplo da visualização por grafo, e da visão de detalhe relativa a uma região selecionada. Fonte: Muelder et al. (2010) . . . . . . . . . . . . . .

4.8 Exemplo de desenhos de listas de reprodução em um mapa com 45 artistas. O agrupamento está baseado no ano de lançamento. Fonte: Van Gulik e Vignoli (2005) . . . . . . . . . . . . . . . . . . . .

4.9 Visualização MIDIvis da música The Magical Mystery Tour, dos Beatles. Fonte: Wolkowicz et al. (2009) . . . . . . . . . . . . . . . . . . . . 32

4.10 Scape plot estruturado da música While My Guitar Gently Weeps, dos Beatles. Nesta figura é refletida a forma musical em geral, na qual cada um dos quatro segmentos verso consiste de subpartes repetidas, $I$ é a introdução e $O$ é o outro (conclusão ou epílogo de uma música). Fonte: Müller e Jiang (2012) . . . . . . . . . . . . . . . . . . . . . . . .

4.11 The Shape of Song para a música Like a prayer, de Madonna. Fonte: http://www.turbulence.org/Works/song/ . . . . . . . . . . . . . . 34

4.12 The Shape of Song para a música Fur Elise, de Beethoven. Fonte: Wattenberg (2002) . . . . . . . . . . . . . . . . . . 34

5.1 Visão global do processo de visualização de músicas. . . . . . . . . . . . 36

5.2 Barra divisória. . . . . . . . . . . . . . . . 38

5.3 Processo de reconhecimento de acordes . . . . . . . . . . . . . . . 42

5.4 Exemplo de um histograma de notas. . . . . . . . . . . . . . . . . 44

5.5 Imagem da interface do JSymbolic. Fonte: McKay (2010). . . . . . . . . 45

5.6 Etapas do processo de criação de um ícone da música. . . . . . . . . . . . 46

5.7 (a) Ícone da estrutura musical da música Wind of change, dos Scorpions, e (b) seu vetor de características correspondente, visto como uma série temporal.

5.8 Resultados visuais das diversas técnicas estudadas de projeção multidimensional, para um conjunto de 1.300 músicas distribuídas em três gêneros musicais. A cor de cada círculo indica o agrupamento: azul para música clássica, vermelho para rock e verde para sertanejo. . . . . . . . . 
5.9 Resultados visuais das diversas técnicas estudadas de projeção multidimensional, para um conjunto de 1.300 músicas distribuídas em três gêneros musicais. A cor de cada círculo indica o agrupamento: azul para música clássica, vermelho para rock e verde para sertanejo. . . . . . . . .

5.10 Resultados visuais das diversas técnicas estudadas de projeção multidimensional, para um conjunto de 1.300 músicas distribuídas em três gêneros musicais. A cor de cada círculo indica o agrupamento: azul para música clássica, vermelho para rock e verde para sertanejo. . . . . . . . . 51

5.11 Splatting com vizinhos mais próximos. . . . . . . . . . . . 53

5.12 Pontos a contribuir no Nearest Neighbors Splatting. (Passo a passo). . . . 54

5.13 Representação de distribuição espacial de uma coleção de 1.970 músicas. 55

5.14 Estrutura Axis Aligned Bounding Square (AABS). . . . . . . . . . . . . 57

6.1 Interface do sistema de visualização de músicas desenvolvido neste trabalho. 61

6.2 Botões na parte superior da região 2 do sistema de visualização. . . . . . . 61

6.3 Duas maneiras de fazer zoom: (a) Interagindo com o mouse e (b) Usando uma lente. . . . . . . . . . . . . . . . . 62

6.4 Resultados visuais para os botões das Figuras 6.2.c, 6.2.e e 6.2.f, respectivamente. . . . . . . . . . . . . . . . 62

6.5 Resultados visuais para as 5 maneiras de exibir os elementos do conjunto de dados. . . . . . . . . . . . . . . . . . . 63

6.6 Resultados dos dois tipos de feedback visual implementados. . . . . . . . 64

6.7 Botões na parte inferior da região 2 do sistema de visualização. . . . . . . . 64

6.8 Resultados visuais relativos às funcionalidades dos botões das Figuras 6.7.a, 6.7.b, 6.7.c, 6.7.d e 6.7.e. . . . . . . . . . . . . . 65

6.9 Gráficos gerados para os tempos de processamento das técnicas de representação por densidade. . . . . . . . . . . . . . . . . .

6.10 Resultados visuais das técnicas de representação por densidade do conjunto de 1.300 músicas. (GS = GraphSplatting, TS = Triangular Splatting, NNS = Nearest Neighbors Splatting, GB = Desfocagem Gaussiana, $\mathrm{AS}=$ Aproximação baseada na sobreposição e AR =Aproximação consi-

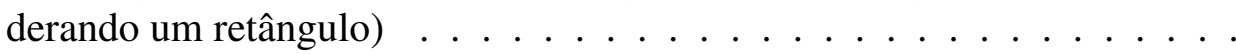

6.11 Representação iconográfica de uma seleção de músicas do mapa de similaridade, na qual nota-se que foram posicionadas como vizinhas duas versões distintas da música Friends in low places de Garth Brooks. . . . . .

6.12 Projeções do conjunto de 1.300 músicas geradas com a LSP a partir dos vetores de características obtidos por meio das técnicas de extração. As cores dos círculos indicam o gênero musical, azul para música clássica, vermelho para rock e verde para sertanejo. . . . . . . . . . . . . . .

6.13 Mapa de similaridades de 1.300 músicas, com mostras de música clássica (azul), rock (vermelho) e sertanejo (verde), e seus ícones musicais relativos ás seleções.

6.14 Mapa de similaridades de 1.396 músicas, com mostras de música clássica (azul), jazz (cinza), rock (vermelho) e sertanejo (verde), e seus ícones musicais relativos ás seleções. . . . . . . . . . . . . . . . 73

6.15 Ícones das estruturas para exemplos de jazz e música clássica na coleção. 73 
6.16 Metáfora de ícones representativos por célula da projeção do conjunto de 1.300 músicas. . . . . . . . . . . . . . . . . . . . . . 74

6.17 Os ícones musicais revelam diferencias em múltiplas versões (arquivos MIDI) de uma música. . . . . . . . . . . . . . . . . . . 76

6.18 Visão geral das músicas do Beatles, em diferentes épocas da sua produção, e as vistas detalhadas das estruturas das músicas de cada período

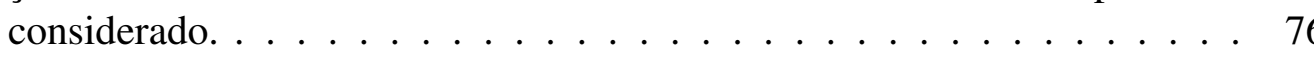




\section{Lista de Tabelas}

5.1 Figuras musicais: unidades do tempo. . . . . . . . . . . . . . . 37

5.2 Armadura chave. . . . . . . . . . . . . . . . . . 39

5.3 Tríades de um acorde maior . . . . . . . . . . . . . . . . . 39

5.4 Tríades de um acorde menor . . . . . . . . . . . . . . . . . . 39

5.5 Campos harmônicos para cada tonalidade maior . . . . . . . . . . . . 40

5.6 Campos harmônicos para cada tonalidade menor . . . . . . . . . . 40

6.1 Conteúdo da coleção de música em formato MIDI. . . . . . . . . . . . . . 60

6.2 Tempos de processamento, em segundos, das técnicas de representação por densidade. $(\mathrm{GS}=$ GraphSplatting, $\mathrm{TS}=$ Triangular Splatting, NNS = Nearest Neighbors Splatting, GB = Desfocagem Gaussiana, AS = Aproximação baseada na sobreposição e $\mathrm{AR}=$ =Aproximação considerando um

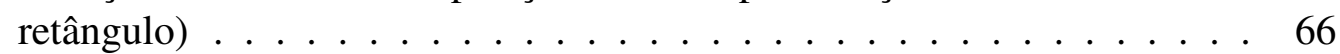





\title{
Lista de Siglas
}

\author{
AABB Axis Aligned Bounding Box \\ AABS Axis Aligned Bounding Square \\ CPU Central Processing Unit \\ DNA Deoxyribonucleic acid \\ DTW Dynamic Time Warping
}

Glimmer MDS multinível na GPU

LAMP Local Affine Multidimensional Projection

LSP Least Square Projection

MIDI Musical Instrument Digital Interface

MDS Multidimensional Scaling

NNS Nearest Neighbors Splatting

NJ Neighbor-Joining

PCA Principal Component Analysis

PLMP Part-Linear Multidimensional Projection

PLP Piecewise Laplacian Projection

PLSP Piecewise Least Square Projection

PPQN Parts per quarter note

PNJ Promoting Neighbor Joining

SOM Self-organizing map 



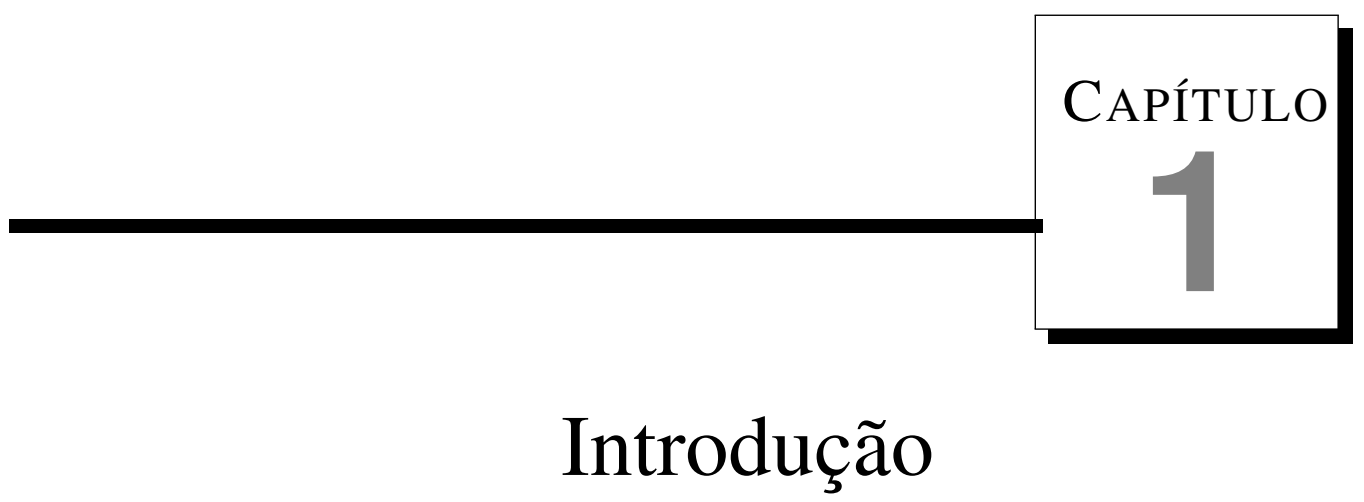

\section{Segundo o dicionário Shorter Oxford English, visualizar é construir na mente uma representação visual.}

Uma das características que distinguem a espécie humana de outras espécies é a sua capacidade de internalizar e processar dados, transformando-os em conhecimento. Desde os primórdios da humanidade são utilizadas representações gráficas como meio de comunicar esse conhecimento, sendo uma necessidade do nosso cotidiano.

A revolução da informação mudou a maneira como muitas pessoas vivem e pensam. O avanço exponencial da tecnologia da informação, torna cada vez mais simples e rápido, produzir, armazenar, publicar e disseminar dados. Nesse contexto, a busca por informações úteis torna-se frustrante, uma vez que é praticamente impossível uma pessoa identificar tendências e padrões em dados brutos.

Esse cenário motivou a área de Visualização de Informação, sendo utilizada para revelar padrões subjacentes a estes dados e tornar o conhecimento compreensível, discriminando dados irrelevantes para algumas necessidades e interesses, a fim de evitar a sobrecarga. Gershon (1992) afirma que: "Visualização é mais do que um método de computação, é o processo de transformar dados em uma representação visual".

Tradicionalmente, pode-se distinguir a área de visualização entre duas grandes categorias: Visualização Científica e Visualização da Informação. Embora as duas manipulem com dados não visíveis, a primeira se refere a dados físicos, como a visualização de moléculas, DNA, órgãos humanos, o universo, entre outros; e a segunda a dados abstratos, 
estruturas não visíveis como a colaboração entre pesquisadores ou a similaridade semântica entre documentos (Polanco e Zartl, 2002).

A Visualização Computacional é uma área relativamente jovem, de interesse transversal e interdisciplinar, e ainda com muitos problemas em aberto. Um desses problemas é como tratar o excesso de dados, outro é a dificuldade de interpretar e analisar dados descritos por muitos atributos. Uma solução alternativa é utilizar projeções multidimensionais, que permitem mapear os vetores de atributos que descrevem os dados como pontos em um espaço de baixa dimensionalidade, de acordo com uma medida de (dis)similaridade. Cada instância de dados é visualmente associada a um marcador gráfico, por exemplo um círculo. Como resultado final, é obtida uma visualização denominada "mapa de similaridade" ou layout. O objetivo desse mapa é oferecer uma visão global do conjunto de dados, refletindo as vizinhanças no espaço multidimensional, a partir da qual o usuário pode identificar visualmente grupos de elementos (dis)similares, e visualizar esses grupos em busca de informações adicionais.

Entretanto, é fato que usuários têm certa dificuldade em interagir com esses mapas representados como nuvens de pontos. Um dos problemas é que se trata de uma representação abstrata que não é, necessariamente, intuitiva. As dificuldades aumentam quando um grande número de objetos é exibido, devido à sobreposição de elementos e sobrecarga visual decorrente, que dificultam a identificação de grupos de interesse, ainda que eles existam, como ilustrado na Figura 1.1.

A Figura 1.1 ilustra um mapa de similaridade, obtido com a técnica de projeção multidimensional Least Square Projection (LSP) (Paulovich et al., 2008), de uma coleção de 6.174 músicas, distribuídas em diferentes gêneros musicais. A técnica LSP foi aplicada sobre a matriz de distâncias, computada a partir de uma representação das estruturas de um conjunto de músicas, extraída de sua descrição em formato MIDI. Para calcular a distância entre duas estruturas foi utilizada a medida de similaridade Dynamic Time Warping (DTW) (Berndt e Clifford, 1994). A cor de cada círculo indica a categoria musical. Note que a sobreposição dos círculos na representação dificulta a interpretação. Ademais, os círculos não fornecem informação que ajude a identificar uma música em particular, ou a interpretar os grupos. Este problema ocorre em diversos domínios de aplicação, como por exemplo o domínio da música.

Coleções de músicas estão amplamente disponíveis na Web, em decorrência da facilidade de intercâmbio de arquivos, da proliferação de redes peer-to-peer e de lojas de música na Web, que têm facilitado a coleta de grandes quantidades de áudio, em diversos formatos como Mp3, MIDI e outros. Nesse cenário, é importante criar representações visuais que facilitem a manipulação de coleções de músicas.

A visualização de músicas requer um pré-processamento, no qual a música é descrita 


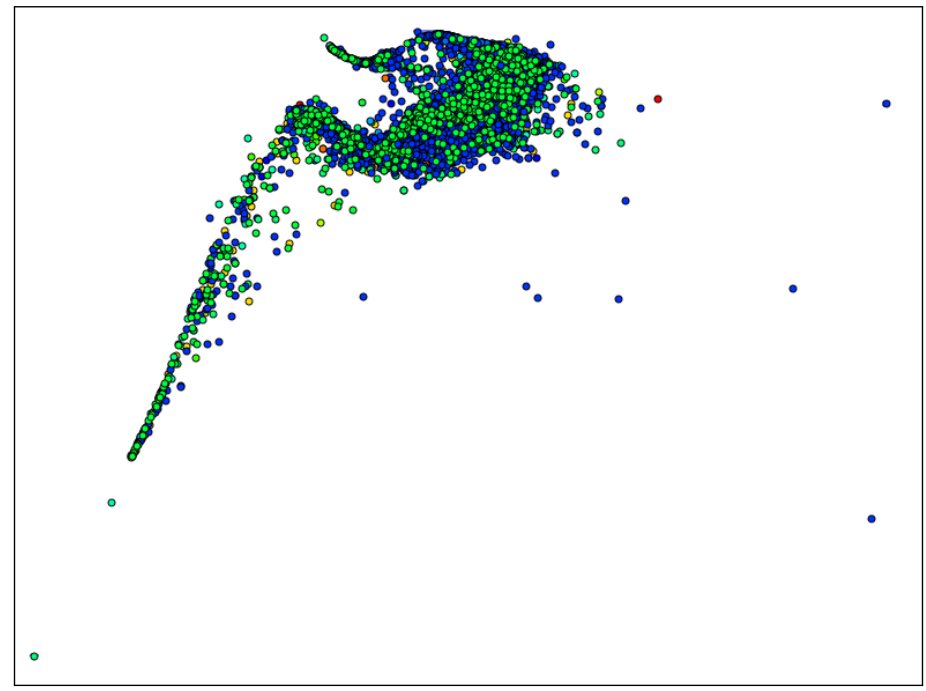

Figura 1.1: Mapa de similaridade de uma coleção de 6.174 músicas projetada com a técnica LSP. As cores indicam diferentes categorias musicais.

por um vetor de características. Geralmente tais vetores são gerados a partir de metadados fornecidos pela gravadora ou pelos usuários, a partir de espectrogramas (Yang, 2001), de históricos de reprodução ou histogramas (Lartillot et al., 2007). Neste trabalho, estes vetores são obtidos a partir de estruturas musicais das descrições no MIDI, uma vez que estas estruturas são independentes dos dados fornecidos pelos usuários, os quais apresentam erros, ambiguidades e subjetividades. Uma vez obtidos, eles podem ser usados em diferentes metáforas de visualização, possivelmente após um processo de redução de dimensionalidade.

A representação MIDI das músicas inclui dados sobre as notas, suas velocidades e os instrumentos usados. Essas informações não podem ser extraídas facilmente de outros formatos. O formato MIDI facilita o tratamento e análise da música de forma mais intuitiva do que uma representação do sinal de áudio, além de não apresentar ruído. Nossa escolha é ainda mais motivada pelo fato de que o MIDI é o formato adotado pelas gravadoras e profissionais da música, e como tal, fornece a interessante e, potencialmente confiável, fonte de informações para a experimentação de novas soluções de visualização de música.

Neste trabalho, propomos metáforas alternativas à representação por nuvem de pontos dos layouts. Uma das metáforas propostas permite representar o conjunto de dados por densidade, o que revela uma ideia global das áreas de maior incidência e os agrupamentos formados. Esta metáfora é interativa e proporciona uma transição entre os diferentes níveis de detalhe, partindo de uma visão global até chegar ao nível de informação desejado pelo usuário, capaz de revelar relacionamentos relevantes dentro de um sub-grupo de interesse. Esta metáfora não é restrita a um domínio específico de aplicação. 
Além disso, apresentamos uma nova metodologia para a visualização de músicas. Mais especificamente, apresentamos um novo mecanismo para extrair estruturas a partir das músicas, permitindo medir a similaridade entre elas, bem como construir representações visuais. As metáforas visuais propostas favorecem a análise das estruturas das músicas de forma individual e coletiva. Baseia-se em uma representação icônica combinada com o posicionamento espacial fornecido pelos layouts que refletem a semelhança estrutural das músicas, informação que pode ser útil em diversos contextos exploratórios. O posicionamento espacial com base na similaridade é obtido projetando os vetores de características com a técnica de projeção multidimensional Least Square Projection (LSP) (Paulovich et al., 2008), avaliando as similaridades com a distância Dynamic Time Warping (DTW) (Berndt e Clifford, 1994).

Esta dissertação está estruturada da seguinte forma:

- O Capítulo 2 apresenta uma revisão bibliográfica sobre as técnicas de posicionamento de pontos por similaridade. Neste capítulo, é descrita detalhadamente a técnica de projeção multidimensional Least Square Projection (LSP), que é a base para a geração dos posicionamentos no mapa de similaridade.

- O Capítulo 3 apresenta uma revisão bibliográfica sobre algumas técnicas recentes de Visualização de Informação que consideram diferentes abordagens de agregação visual para lidar com grandes conjuntos de dados, as quais podem ser usadas sobre coleções de músicas.

- O Capítulo 4 apresenta uma revisão bibliográfica sobre visualizações de música, que visam gerar uma representação visual de coleções de músicas e a representação individual de uma peça musical.

- O Capítulo 5 apresenta o processo adotado neste trabalho para a visualização de músicas, descrevendo alguns conceitos relevantes para o entendimento da abordagem adotada, as diferentes formas de extrair as características do conjunto de músicas e os processos de geração das representações visuais propostas.

- O Capítulo 6 apresenta a descrição do sistema que implementa os recursos do Capítulo 5 com as funcionalidades principais, os experimentos realizados com as visualizações propostas e exemplos das tarefas exploratórias das coleções de músicas que elas apoiam.

- Finalmente, no Capítulo 7, são apresentadas as conclusões deste trabalho, contribuições, limitações e possíveis trabalhos futuros. 


\section{- \\ Técnicas de posicionamento de pontos por similaridade}

Quando a informação é organizada, as ideias surgem (Jim Rohn).

\subsection{Considerações Iniciais}

Dentro das técnicas de posicionamento de pontos por similaridade, encontramos as técnicas de projeção multidimensional e as árvores filogenéticas.

As técnicas de projeção multidimensional têm como objetivo mapear de forma injetiva os pontos de um espaço multidimensional em outro espaço de menor dimensionalidade, buscando preservar informação relevante sobre as relações de distância ou de vizinhança entre as instâncias de dados (Paulovich, 2008).

Entretanto, exibir o resultado das projeções multidimensionais usando a típica representação de nuvem de pontos pode apresentar alguns problemas, como a sobreposição de instâncias. Como alternativa pode ser considerada a técnica Neighbor-Joining (NJ), usada na construção de árvores filogenéticas, que refletem a percepção de similaridade entre as instâncias de dados a partir do posicionamento de pontos na hierarquia da árvore. A seguir apresentamos alguns conceitos básicos das técnicas de projeção multidimensional e das árvores filogenéticas. 


\subsection{Projeção Multidimensional: Least Square Projec- tion (LSP)}

Seja $X$ um conjunto de dados em $\mathbb{R}^{m}$ com $\delta: \mathbb{R}^{m} \times \mathbb{R}^{m} \rightarrow \mathbb{R}$ um critério de proximidade entre os dados em $\mathbb{R}^{m}$, seja $Y$ um conjunto de pontos em $\mathbb{R}^{d}, d=\{1,2,3\} \mathrm{e}$ dis $: \mathbb{R}^{d} \times \mathbb{R}^{d} \rightarrow \mathbb{R}$ um critério de proximidade em $\mathbb{R}^{d}$. Uma técnica de projeção multidimensional pode ser descrita como uma função $f: X \rightarrow Y$ que visa tornar $\mid \delta\left(x_{i}, x_{j}\right)-$ $\operatorname{dis}\left(f\left(x_{i}\right), f\left(x_{j}\right)\right) \mid$ o mais próximo possível de zero, $\forall x_{i}, x_{j} \in X$ (Tejada et al., 2003).

Assim, cada ponto do conjunto $Y$ representa uma instância dos dados, refletindo informações sobre a estrutura e distribuição do conjunto de dados, tais como a proximidade entre pares de instâncias, a formação de grupos ou o relacionamento entre tais grupos. Estes pontos podem ser usados para gerar uma representação visual. Os elementos posicionados próximos uns aos outros na representação indicam que as instâncias de dados que eles representam são similares, com relação a uma certa medida de (dis)similaridade. A criação de uma matriz de (dis)similaridade é necessária como base para a projeção.

Foram estudadas várias técnicas de projeção multidimensional, e foram analisados seus resultados visuais, os quais mostraram que a técnica Least Square Projection (LSP) é adequada para as representações propostas, o qual será mostrado no decorrer da dissertação. A Least Square Projection (LSP) é uma técnica proposta por Paulovich et al. (2008), baseada na solução de sistemas lineares. Inicialmente, a técnica considera um subconjunto de pontos fornecido pelo usuário, chamados pontos de controle, os quais são projetados no espaço visual por algum método de redução de dimensionalidade que preserve as relações de distância com precisão. Depois, constrói sistemas lineares considerando as relações de similaridade entre os pontos do espaço original e as respectivas coordenadas cartesianas dos pontos de controle. A solução desses sistemas lineares define as posições restantes no espaço de menor dimensionalidade.

Dado um conjunto de pontos de $S=p_{1}, \ldots, p_{n}$, em $\mathbb{R}^{m}$, o algoritmo visa representar os pontos de $S$ em um de menor dimensionalidade $\mathbb{R}^{d}$, sendo $d \leqslant m$, de modo a preservar a relação de vizinhança entre os pontos, tanto quanto seja possível. Para construir os sistemas lineares, é necessário definir um conjunto de pontos vizinhos $k_{i}, V_{i}=p_{i_{1}}, \ldots, p_{i_{k}}$ em uma vizinhança de um ponto $p_{i}$, e $\tilde{p}_{i}$ é a coordenada de $p_{i}$ no espaço $d$-dimensional.

Se a Equação 2.1 é válida para os pontos no espaço $m$-dimensional, então cada $p_{i}$ está no fecho convexo dos pontos em $V_{i}$. Particularmente, quando $\alpha_{i j}=\frac{1}{k_{i}}$, então $p_{i}$ está no centróide dos pontos em $V_{i}$.

$$
\begin{aligned}
& \tilde{p}_{i}-\sum_{p_{j} \in V_{i}} \alpha_{i j} \tilde{p}_{j}=0 \\
& 0 \leq \alpha_{i j} \leq 1 ; \sum \alpha_{i j}=1
\end{aligned}
$$


A Equação 2.1 dá origem a um conjunto de sistemas lineares (Equação 2.2) a partir do qual é possível calcular as coordenadas dos pontos $\tilde{p}_{i}$.

$$
L x_{1}=0, L x_{2}=0, \ldots L x_{d}=0
$$

na qual $x_{1}, x_{2}, \ldots, x_{d}$ são os vetores contendo as coordenadas cartesianas $\left(x_{1}, \ldots, x_{n}\right)$ dos pontos e $L$ é a matriz $n \times n$, cujas entradas são dadas por:

$$
l_{i j}=\left\{\begin{array}{cc}
1 & i=j \\
-\alpha_{i j} & p_{j} \in V_{i} \\
0 & \text { caso contrário }
\end{array}\right.
$$

Informação geométrica é adicionada ao sistema, através das projeções de alguns pontos de $S$ no espaço $d$ dimensional, chamados pontos de controle. Os pontos de controle são adicionados ao sistema linear como novas filas na matriz. As coordenadas cartesianas dos pontos de controle são adicionadas ao lado direito do sistema. Assim, dado um conjunto de pontos de controle $S_{c}=\left\{p_{c_{1}}, \ldots, p_{c_{n c}}\right\}$, a Equação 2.2 pode ser reescrita na forma:

$$
A \mathbf{x}=\mathbf{b}
$$

na qual $A$ é uma matriz retangular $(n+n c) \times n$ dada pela Equação 2.5.

$$
A\left(\begin{array}{l}
L \\
C
\end{array}\right), c_{i j}=\left\{\begin{array}{cc}
1 & \text { se } p_{j} \text { é um ponto de controle } \\
0 & \text { caso contrário }
\end{array}\right.
$$

e b é o vetor:

$$
b_{i}=\left\{\begin{array}{cc}
0 & i \leqslant n \\
x_{p_{c_{i}}} & n<i \leqslant n+n c
\end{array}\right.
$$

na qual $x_{p_{c_{i}}}$ é a coordenada cartesiana do ponto de controle $p_{c_{i}}$. O sistema linear com os pontos de controles pode ser resolvido com mínimos quadrados, assim temos que encontrar $\mathbf{x}$ que minimize $\|A x-b\|^{2}$, sendo $\mathbf{x}=\left(A^{T} A\right)^{-1} A^{T} \mathbf{b}$. Assim, o sistema a ser resolvido $A^{T} A \mathbf{x}=A^{T} \mathbf{b}$ é simétrico e esparso, facilitando a sua solução. Para escolher os pontos de controles, o conjunto de dados é dividido em $n c$ conjuntos utilizando o algoritmo $k$-medoids, e o ponto mais próximo ao centróide de cada agrupamento é utilizado como ponto de controle. Os pontos de controle são projetados com alguma técnica multidimensional scaling como: force scheme ou sammom mapping.

A complexidade global da LSP pode ser definida como $O(C+V+S)$, em que $C$ é a complexidade de escolher pontos de controle, $V$ é a complexidade para definir a vizi- 
nhança, e $S$ é a complexidade para resolver o sistema linear. Se foram escolhidos $\sqrt{n}$ pontos de controle, sendo $n$ o número total de pontos, então $C=V=O\left(n^{\frac{3}{2}}\right)$. Como os sistemas lineares são simétricos e definidos positivos, um método de solução iterativa pode ser aplicado. Nesse caso, a complexidade para resolver esse sistema linear é $O(n \sqrt{k})$, na qual $k$ é o número de condição da matriz $A^{T} A$, usada para calcular os vetores das coordenadas cartesianas dos pontos. Assim, a complexidade final da LSP seria $O\left(\max \left\{n^{\frac{3}{2}}, n \sqrt{k}\right\}\right)$. A LSP é capaz de projetar grandes conjuntos de dados; os autores fizeram testes com até 30.000 instâncias de dados, de alta dimensionalidade em um tempo computacional satisfatório, reconstruindo bem as medidas de similaridade originais Paulovich et al. (2008).

A Figura 2.1 ilustra uma projeção obtida com a técnica LSP de uma coleção de 1.396 músicas em formato MIDI, cujos vetores de características estão baseados na estrutura musical, distribuídas em quatro gêneros musicais. A técnica LSP foi aplicada sobre a matriz de distâncias computada a partir dos vetores de características das estruturas do conjunto de músicas, gerados neste projeto (Capítulo 5). Para calcular a distância, foi utilizada a medida de similaridade Dynamic Time Warping (DTW). A cor de cada círculo indica o agrupamento à qual a música pertence: azul para música clássica, cinza para jazz, vermelho para rock e verde para sertanejo. Notar que a maioria dos círculos cinzas estão sobrepostos aos azuis.

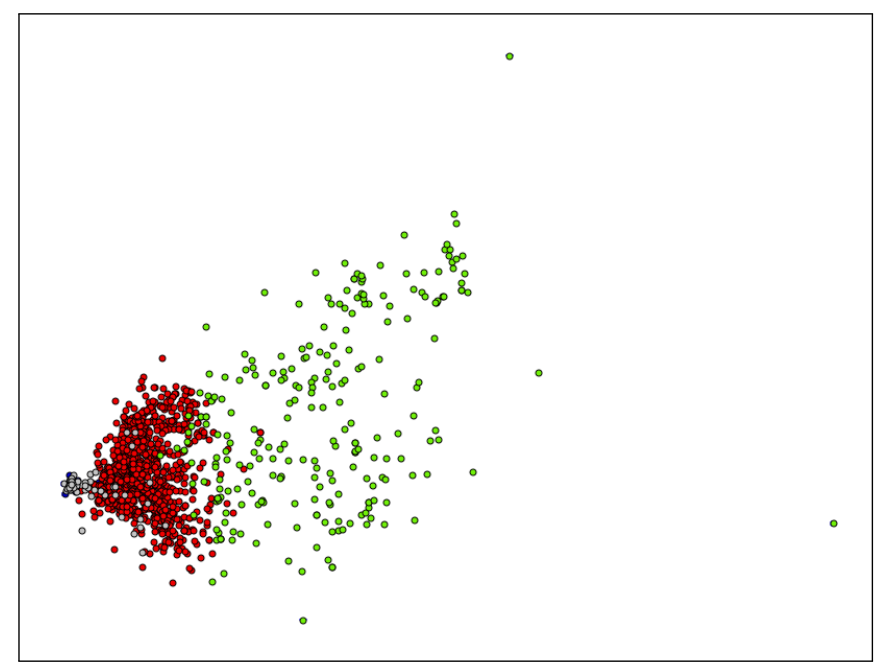

Figura 2.1: Uma coleção de 1.396 músicas projetada com a técnica LSP, a cor de cada círculo indica o agrupamento à qual a música pertence: azul para música clássica, cinza para jazz, vermelho para rock e verde para sertanejo. Notar que a maioria dos círculos cinzas estão sobrepostos aos azuis. 


\section{3 Árvore Filogenética: Neighbor-Joining (NJ)}

Uma árvore filogenética representa as relações evolutivas dentro de um grupo de espécies. As folhas representam espécies atuais e nós internos representantes ancestrais. As arestas representam as relações entre espécies e o seu comprimento pode indicar a distância evolutivas entre elas. Em visualização, uma árvore filogenética é representada por um grafo acíclico, totalmente conectado, em que cada folha representa uma instância de dados distinta e cada aresta representa a relação e a distância entre duas instâncias (Paiva et al., 2011). Na Figura 2.2, são apresentadas as formas mais utilizadas para exibir árvores filogenéticas: filograma, radial e cladograma inclinado, segundo (Carrizo, 2004).

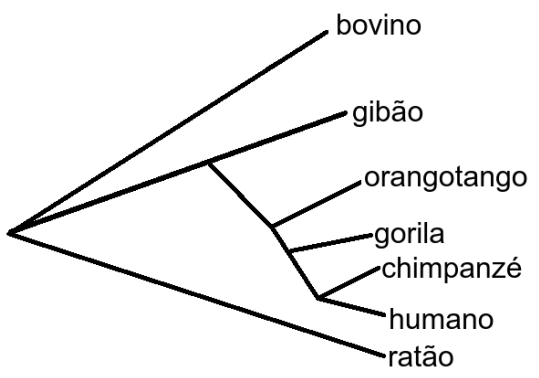

(a)

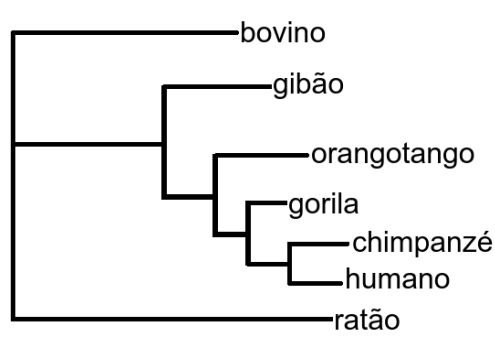

(b)

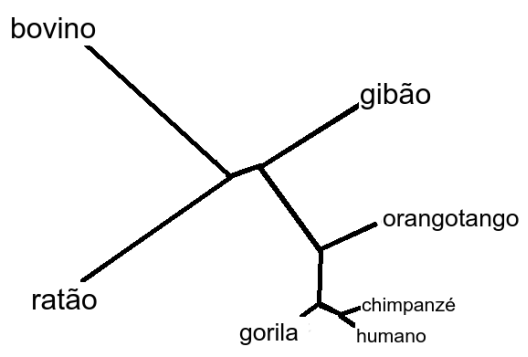

(c)

Figura 2.2: Exemplo de exibições mais usadas para exibir árvores filogenéticas. (a) Cladograma. (b) Filograma. (c) Radial. Fonte: (Carrizo, 2004)

A técnica Neighbor-Joining (NJ) foi proposta por (Saitou e Nei, 1987), e busca posicionar as instâncias de dados em uma árvore, usando as matrizes de distâncias evolutivas. Assim, um nó agrupa instâncias de dados com características similares, que são conhecidas como vizinhas.

$\mathrm{O}$ critério de reconstrução da árvore NJ busca encontrar os pares de instâncias de dados com menor valor de distância e as elege vizinhas, de modo a minimizar o comprimento dos ramos da árvore gerada. Este critério é também conhecido como critério de evolução mínima. Além disso, o critério de reconstrução é responsável tanto pelo tamanho das ramificações em cada estágio do agrupamento de vizinhos, quanto pela criação das bifurcações presentes na topologia da árvore (Machado, 2010). Uma vez escolhido o par de instâncias vizinhas a serem agrupadas em um novo nó, calculam-se os tamanhos dos novos ramos. Considerando duas instâncias mais próximas, é criado um novo nó (nó virtual) que se conecta a essas duas instâncias. O passo seguinte é calcular a distância entre o nó virtual e as demais instâncias do conjunto de dados. As duas instâncias consideradas anteriormente são removidas da matriz de distâncias, e nela são incluídas as distâncias do novo nó virtual. Dessa forma, a cada iteração desse procedimento o número de instâncias da matriz é reduzido em uma unidade. O ciclo é repetido até que o número 
de instâncias torne-se igual a 3, que define o último componente da nova árvore. O algoritmo de construção de uma árvore filogenética pode ser encontrado em (Valdivia et al., 2007).

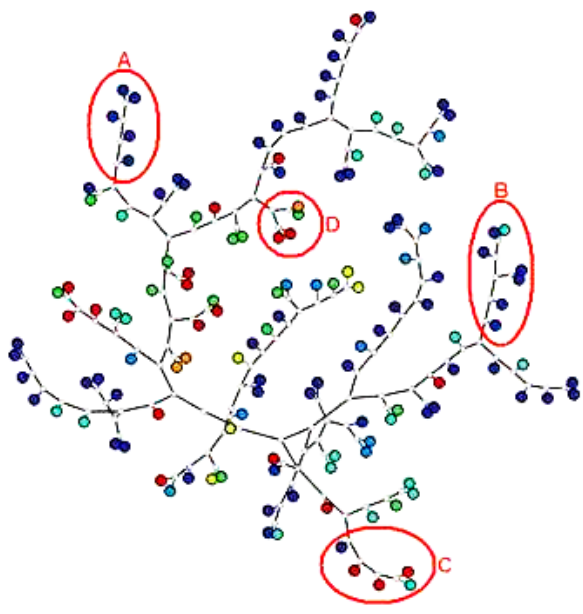

(a)

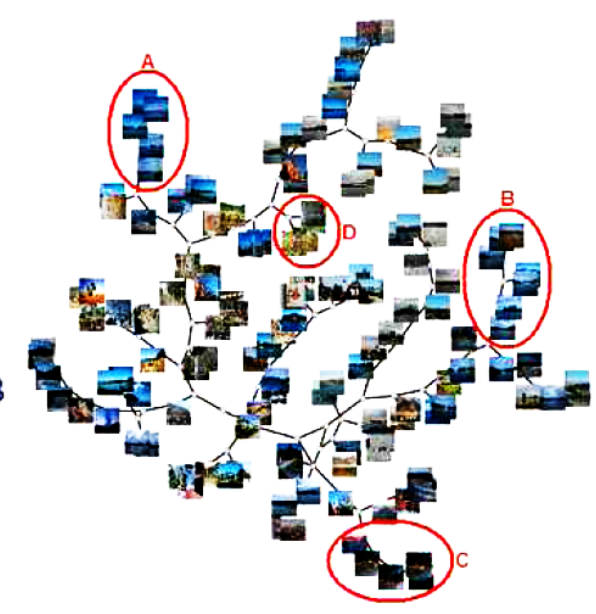

(b)

Figura 2.3: (a) Exemplo de árvore de similaridade de um conjunto de imagens utilizando a técnica NJ. (b) O mesmo exemplo exibindo as imagens associadas. Fonte: (Souza Paiva, 2011)

A Figura 2.3 mostra um exemplo de uma árvore de similaridade construída utilizando o método Neighbor-joining. Esta árvore foi construída a partir de uma coleção de fotografias diversas. Como descritores de características, na construção do espaço vetorial para o cálculo das distâncias foram utilizados descritores de Fourier do histograma da imagem. A medida de distância utilizada foi a Euclidiana. Na Figura 2.3, cada imagem é representada por um círculo, cuja cor representa a sua classe. Os ramos destacados $(A, B, C$ e $D)$ permitem verificar que o método consegue agrupar imagens semelhantes em ramos (Souza Paiva, 2011). A técnica produz um bom resultado visual, mostrando grupos formados pelas ramificações da árvore. No entanto, é uma técnica de alto custo computacional (Eler e Minghim, 2010). O seu custo é $O\left(n^{3}\right)$.

Paiva et al. (2011) apresentam uma variação das árvores NJ, chamada árvore Promoting Neighbor Joining (PNJ), a fim de reduzir a sobrecarga visual. Eles apresentam uma operação para reescrever o grafo ordenado e determinístico, chamada promoção (Figura 2.4). A operação substitui um nó interno por um nó folha quando existe uma certa configuração.

Suponhamos que uma árvore $\mathrm{NJ} A$ tem um par nós folhas $u$ e $v$, ambos conectados ao mesmo nó interno $a$, e outro nó interno $b$ conectado a um nó folha $w$ e a $a$, como mostra a Figura 2.4.a. Já que nenhum outro nó está mais próximo de $w$ do que $a$, então nenhum outro nó está mais próximo de $u$ e $v$ do que $w$. Portanto, $a$ pode ser substituído por $w$ e $b$ pode ser removido completamente, sem perda do poder de representação (Figura 2.4.c). 


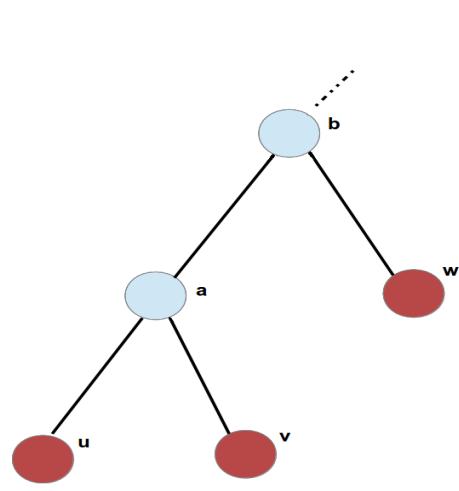

(a) Exemplo original

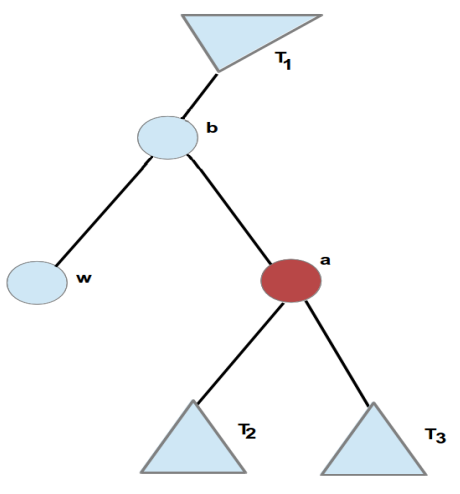

(b) Padrão

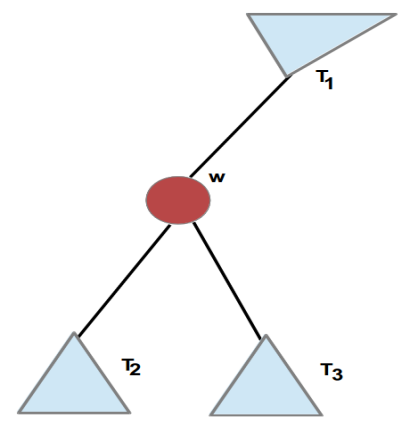

(c) Resultado depois da substituição

Figura 2.4: Promoção: Operação que substitui um nó por um nó folha quando existe uma certa configuração. Os círculos preenchidos representam objetos atuais e os triângulos representam subárvores. Fonte: (Paiva et al., 2011).

A Figura 2.5, mostra os resultados visuais para o banco de imagens Corel, composto de 1.000 fotografias, descritas por 150 atributos. Ambas árvores apresentam 1.000 nós que representam os elementos do conjunto de dados. A Figura 2.5.a exibe a árvore construída com a abordagem NJ original, que possui 998 nós virtuais. A árvore da Figrura 2.5.b, que emprega a estratégia de promoção de nós, possui apenas 412 nós virtuais. Com a abordagem de promoção de nós o uso do espaço é muito mais racional e a desordem visual é reduzida.

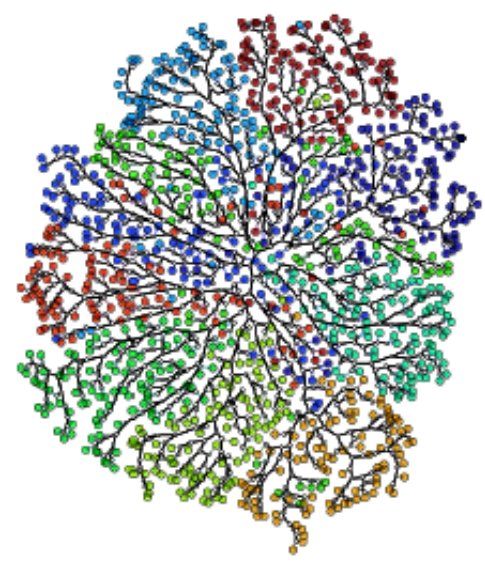

(a) com a técnica $\mathrm{NJ}$

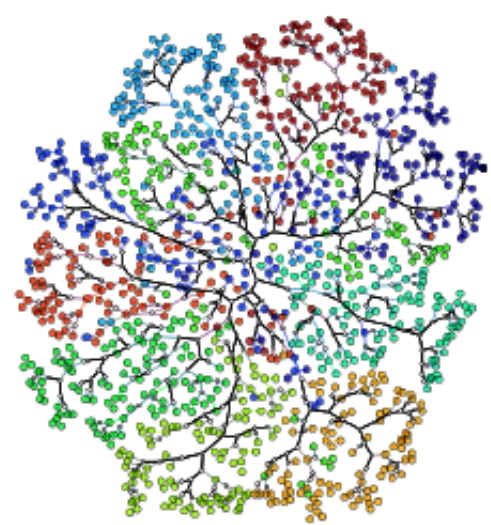

(b) com a técnica PNJ

Figura 2.5: Exemplo de diferentes configurações para a árvore na visualização de 1.000 elementos do conjunto de dados Corel. Empregando a estratégia de promoção de nós, o espaço visual é melhor aproveitado (Figura b), dada a diminuição da quantidade de nós virtuais presentes na abordagem original (Figura a). Fonte: (Paiva et al., 2011). 


\subsection{Considerações finais}

O resultado das técnicas de projeção multidimensional e das árvores Neighbor-Joining (NJ) é exibido por meio de representações visuais que buscam preservar relações de similaridade. As técnicas de projeção multidimensional podem auxiliar na percepção dos agrupamentos e tendências, já que preservam as relações de similaridade, e dessa forma, ajudam o usuário na construção do modelo mental. Por isso, os layouts gerados por projeções multidimensionais acabam sendo ótimos para a representação geral da coleção de dados.

Entretanto, as projeções apresentam limitações que dificultam a interpretação. Uma limitação importante é o alto grau de sobreposição dos pontos no layout gerado, pontos muito próximos ou sobrepostos tornam-se indistinguíveis, gerando confusão. O problema torna-se mais crítico com grandes conjuntos de dados. Além disso, os layouts gerados pelas projeções multidimensionais dificultam a visualização dos relacionamentos individuais entre os pontos, ou seja, não permitem uma boa interpretação dos detalhes. Por outro lado, as árvores NJ apresentam uma organização hierárquica dos dados, sendo agrupados em um ramo os dados que apresentam um alto grau de similaridade. Assim, essas árvores são ótimas para uma análise mais detalhada do conjunto de dados, tornando claras as relações de similaridade. No entanto, a técnica tem alto custo computacional, por isso é uma boa solução alternativa para a representação detalhada de regiões de interesse, como resposta à interação do usuário.

A vantagem da árvore NJ sobre os layouts obtidos por técnicas de projeção multidimensional em geral é que a representação favorece a análise de relações de similaridade locais e globais, enquanto as projeções favorecem a percepção dos relacionamentos globais. 


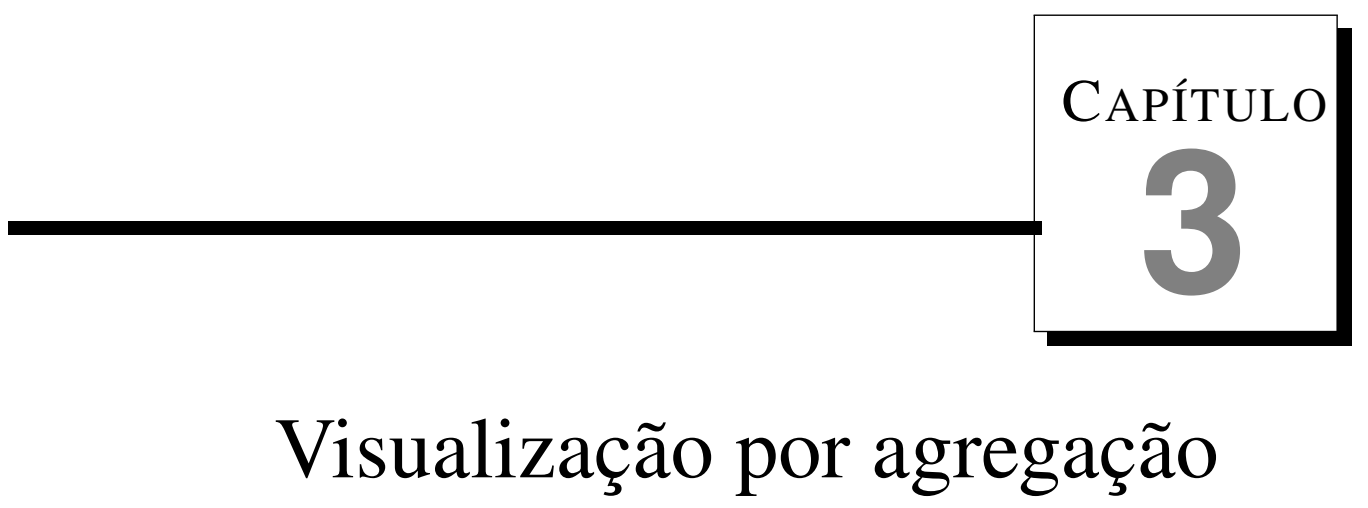

\section{A ordem e a simplificação são os primeiros passos para dominar um assunto -o verdadeiro inimigo é o desconhecido (Thomas Mann).}

\subsection{Considerações Iniciais}

Muitas técnicas de visualização tradicionais, úteis para a análise exploratória de conjuntos de dados de tamanhos moderados, deixam de cumprir sua função quando recebem grandes conjuntos de dados (Andrienko e Andrienko, 2005). Uma das abordagens frequentemente usadas para exibir grandes quantidades de dados é a Agregação Visual. A ideia desta abordagem é agrupar instâncias de dados exibidas, para serem exploradas como grupos.

Neste trabalho, foram estudadas várias abordagens que usam Agregação Visual, nas quais podem-se identificar dois grupos: os baseados no conceito de Splatting e os baseados na representação e exibição de uma hierarquia. Nas seções apresentadas a seguir detalham-se os trabalhos estudados que merecem destaque.

\subsection{Abordagens baseadas no conceito de Splatting}

A técnica Splatting foi introduzida na visualização volumétrica por Westover (1991). Esta técnica representa um volume como um conjunto de splats, que são os gráficos de 
determinadas funções base 3D, comumente Gaussianas. Para cada voxel do volume é calculada e renderizada uma splat. A intensidade da cor e a transparência da splat são obtidos aplicando a função base sobre o voxel atual, considerando a influência que têm todos os voxels do volume sobre o voxel avaliado.

A Splatting pode reduzir drasticamente o volume de dados a serem processados e armazenados. Esta ideia pode ser aplicada a um espaço bidimensional, no qual cada ponto ou aresta é projetado em um campo bidimensional por meio de uma função de splatting. A seguir, são apresentadas algumas técnicas recentes de visualização que consideram o conceito de splatting.

\subsubsection{GraphSplatting}

O método GraphSplatting, proposto por Van Liere e De Leeuw (2003), utiliza a técnica Splatting para representar um grafo ou uma nuvem de pontos como um campo escalar contínuo. O resultado, ao invés de mostrar pontos individuais, apresenta uma variação contínua de densidade, em que cada vértice contribui para o campo segundo uma função Gaussiana 2D. O campo resultante para um vértice dado é obtido pela soma de todas as contribuições dos vértices do grafo, e é chamado campo Splat. A seguir, esta técnica será explicada em detalhe, já que foi implementada uma versão e diversas variações desta.

O campo splat para cada vértice, é calculado por meio de uma função $F$, a qual calcula as contribuições individuais de todos os vértices do conjunto sobre o vértice atual $(x, y)$, como mostra a Figura 3.1. Estas contribuições são obtidas mediante a função base Gaussiana $G^{\sigma}$, a qual é aplicada sobre a substração do vértice atual $(x, y)$ e cada vértice do conjunto $\left(p_{i_{x}}, p_{i_{y}}\right)$. A função Gaussiana $G^{\sigma}$ é definida na Equação 3.1.

$$
G^{\sigma}(x, y)=\frac{1}{2 \pi \sigma^{2}} e^{-\frac{\left|x^{2}+y^{2}\right|}{2 \sigma^{2}}}
$$

A função $G^{\sigma}(x, y)$ é calculada na posição do vértice atual e a amplitude da contribuição é controlada pelo parâmetro $\sigma$. Assim, a função do campo splat $F$ pode ser definida pela Equação 3.2.

$$
F(x, y)=\sum_{i=1}^{n} G^{\sigma}\left((x, y)-\left(p_{i_{x}}, p_{i_{y}}\right)\right)=\sum_{i=1}^{n} G^{\sigma}\left(x-p_{i_{x}}, y-p_{i_{y}}\right)
$$

na qual, $n$ é a quantidade de vértices do conjunto, $(x, y)$ é a posição do vértice atual e $\left(p_{i_{x}}, p_{i_{y}}\right)$ é a posição do vértice $i$.

Note-se que o resultado da função $F$ é um valor escalar, portanto, para poder visualizar o campo splat é gerada uma matriz Gaussiana $M$ aplicando a Equação 3.1. O tamanho da matriz é dado por um parâmetro fornecido pelo usuário. O resultado da função $F$ é 


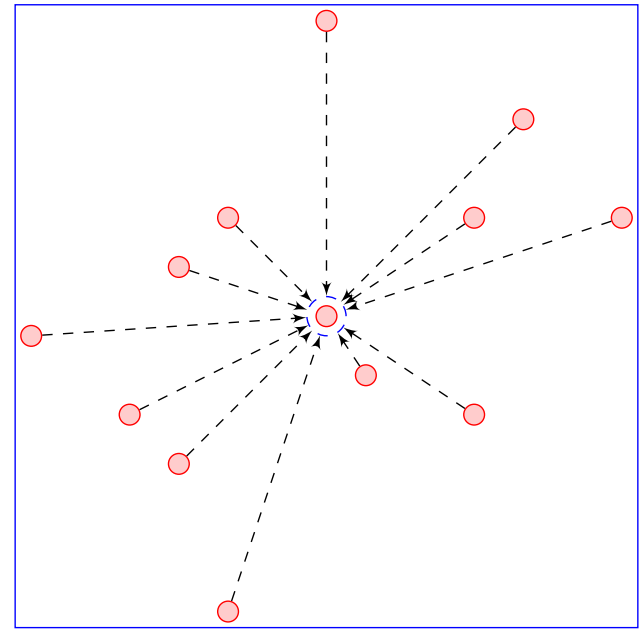

Figura 3.1: Contribuições de todos os pontos para o ponto atual.

multiplicado por todos os elementos da matriz Gaussiana. A matriz resultante $S$ representa o campo splat discretizado. Uma vez que os valores RGB dos pixels na tela encontram-se no intervalo $[0,1]$, os valores do campo splat discretizado devem ser normalizados neste mesmo intervalo. O normalização da matriz $S$ é definida na Equação 3.3.

$$
S_{i j}=1-\frac{F(x, y) \times M_{i j}}{\max (F) \times G^{\sigma}(0,0)}
$$

na qual, $F(x, y)$ é o resultados da função $F$ para o ponto atual $(x, y)$, a função $\max (F)$ retorna o maior valor obtido da função $F$ aplicada sobre todos os pontos. Portanto, a cor visualizada é obtida colocando o centro da matriz $S$ sobre o vértice $(x, y)$ na tela, a fim de multiplicar os valores da matriz pelo valor dos pixels coincidentes na tela. A Figura 3.2 mostra um exemplo da matriz Gaussiana e a matriz resultante após multiplicar o valor da função $F$ pelos elementos da matriz Gaussiana. A Figura 3.3 ilustra um exemplo do resultado final da técnica, ou seja, splats visualizados na tela. 


\begin{tabular}{|l|l|l|l|l|}
\hline 0.002 & 0.013 & 0.021 & 0.013 & 0.002 \\
\hline 0.013 & 0.058 & 0.096 & 0.058 & 0.013 \\
\hline 0.021 & 0.096 & 0.159 & 0.096 & 0.021 \\
\hline 0.013 & 0.058 & 0.096 & 0.058 & 0.013 \\
\hline 0.002 & 0.013 & 0.021 & 0.013 & 0.002 \\
\hline
\end{tabular}

(a) Matriz Gaussiana $(5 \times 5), \sigma=1.0$.

\begin{tabular}{|l|l|l|l|l|}
\hline 0.988 & 0.919 & 0.868 & 0.919 & 0.988 \\
\hline 0.919 & 0.636 & 0.397 & 0.636 & 0.919 \\
\hline 0.868 & 0.397 & 0.000 & 0.397 & 0.868 \\
\hline 0.919 & 0.636 & 0.397 & 0.636 & 0.919 \\
\hline 0.988 & 0.919 & 0.868 & 0.919 & 0.988 \\
\hline
\end{tabular}

(b) Campo splat normalizado, $M=15$.

Figura 3.2: A matriz Gaussiana é multiplicada pelo resultado da função $M$ para gerar o campo splat a ser visualizado na tela.

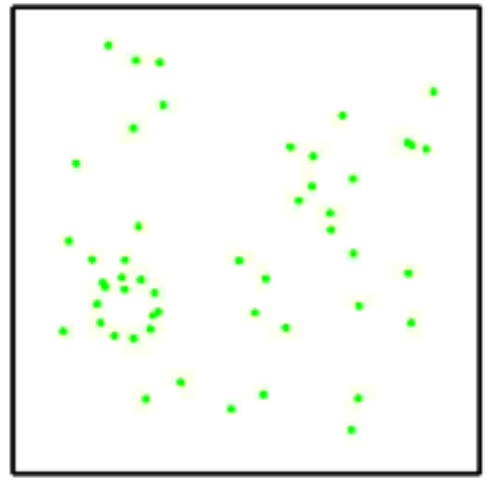

(a)

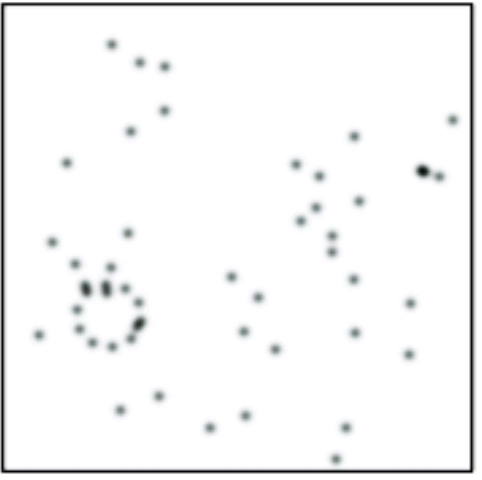

(b)

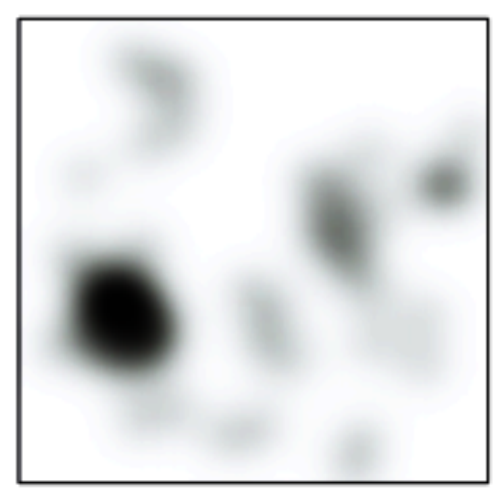

(c)

Figura 3.3: (a) Exemplo com 40 pontos. (b) Splatting com valor menor de $\sigma$. (c) Splatting com valor maior de $\sigma$. Fonte: (Van Liere e De Leeuw, 2003) 


\subsubsection{Splatting de linhas em Coordenadas Paralelas}

A técnica de Coordenadas Paralelas (Inselberg e Dimsdale, 1990) visualiza as dimensões como eixos paralelos e os dados como polilinhas conetando seu valor escalar nos eixos. Com esta técnica é possível representar dados multidimensionais em espaços bidimensionais. Porém, esta abordagem apresenta um problema que acontece quando os conjuntos de dados tornam-se tão grandes que milhões de linhas sobrecarregam o display. Assim, a visualização por Coordenadas Paralelas pode se tornar demasiado densa para ser interpretada.

Zhou et al. (2009) abordam este problema com o uso do splatting, com o qual geram uma visualização interativa e animada para revelar padrões em Coordenados Paralelas, eles propõem o uso da splatting como um esquema de animação para a redução de desordem e detecção de padrões. A abordagem é composta por duas partes importantes. A primeira parte visa detectar grupos ou clusters mediante o splatting das polilinhas plotadas nas Coordenadas Paralelas. Isto é realizado calculando e visualizando o splat de cada linha, além de realçar as linhas vizinhas e suprimir as irrelevantes. A segunda parte reduz o clutter causado pelo cruzamento e sobreposição das linhas plotadas nos eixos paralelos. Esta redução é realizada mediante o splatting de segmentos, o qual representa cada polilinha como um segmento e visualiza o splat destes segmentos com diferentes velocidades, cores e comprimentos a partir dos eixos de esquerda a direita. O usuário pode controlar ambas as partes, tanto o splatting de polilinhas, quanto o splatting de segmentos a fim de enfatizar as características nas quais tenha interesse.

Para o processo de splatting de polilinhas, inicialmente, são colocados aleatoriamente todos os dados em uma lista encadeada circular e as polilinhas são selecionadas uma a uma. Em seguida, são encontrados os vizinhos da polilinha selecionada com base nas distâncias dos itens correspondentes e um limiar $d$. Esta distância pode ser medida em um espaço multidimensional ou em qualquer sub-espaço bidimensional. Uma vez encontrados os vizinhos da polilinha secionada, são incrementadas suas opacidades mediante a Equação 3.4 iterativa.

$$
\tilde{O}_{j}=O_{j}+O_{j} G\left(D_{i j}\right)
$$

na qual $O_{j}$ é a opacidade da linha $j$ na iteração prévia; $D_{i j}$ é a distância entre a linha $i$ e a $j$; e $G\left(D_{i j}\right)$ é a função de distribuição gaussiana, usada para definir a intensidade. A maior distância resulta em menor intensidade e vice-versa. O operador Gaussiano e definido na Equação 3.5.

$$
G\left(D_{i j}\right)=w_{\max } e^{-\frac{2 D_{i j}}{d^{2}}}
$$


em que $d$ é o limiar da distância e $w_{\max }$ um peso. Em geral podem ser usadas outras funções de distribuição, mas os testes mostraram que a função definida anteriormente é suficiente para obter os resultados desejados.

O processo do splat de polilinhas faz iterativamente que as polilinhas que representam outliers sejam cada vez mais transparentes e as polilinhas próximas dos centroides dos grupos sejam gradualmente realçadas com altos valores de opacidade. Portanto, os principais grupos serão automaticamente visualizados com os maiores valores de opacidade. No entanto, o usuário pode deter o processo se os padrões dos grupos foram claramente revelados. Por outro lado, o sistema permite ao usuário determinar o número de grupos ou diretamente selecionar os seus centros com base nas suas observações, a fim de aplicar o algoritmo $k$-means para agrupar os dados.

O splat de polilinhas pode detetar grupos em dados desordenados e usar cores para indicar estes grupos. No entanto, a desordem visual pode ainda ser um problema. A Figura 3.4 ilustra um exemplo de desordem visual em que os grupos são mostrados com diferentes cores. No entanto, quando as linhas de diferentes cores apresentam muitos cruzamentos e sobreposição, as relações entre os grupos e suas estruturas mostram-se pouco claras.

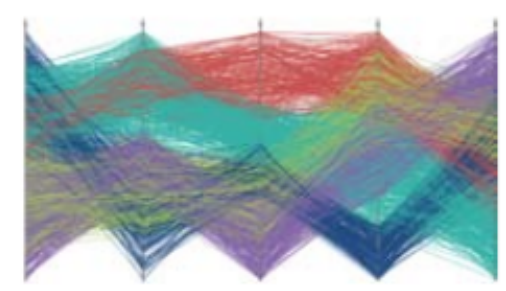

Figura 3.4: Grupos representados com cores diferentes. Fonte: (Zhou et al., 2009)

A fim de diminuir a desordem visual é usado o splat de segmentos, no qual cada polilinha é mostrada como um segmento. Uma vez que é um esquema animado, estes segmentos movem-se ao longo do caminho da polilinha original com diferentes velocidades, desde o eixo mais a esquerda até o eixo mais a direita. Para cada agrupamento é definido um valor de velocidade pelo meio da Equação 3.6.

$$
v_{g}=\frac{N_{g}}{N_{\text {total }}}+\triangle v_{g_{t}}^{\prime}
$$

na qual $N_{g}$ é o número de elementos no agrupamento $g, N_{\text {total }}$ é o número total de elementos e $\triangle v_{g_{t}}^{\prime}$ está definida pela Equação 3.7 .

$$
\triangle v_{g_{t}}^{\prime}=\frac{\sum_{i=1}^{n} F_{i g}}{m_{g}} \triangle t
$$

na qual $F_{g k}$ é a gravitação universal definido por $G m_{g} m_{k} / r_{g k}^{2}$, sendo $r_{g k}$ a distância entre 
os dois centros dos agrupamentos e $m_{g}$ e $m_{k}$ determinados pelo tamanho do agrupamento. Agrupamentos maiores têm maior $m$ e vice-versa.

Esta função codifica as informações de agrupamentos e separa diferentes agrupamentos no domínio do tempo. Segmentos em diferentes grupos movem-se entre eixos adjacentes com diferentes velocidades, enquanto que segmentos nos mesmos grupos movem-se com a mesma velocidade. Além disso, o comprimento dos segmentos codifica as estruturas locais ou informação estatística. Por outro lado, para compensar a falta de relações espaciais entre linhas diferentes é definida una função de cor, na qual quando dois grupos se intersectam, suas cores se fundem mutuamente. Os grupos maiores podem injetar mais cor nos grupos menores. A intensidade de cor injetada diminui e atinge o mínimo quando dois grupos são perpendiculares entre si. Além disso, se dois grupos são paralelos no mesmo intervalo de eixos, eles infundem suas cores entre si. Quanto maior distância entre eles, menor é o nível de difusão de cor, e vice-versa. Combinando as funções de velocidade, comprimento e cor, o splat de segmentos pode revelar visualmente tanto as estruturas dos grupos locais quanto a global.

A Figura 3.5 apresenta os resultados desta abordagem sobre um banco de dados sintético, a Figura 3.5.a mostra as Coordenadas Paralelas originais, a Figura 3.5.b mostra as coordenas paralelas com Splatting depois de 800 iterações, a Figura 3.5.c mostra as coordenas paralelas com Splatting depois de 2.000 iterações e finalmente, a Figura 3.5.d apresenta o resultado com diferentes cores indicando diferentes agrupamentos.

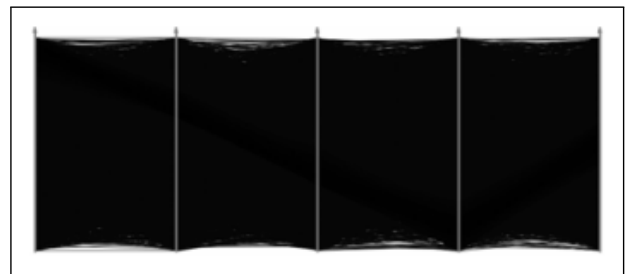

(a)

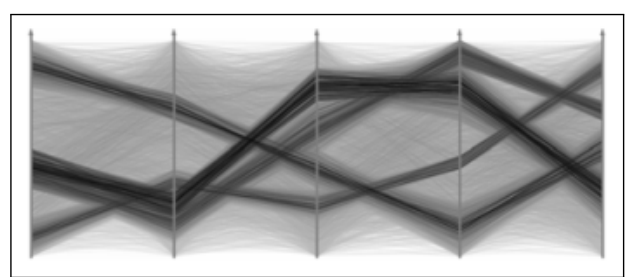

(c)

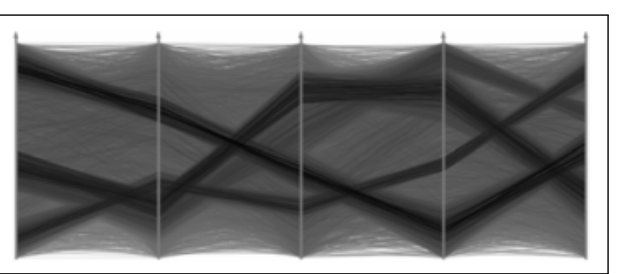

(b)

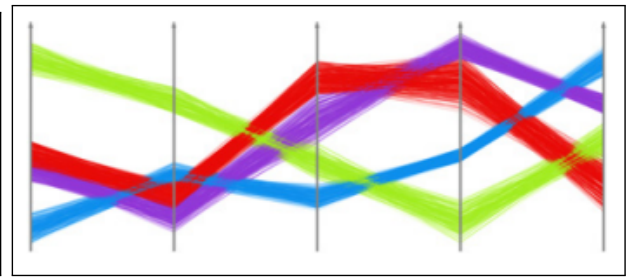

(d)

Figura 3.5: Exibição de um banco de dados sintético. (a) Coordenadas paralelas Originais (b) Com splatting depois de 800 iterações. (c) Com splatting depois de 2.000 iterações (d) Resultado do splatting com cores indicando diferentes agrupamentos. Fonte: (Zhou et al., 2009) 


\subsection{Abordagens baseadas na representação e exibi- ção de uma hierarquia}

A seguir são apresentados trabalhos que consideram a abordagem de agregação visual, que estão baseados na representação e exibição de uma hierarquia.

\subsubsection{Agregação Hierárquica em Visualização de Informação}

Elmqvist e Fekete (2010) apresentam um modelo para a construção, visualização e interação com representações de técnicas de visualização de informação usando agregação hierárquica, para obter representações visuais mais escaláveis e menos confusas. $\mathrm{O}$ modelo de agregação hierárquico é baseado na agregação de dados no espaço, sendo sua representação visual o correspondente simplificado daqueles dados agregados. Assim, o processo de agregação transforma qualquer visualização em uma estrutura multi-escala que pode ser mostrada em qualquer nível de detalhe, fornecendo ao usuário uma visão manejável e sem desordem com o uso de um conjunto de interações. Além disso, a interação permite que o usuário aprofunde no detalhe e recupere informações sob demanda.

Dado um conjunto de dados, a agregação hierárquica baseia-se na construção iterativa de uma árvore de itens agregados de maneira ascendente ou descendente. Cada item agregado é composto de um ou mais filhos, em que um filho pode ser um dado original ou itens agregados. A raiz da árvore é um item agregado que representa todo o conjunto de dados. A agregação ascendente começa com o tratamento de cada item como seu próprio agregado, então combina-se iterativamente agregados similares até obter apenas um. A agregação descendente começa com um agregado contendo todos os itens e repetidamente dividem-se agregados até que um nível específico seja alcançado, ou todos os itens pertençam a apenas um agregado. O comum entre estas duas abordagens é a medida de similaridade definida utilizando uma função de distância específica.

Existem vários algoritmos para realizar a agregação, os mais comuns são as abordagens de agrupamento, como as baseadas em grafos ou k-means (MacQueen, 1967). Outros exemplos incluem métodos baseados em quadtree (Finkel e Bentley, 1974) e octree (Zhang e Owen, 2004), tais como a fusão recursiva de quatro arestas adjacentes em uma aresta. A árvore agregada torna-se uma estrutura multi-escala para controlar o nível de detalhe da visualização. Renderizar a visualização agregada hierárquica equivale a percorrer a hierarquia agregada visual.

Dependendo do estado atual da visualização, existem quatro tipos principais de rendering:

- Trajeto ascendente (Figura 3.6(a)): Todos os nós acima da altura atual são ren- 
derizados. Aqui, os itens são abstraídos pela agregação visual de maior nível, ocultando os detalhes para evitar sobrecarrega.

- Trajeto descendente (Figura 3.6(b)): Todos os nós abaixo da altura atual são renderizados. Isto dá uma indicação de como os itens são agrupados.

- Trajeto em nível (Figura 3.6(c)): Todos os nós no mesmo nível da altura atual são renderizados. Isto dá um instantâneo da abstração de dados em um nível específico.

- Trajeto em intervalo (Figura 3.6(d)): Todos os nós em um intervalo de níveis são renderizados. Como o trajeto em nível, dá um instantâneo da abstração de dados em um nível específico, com um nível adicional menor da hierarquia de agregação.

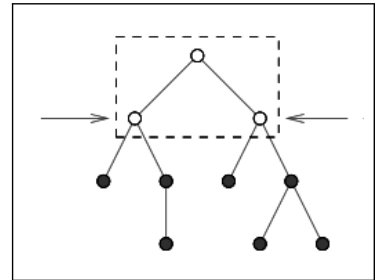

(a) ascendente

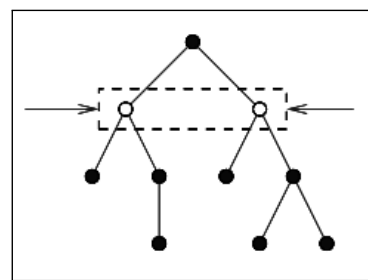

(c) em nível

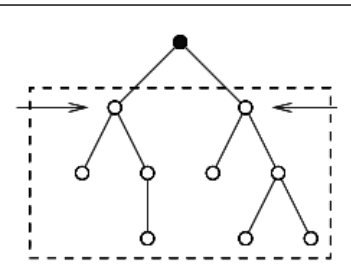

(b) descendente

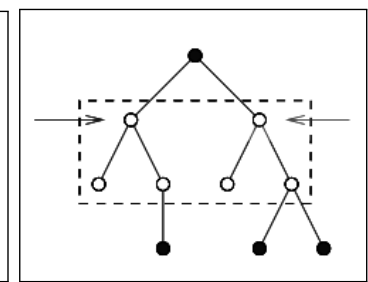

(d) em intervalo

Figura 3.6: Trajetos de visualizações de agregação hierárquica. As setas indicam a altura atual da agregação. Nós brancos são renderizados enquanto os nós pretos são omitidos. Fonte: (Elmqvist e Fekete, 2010)

Claramente, o benefício de uma hierarquia de agregação de dados e uma hierarquia de agregação visual correspondente é que a visualização resultante pode ser adaptada aos requisitos do usuário e a imagem resultante irá permanecer coerente com os dados atuais. A Figura 3.7 apresenta alguns resultados obtidos com a aplicação da técnica sobre as Coordenadas Paralelas.

\subsubsection{HiPP: Projeção por Posicionamento Hierárquico}

A HiPP foi proposta por Paulovich e Minghim (2008) e consiste em uma técnica hierárquica de posicionamento de pontos que usa círculos de diferentes tamanhos para refletir visualmente a hierarquia de similaridades. A técnica define uma estrutura hierárquica 


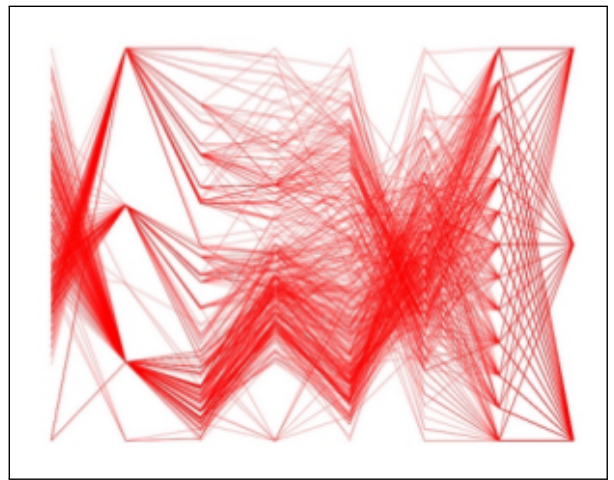

(a) Coordenadas Paralelas

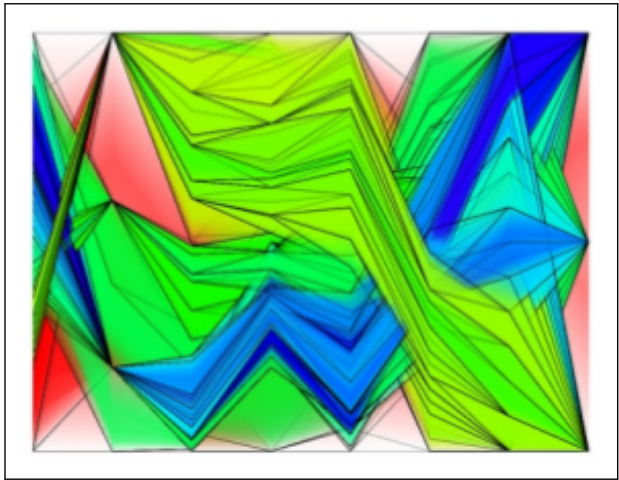

(b) Agregação usando opacidade (trajeto ascendente)

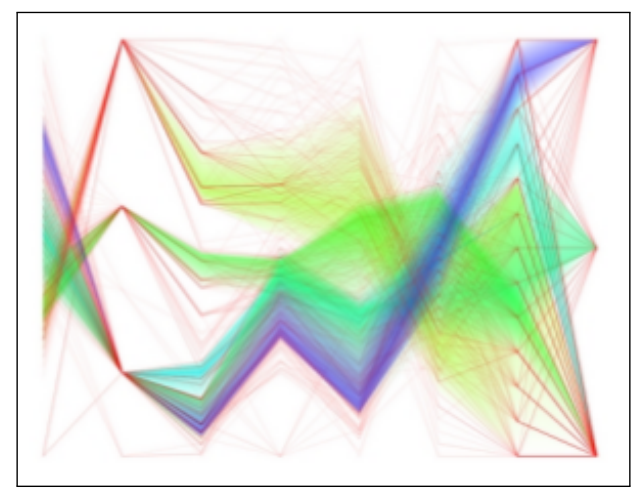

(c) Agregação usando opacidade (trajeto descendente)

Figura 3.7: Coordenadas Paralelas de um conjunto de dados com 8 dimensões. Fonte: (Elmqvist e Fekete, 2010)

do conjunto de dados e projeta essa estrutura no plano de visualização. Essa estrutura é construída usando um processo recursivo de particionamento. O primeiro nível representa os agrupamentos mais abstratos, e os níveis subsequentes representam sub-grupos mais detalhados até instâncias de dados individuais.

Primeiramente, são projetados os nós de mais alto nível, depois os nós internos ou de mais baixo nível, são projetados conforme a interação do usuário. Essa projeção é realizada com a técnica $L S P$ e em seguida é realizado um espalhamento para evitar sobreposição dos pontos. Na HiPP, os elementos visuais podem representar tanto instâncias de dados individuais quanto grupos. O usuário pode interagir com os nós de alto nível e verificar como os dados estão sendo organizados, o que facilita a navegação em diferentes níveis de abstração ou detalhamento. Além disso, o usuário pode agrupar nós conforme sua escolha. Isso possibilita começar com uma visão geral do conjunto de dados, para finalmente alcançar as instâncias de dados individuais.

A Figura 3.8 mostra a visualização de uma coleção de 675 documentos científicos. A cor indica o agrupamento, o tamanho do círculo indica o número de documentos dentro daquele nível da hierarquia e o texto revela o tópico dos documentos contidos naquele nó. 


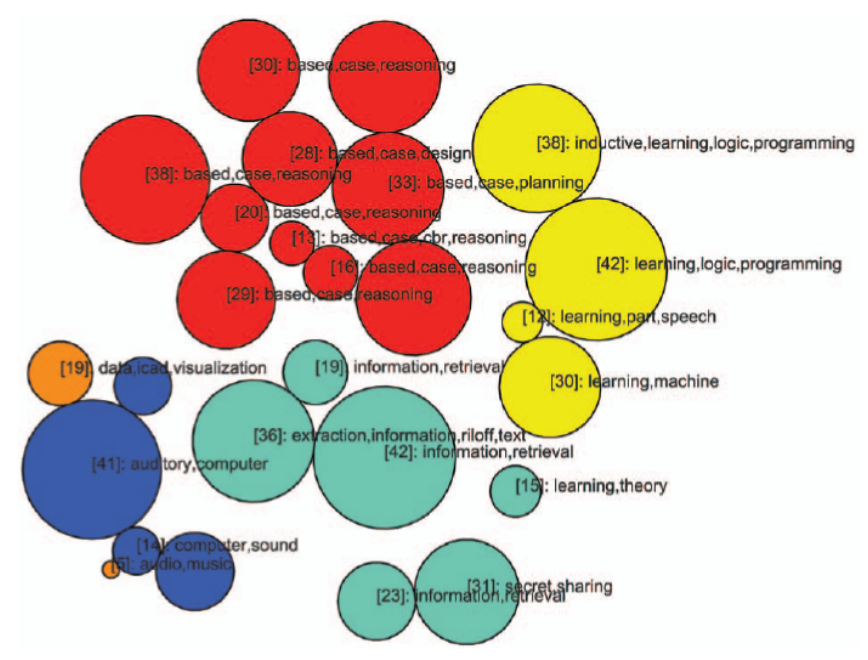

Figura 3.8: Mapa de 675 documentos de quatro áreas distintas gerado pela técnica HiPP. O primeiro nível representa os agrupamentos mais abstratos, e os níveis subsequentes representam sub-grupos mais detalhados até instâncias de dados individuais. Fonte: (Paulovich e Minghim, 2008)

\subsection{Considerações finais}

Visualização de nuvens de pontos $2 D$ é uma das tarefas mais básicas, mas importante em muitos cenários de análise de dados. Métodos típicos baseados em visualizações de pontos não conseguem lidar com grandes conjuntos de dados. Isso pode ser confirmado na dificuldade dos usuários de interagir e interpretar essas coleções, é muito difícil distinguir grupos e pontos corretamente. Neste capítulo, foram apresentadas algumas técnicas de visualização que consideram a abordagem de agregação visual para tratar os problemas dessa natureza.

A agregação envolve a condensação ou síntese visual dos dados, permitindo reconhecer as regiões com maior aglomeração de pontos reduzindo a quantidade de esforço mental exigido. Essa ideia permite reduzir o problema de sobreposição nos layouts de grandes conjuntos de dados, tornando a análise mais simples e mais legível. Assim, essa abordagem pode ser aplicada sobre o layout gerado por projeções multidimensionais. 



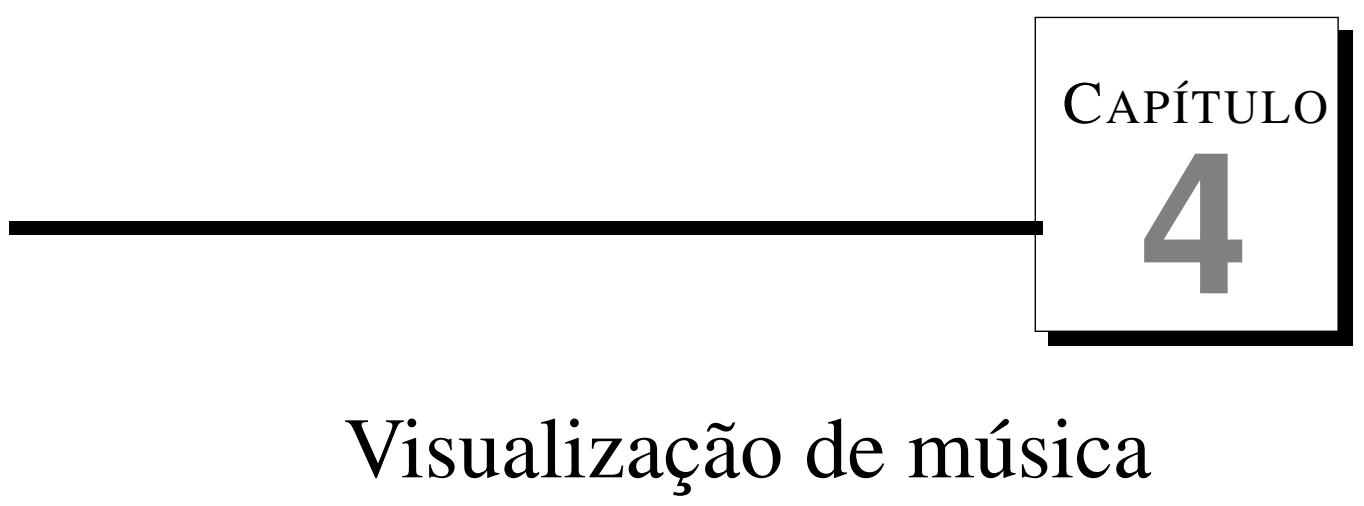

Não basta apenas ouvir a música, é preciso também enxergá-la (Igor Stravinsky).

\subsection{Considerações Iniciais}

Como este trabalho aborda a visualização de músicas, neste capítulo, discutimos algumas interfaces visuais propostas para lidar com coleções de músicas e outras para visualizar peças musicais individuais. As visualizações que lidam com coleções visam destacar alguma propriedade de similaridade. A similaridade normalmente é calculada a partir de características extraídas automaticamente a partir dos sinais de áudio, ou baseadas em tags, ou na combinação dos dois. As diversas abordagens variam na seleção das características representativas, bem como do critério de similaridade e das metáforas visuais. Entre os trabalhos de visualização de músicas, identificamos dois grandes grupos: aqueles que lidam com uma coleção de músicas e aqueles que visualizam peças musicais. Dentro daqueles que visualizam uma coleção encontramos dois tipos de dados de entrada: os trabalhos que usam tags e os que usam características extraídas do sinal de áudio.

\subsection{Visualizações de uma coleção de músicas}

Nesta seção, são apresentados aqueles trabalhos que visualizam uma coleção de músicas, subdivididos em aqueles que usam tags e aqueles que usam características a partir 
dos sinais de áudio.

\subsubsection{Visualizações usando tags}

Torrens et al. (2004) apresentam três visualizações interativas, em formato de disco (Figura 4.1.a), de retângulo (Figura 4.1.b) e treemap (Figura 4.1.c), que organizam uma coleção de músicas considerando múltiplas dimensões, tais como gênero, artista, ano, contador de reprodução ou a última data de reprodução. As visualizações permitem ao usuário uma visão global da coleção de músicas e a criação de listas de reprodução. As visualizações em formato de disco e de retângulo oferecem basicamente a mesma funcionalidade, enquanto a visualização treemap dá uma visão global do conteúdo. No entanto, as visualizações em formato de disco e de retângulo podem ser usadas para visualizar e mais importante, criar e editar listas de reprodução, por outro lado a visualização treemap não oferece esta possibilidade, já que as músicas não são apresentadas em separado.

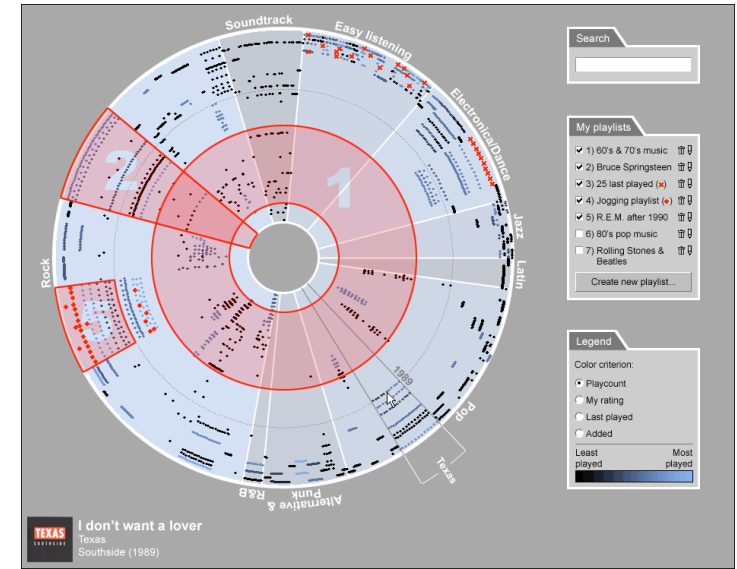

(a) Visualização por disco

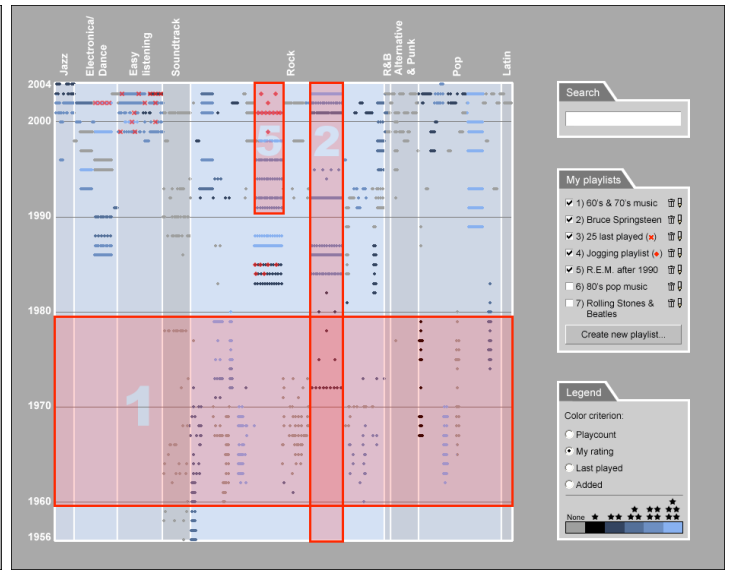

(b) Visualização por retângulo

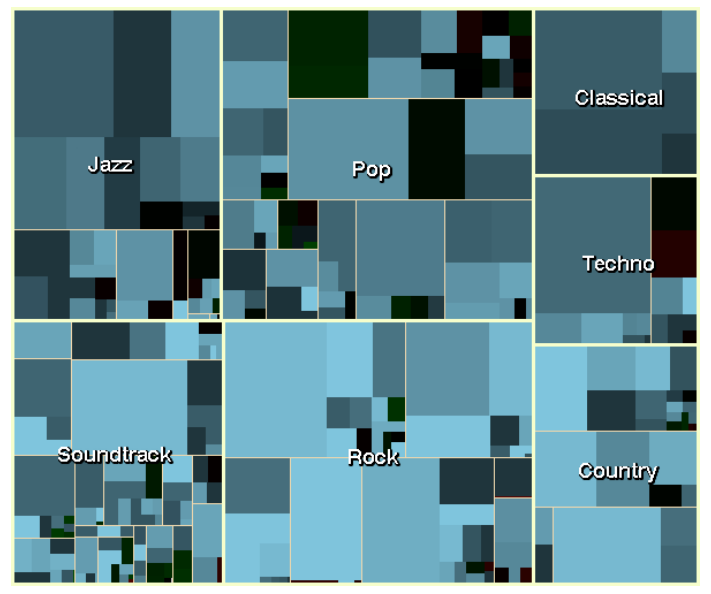

(c) Visualização por treemap

Figura 4.1: Visualizações alternativas de uma coleção de músicas. Fonte: Torrens et al. (2004) 
Outro trabalho que visualiza coleções de músicas, proposto por Dalhuijsen e van Velthoven (2010), é o MusicalNodes. Este sistema permite ver, pesquisar e gerenciar um conjunto de músicas. O sistema permite que uma música seja relacionada a mais de um gênero. Assim, o usuário pode estabelecer a porcentagem de semelhança a um gênero, por exemplo $50 \%$ jazz e $20 \%$ eletrônica. Além disso, permite ao usuário criar novos tags relacionados a uma música, por exemplo a "felicidade/tristeza" de uma música. Cada álbum é representado como um nó em um espaço bidimensional. Estes nós são desenhados com diferentes cores e saturações de acordo ao gênero e o ano. Para a organização espacial dos álbuns, é usado um modelo de atração e repulsão de forças. A Figura 4.2 mostra um exemplo de uma coleção de músicas de tamanho médio (Os autores não especificaram o número de músicas).

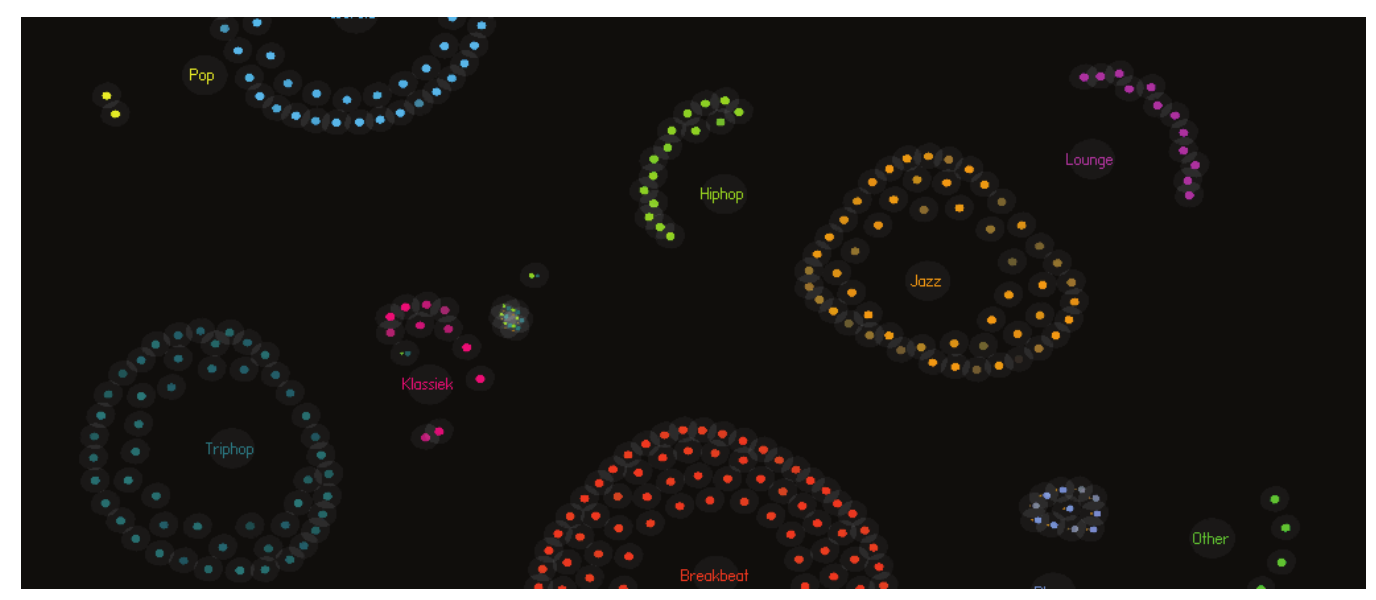

Figura 4.2: Exemplo de uma coleção de músicas de tamanho médio (Os autores não especificaram o número de músicas). Fonte: Dalhuijsen e van Velthoven (2010)

Os tags podem vir tanto das gravadoras como de usuários, contendo muitas vezes informações errôneas ou incompletas, mesmo porque este processo de rotulação pode ser muito subjetivo. Assim, um usuário pode classificar uma música simplesmente como Rock, ou pode classificá-la como Hard-Rock, tendo um número infinito de possibilidades. Aliás, a maioria dos músicos desenvolvem estilos diferentes ao longo da sua carreira musical. Depender exclusivamente dos tags atribuídos às músicas tem estas limitações, que afetam a precisão das visualizações resultantes. 


\subsubsection{Visualizações usando características extraídas do sinal}

Islands of music, proposto por Pampalk (2001), é uma interface gráfica baseada em metáforas de mapas geográficos, que apoia a exploração de coleções de músicas em formato MP3. As músicas são organizadas em ilhas, de acordo com a sua similaridade, usando 1.200 características extraídas do sinal. O número de características é reduzido a 80 dimensões com a técnica Principal Component Analysis (PCA) (Jolliffe, 1986). Estas características são a entrada da rede neuronal Self-organizing map (SOM), para distribuí-las no espaço e gerar a metáfora de mapa geográfico. Cada ilha representa um gênero musical, sendo que ilhas próximas representam gêneros semelhantes. As montanhas identificadas dentro das ilhas podem ser rotuladas com palavras que descrevam o conjunto de músicas existente. A Figura 4.3 apresenta um exemplo da metáfora criada para um conjunto de 77 músicas.

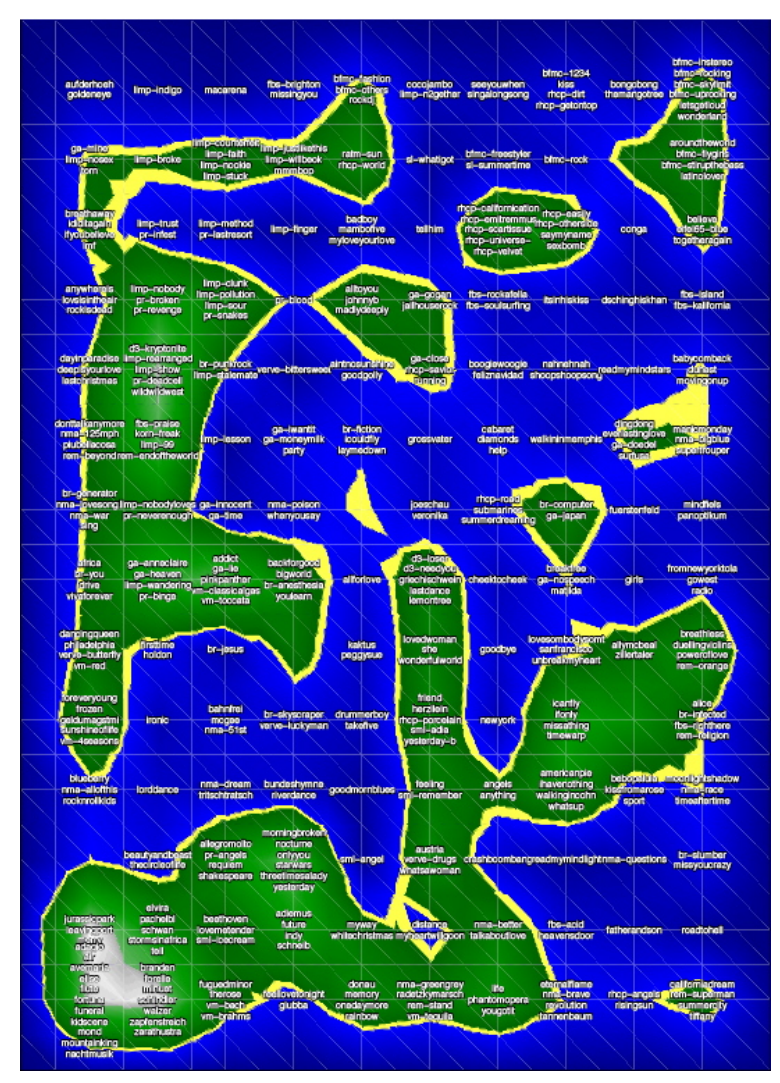

Figura 4.3: Islands of music apresentando 77 músicas. Fonte: Pampalk (2001)

Neumayer et al. (2005) também usam SOM para criar interfaces visuais para PDAs e Tablets. Esse trabalho visa extrair recursos de áudio, capazes de caracterizar sons para classificar músicas de acordo com seus padrões rítmicos de forma automática. Na visualização resultante, cada posição de uma música no mapa é pintada de acordo com estas características. Os diversos experimentos apresentados demonstram sua adequação para 
o reconhecimento de gêneros musicais. A Figura 4.4 apresenta a visualização, em um iPaq PDA, de um repositório de música localizado em um servidor (executado em outra máquina), em que os rótulos foram atribuídos manualmente a cada agrupamento.

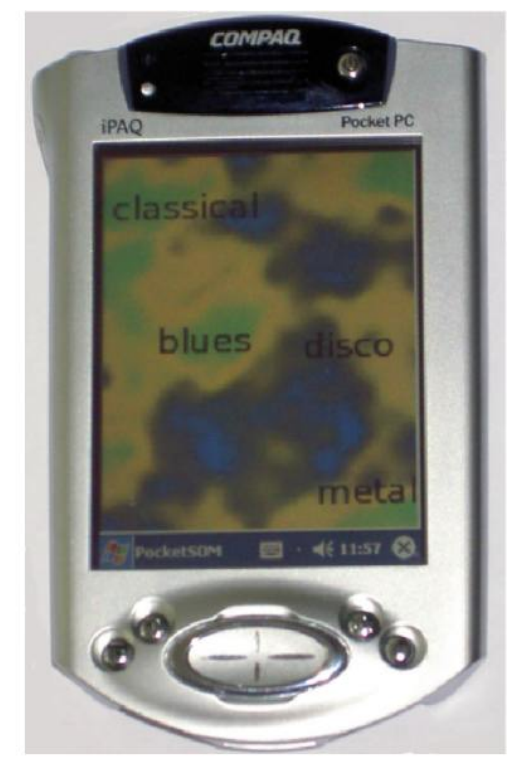

Figura 4.4: Visualização de músicas em um iPaq PDA. Fonte: Neumayer et al. (2005)

MusicBox (Lillie, 2008) mapeia um conjunto de músicas, em formato Mp3, em um espaço bidimensional. Para realizar esse mapeamento são usadas características baseadas no conteúdo (extraídas do sinal) e descritores contextuais coletados a partir de fontes online. Para o posicionamento das músicas é usada a técnica de redução de dimensionalidade PCA a partir destas características. O mapa resultante mostra músicas semelhantes próximas e músicas diferentes afastadas. MusicBox é configurável, os usuários podem adicionar e remover características a serem consideradas. Além disso, a música que está sendo reproduzida é representada por um ícone chamado Soundsieve, que tenta fornecer uma visualização da estrutura da música. O Soundsieve é independente das características utilizadas no mapeamento total, e visualiza o tempo, tom, intensidade e timbre em uma grade de notas ao longo do tempo. A Figura 4.5 apresenta um exemplo do resultado do Soundsieve para a música Fur Elise, de Beethoven e a Figura 4.6 apresenta a visualização resultante para um coleção de músicas.

A interface visual baseada em grafos, proposta por Muelder et al. (2010), destaca também as similaridades entre as músicas. Os arquivos de áudio são convertidos em espectrogramas no espaço de frequência utilizando a Transformada Discreta de Fourier. Estes espectrogramas são estatisticamente reduzidos a assinaturas e comparados com uma função de similaridade. As músicas são mostradas como vértices conetados com arestas ponderadas que indicam as semelhanças entre pares. Os usuários podem interagir com 


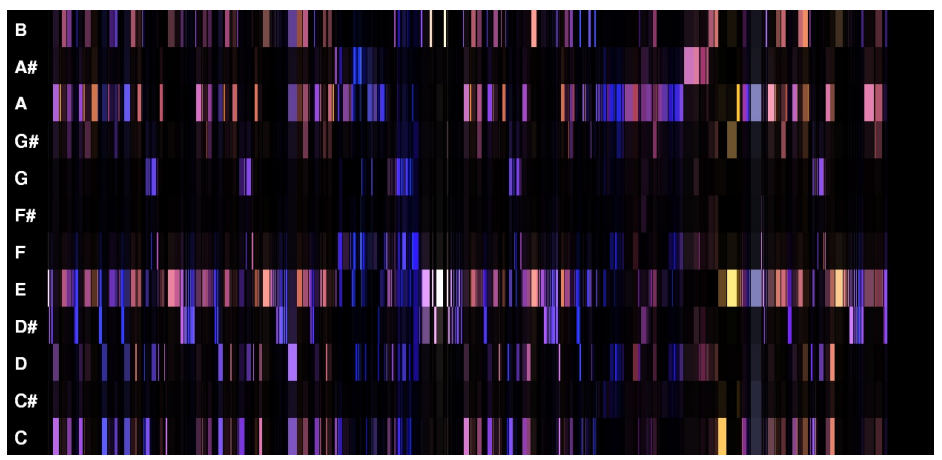

Figura 4.5: Soundsieve obtido para a música Fur Elise, de Beethoven. Fonte: Lillie (2008)

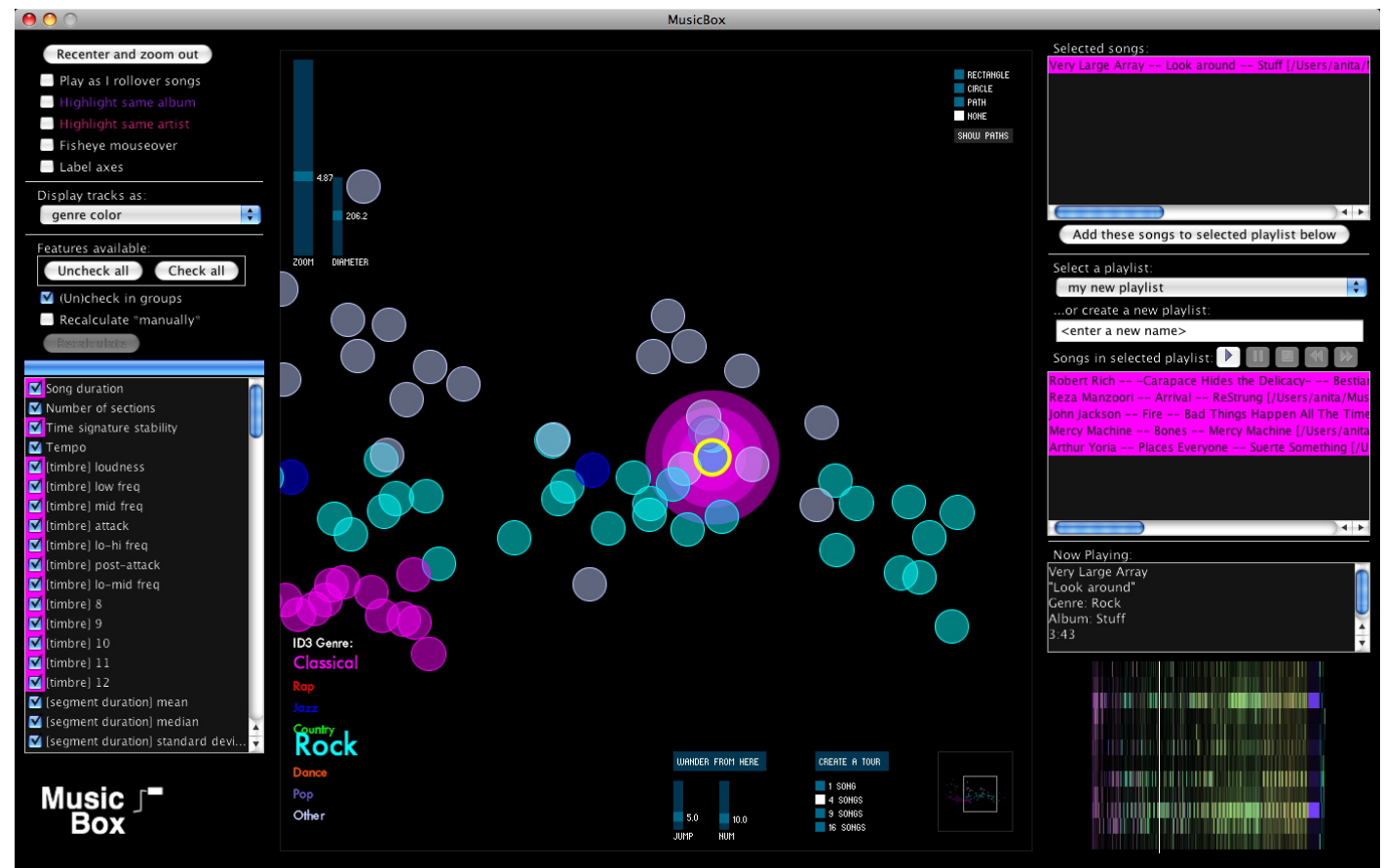

Figura 4.6: Imagem da tela de MusicBox. Fonte: Lillie (2008)

o grafo, selecionando subgrafos que apresentam visões detalhadas. A Figura 4.7 apresenta um exemplo da visualização, na qual foi selecionada uma região que contém uma variedade de músicas, mostrando uma visão detalhada na imagem inferior.

A combinação dos tipos de entrada tags e características extraídas do sinal, pode enriquecer a visualização. Assim, Van Gulik e Vignoli (2005) apresentam uma visualização de coleções de músicas em Mp3, baseada em grafos, para navegar em dispositivos de tela pequena. Esta visualização, chamada artist map, destaca a semelhança entre os artistas usando características extraídas diretamente do sinal de áudio, mas com tags adicionados para fornecer informações contextuais, tais como gênero, humor e ano. Alguns destes tags podem ser obtidos a partir de serviços de música. O posicionamento das músicas é baseado em forças para a criação de listas de reprodução. A Figura 4.8 apresenta um 


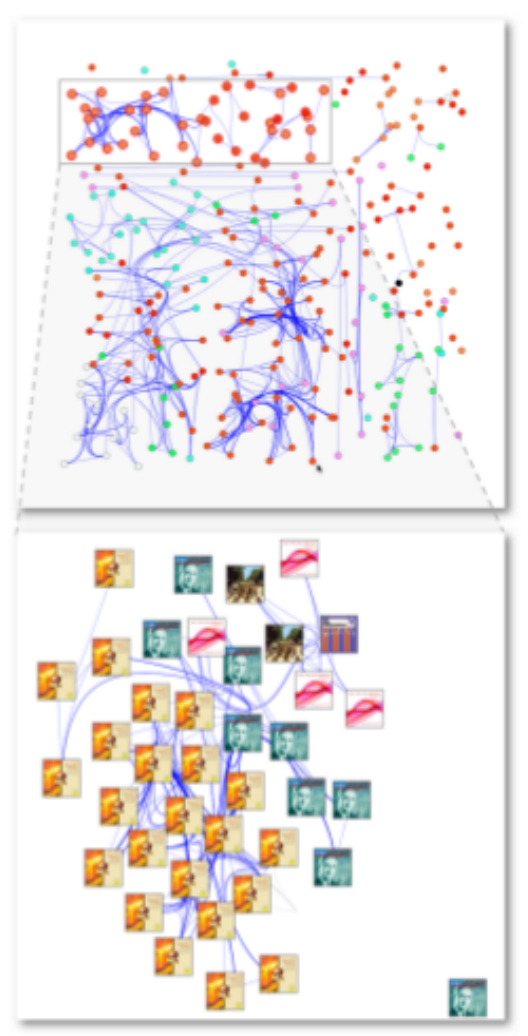

Figura 4.7: Exemplo da visualização por grafo, e da visão de detalhe relativa a uma região selecionada. Fonte: Muelder et al. (2010)

exemplo de desenhos de listas de reprodução em um mapa com 45 artistas, no qual o agrupamento é baseado no ano de lançamento.

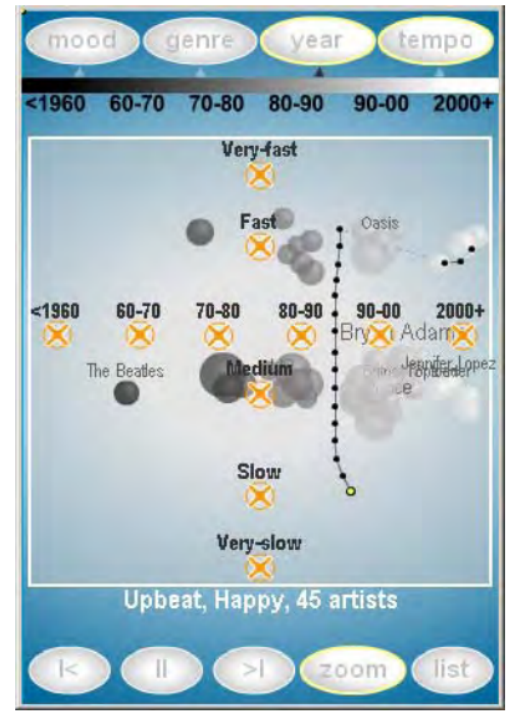

Figura 4.8: Exemplo de desenhos de listas de reprodução em um mapa com 45 artistas. O agrupamento está baseado no ano de lançamento. Fonte: Van Gulik e Vignoli (2005) 
Todas estas abordagens dependem das características extraídas diretamente do sinal de áudio para gerar representações baseadas nas similaridades. Tais características não apoiam a identificação de certas relações, por exemplo, as composições musicais que compartilham estruturas semelhantes, mas que usam ajustes musicais distintos.

\subsection{Visualizações de músicas individuais}

Wolkowicz et al. (2009) propõem a visualização MIDIvis, a qual gera uma imagem a partir de uma música em formato MIDI. A música é exibida como uma imagem retangular com quadrados de diferentes cores, em que cada quadrado representa a similaridade entre duas notas correspondentes tocadas em tempos $t_{i}$ e $t_{j}$. Para criar a visualização são utilizadas as matrizes de similaridade (Foote, 1999), permitindo revelar a estrutura das músicas. Não é adequado mapear os comprimentos das notas e os tons diretamente para uma função de comparação, uma vez que duas musicas semelhantes em diferentes escalas não teriam semelhanças melódicas e duas músicas com a mesma melodia, só que uma tocada mais lenta do que a outra, não teriam semelhanças rítmicas. Assim, como solução a este problema, os autores consideram um tom relativo e uma duração relativa (intervalos de tom e duração). Wolkowicz et al. (2009) introduzem a noção de unigramas, ou as menores unidades de melodia e ritmo. Cada unigrama representa o tom e o tempo relativo entre duas notas consecutivas: o primeiro valor é a diferença de tons das notas correspondentes, e o segundo valor é o logaritmo binário da proporção entre as durações correspondentes das notas. A mesma melodia tocada em vários tempos e em diferentes tons resultará na mesma sequência de unigramas. A qualidade da visualização é, obviamente, dependente da qualidade da codificação do MIDI. A Figura 4.9 apresenta um exemplo da visualização MIDIvis para a música The Magical Mystery Tour, dos Beatles.

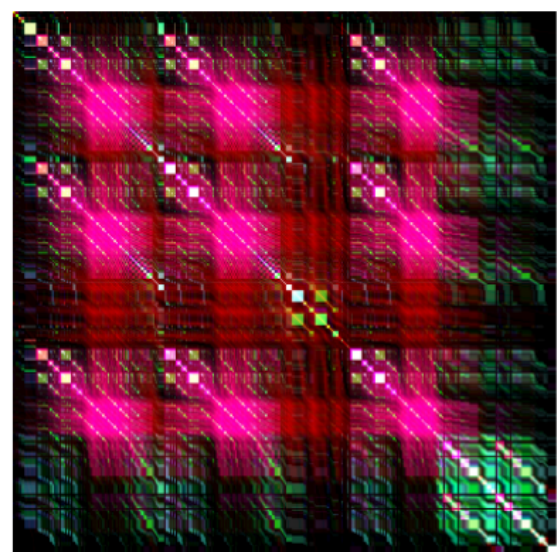

Figura 4.9: Visualização MIDIvis da música The Magical Mystery Tour, dos Beatles. Fonte: Wolkowicz et al. (2009) 
Outro trabalho que visualiza músicas individuais foi proposto por Müller e Jiang (2012), o qual explora a ideia de transmitir visualmente estruturas repetidas em uma música em formato Mp3. Eles realizam uma análise da estrutura da música para segmentá-la e calcular uma medida de aptidão que atribui a cada segmento da música um valor de aptidão. Com base na segmentação induzida, os autores definem uma medida de distância que permite comparar dois segmentos arbitrários, e, em seguida, mapeiam os segmentos semelhantes a cores semelhantes. Com tais informações e valores de aptidão, geram visualizações scape plot que indicam as propriedades repetitivas dos segmentos e as suas relações. Estes scape plots podem ser combinados em uma única representação hierárquica chamada scape plot estruturado. A Figura 4.10 apresenta um exemplo do scape plot estruturado para a música While My Guitar Gently Weeps, dos Beatles. Nesta figura é refletida a forma musical em geral, na qual cada um dos quatro segmentos verso consiste de subpartes repetidas, $I$ é a introdução e $O$ é o outro (conclusão ou epílogo de uma música).

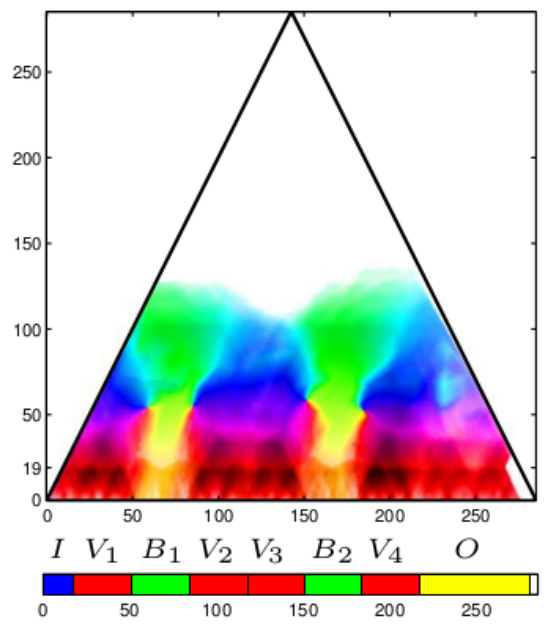

Figura 4.10: Scape plot estruturado da música While My Guitar Gently Weeps, dos Beatles. Nesta figura é refletida a forma musical em geral, na qual cada um dos quatro segmentos verso consiste de subpartes repetidas, $I$ é a introdução e $O$ é o outro (conclusão ou epílogo de uma música). Fonte: Müller e Jiang (2012)

Outro exemplo interessante é a visualização chamada The Shape of Song criada por Wattenberg (2002), especialista em visualização de informação na IBM Research. Os diagramas visuais exibem músicas como sequências de arcos translúcidos em que cada arco coneta dois trechos idênticos repetidos em uma composição, refletindo sua estrutura. Os arquivos MIDI descrevem várias faixas que representam diferentes instrumentos ou vozes. Cada faixa é analisada em separado para produzir as visualizações. 
Por último, cada descrição MIDI tem características únicas de tempo e ritmo, as quais afetam os diagramas resultantes. A Figura 4.11 apresenta um exemplo para a música Like a prayer, de Madonna e a Figura 4.12 é a visualização da música Fur Elise, de Beethoven.

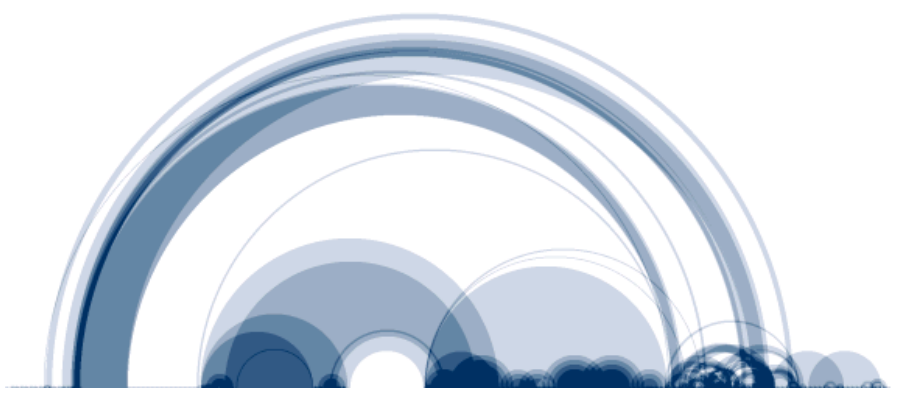

Figura 4.11: The Shape of Song para a música Like a prayer, de Madonna. Fonte: http://www.turbulence.org/Works/song/

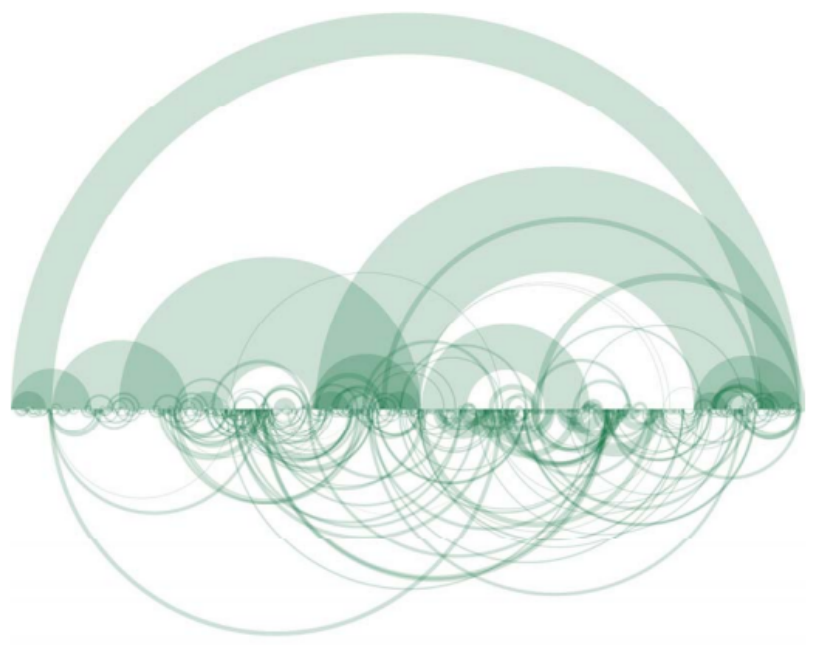

Figura 4.12: The Shape of Song para a música Fur Elise, de Beethoven. Fonte: Wattenberg (2002) 


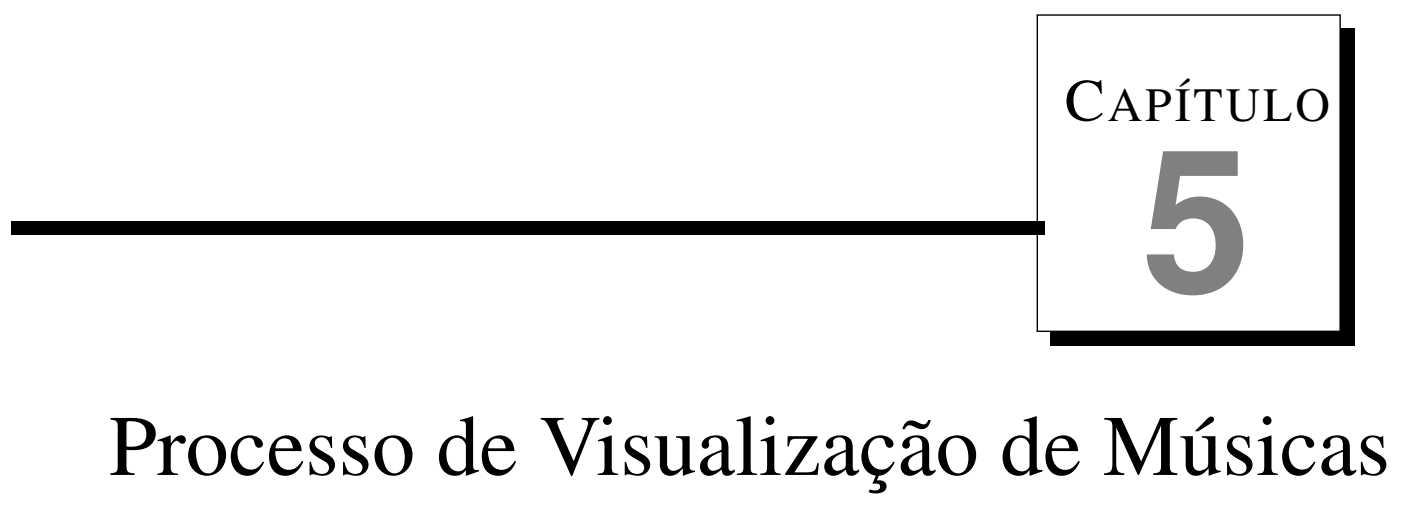

O uso de metáforas visuais é eficaz para a comunicação do conhecimento (Burkhard e Meier, 2004).

\subsection{Considerações Iniciais}

A Figura 5.1 apresenta o processo realizado para a visualização de músicas. A partir de uma coleção de músicas em formato MIDI são obtidos vetores de características. A técnica de projeção Least Square Projection (LSP) é aplicada sobre esses vetores, para reduzir a dimensionalidade e obter o posicionamento das músicas na visualização proposta. Ressalta-se que o formato MIDI foi escolhido por apresentar dados mais intuitivos à percepção humana, como as notas musicais, suas velocidades, instrumentos usados, etc. Os passos desse processo e as metáforas propostas neste trabalho são detalhados neste capítulo.

\subsection{Conceitos básicos sobre teoria musical}

Nesta seção são descritos os conceitos musicais básicos para entender as abordagens propostas neste trabalho.

- Nota musical Uma nota musical é um sinal, cuja altura representa o som musical, e a largura a frequência. Existem apenas sete notas musicais básicas. O monge 


\section{(Entrada)}

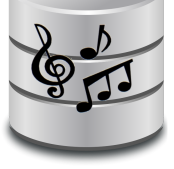

Coleção de música

em formato MIDI

(2)

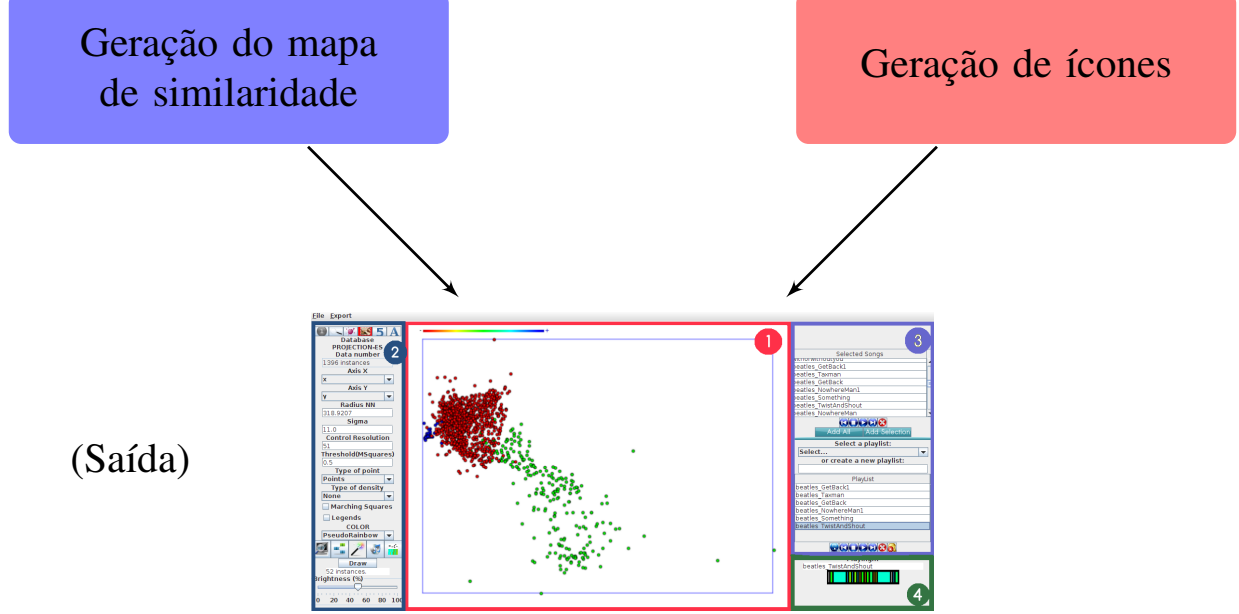

(3)

Figura 5.1: Visão global do processo de visualização de músicas. 


\begin{tabular}{|c|c|c|}
\hline Duração & Nota & Nome \\
\hline 1 & o & Semibreve \\
\hline 2 & $d$ & Mínima \\
\hline 4 & $d$ & Semínima \\
\hline 8 & $d$ & Colcheia \\
\hline 16 & Semicolcheia \\
\hline 32 & & Fusa \\
\hline 64 & & Semifusa \\
\hline
\end{tabular}

Tabela 5.1: Figuras musicais: unidades do tempo.

Guido d'Arezzo, considerado o pai da notação musical, desenvolveu uma estrutura para a notação atual, atribuindo nomes às notas, exceto para a sétima nota, SI-B, que naquela época era considerada um tom diabólico. Atualmente, existem diferentes sistemas utilizados para dar nomes às notas, os mais usados são o sistema latino e o sistema inglês. De acordo com o sistema latino, os nomes das notas são: DO - RE - MI - FA - SOL - LA - SI, mas no sistema inglês são usadas letras para representar cada nota, sendo: C - D - E - F - G - A - B. Neste trabalho é usada a notação inglesa.

\section{- Unidades do Tempo}

Estas unidades são chamadas também figuras musicais e são símbolos que representam a duração das notas musicais. A duração real (medida em segundos) de uma nota depende da fórmula do compasso e do tempo utilizado. Isto significa que a mesma nota pode ser executada com uma duração diferente em músicas diferentes, ou dentro da mesma música, se houver uma alteração do ritmo. A Tabela 5.1 apresenta as figuras musicais em ordem decrescente, com o seu nome, duração e representação.

\section{- Tempo e compasso}

O tempo e o compasso regulam as unidades temporais que devem existir em cada barra ou compasso. Os compassos são definidos como a medida de tempo que divide a música em pequenas seções, indicados por linhas que dividem o pentagrama em várias partes e determinam a estrutura rítmica da música. A Figura 5.2 apresenta um exemplo da barra divisória utilizada para separar dois compassos. O compasso escolhido está diretamente associado ao gênero musical. Uma valsa, por exemplo, tem o ritmo de $3 / 4$ e um rock, normalmente, usa o compasso 4/4. Em uma fracção do compasso, o denominador indica a unidade de medida, que define em quantas partes uma semibreve deve ser dividida. O numerador proporciona o número de tempos em cada compasso. Por exemplo, um compasso 3/4 corresponde a 3 
unidades $1 / 4$ da semibreve ou seja uma semínima.

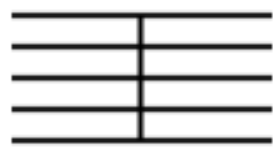

Figura 5.2: Barra divisória.

\section{- Acidentes ou alterações musicais}

Acidentes ou alterações musicais são símbolos utilizados dentro da notação musical para modificar a altura da nota, tornando-as meio tom mais graves ou meio tom mais agudas. São representadas pelo símbolo \# que é o sustenido e $b$ que é o bemol. O sustenido representa o aumento da nota em um meio tom e o bemol representa a diminuição de um meio tom da mesma. Existem outras alterações musicais que não são utilizadas neste trabalho, e portanto são desconsideradas. É necessário ressaltar que existem equivalências entre os nomes de algumas notas, por exemplo: $E b$ é a mesma nota que $D \#$, a notação \# acrescenta um semitom à nota $D$, e a notação $b$ diminui um semitom à nota $E$.

\section{- Armadura de chave}

A armadura de chave é o conjunto de alterações musicais (sustenidos ou bemóis) que dão nome a uma tonalidade, indicando a escala em que a música será expressa. Por exemplo, uma representação sem sustenidos ou bemóis, será a escala de $C$ Maior ou $A$ menor. As diferentes tonalidades são caracterizadas pelo número de alterações. As alterações possíveis de bemóis são: $\mathrm{B} b-\mathrm{E} b-\mathrm{A} b-\mathrm{D} b-\mathrm{G} b-\mathrm{C} b-$ $\mathrm{F} b$, e por exemplo se são utilizadas apenas as dois primeiras alterações de bemóis, corresponde a uma tonalidade $\mathrm{B} b$ maior ou $\mathrm{G}$ menor. As alterações de sustenidos são: F\# - C\# - G\# - D\# - A\# - E\# - B\#, e por exemplo se são utilizadas apenas os 4 primeiros sustenidos então a tonalidade é E maior ou C\# menor. A Tabela 5.2 apresenta um recurso útil na identificação da tonalidade.

- Acorde Usualmente, um acorde está formado por três ou mais notas diferentes soando simultaneamente ou em sucessão, as quais são consideradas uma unidade harmoniosa; o conjunto mais simples é de três notas (tríade), formada por três notas da escala seguindo certa regra, estas notas podem ser executadas por um mesmo instrumento, ou com notas executadas por diferentes instrumentos (incluindo a voz), como é ilustrado na Figura 5.3.4. A Tabela 5.3 apresenta a conformação de tríades de um acorde maior e a Tabela 5.4 de um acorde menor. 


\begin{tabular}{|c|c|c|}
\hline Armadura & Tonalidade maior & Tonalidade menor \\
\hline $\mathrm{Bb}, \mathrm{Eb}, \mathrm{Ab}, \mathrm{Db}, \mathrm{Gb}, \mathrm{Cb}, \mathrm{Fb}$ & Cb maior & Ab menor \\
\hline $\mathrm{Bb}, \mathrm{Eb}, \mathrm{Ab}, \mathrm{Db}, \mathrm{Gb}, \mathrm{Cb}$ & Gb maior & Eb menor \\
\hline $\mathrm{Bb}, \mathrm{Eb}, \mathrm{Ab}, \mathrm{Db}, \mathrm{Gb}$ & Db maior & Bb menor \\
\hline $\mathrm{Bb}, \mathrm{Eb}, \mathrm{Ab}, \mathrm{Db}$ & Ab maior & F menor \\
\hline $\mathrm{Bb}, \mathrm{Eb}, \mathrm{Ab}$ & Eb maior & C menor \\
\hline Bb, Eb & Bb maior & G menor \\
\hline Bb & F maior & D menor \\
\hline & C maior & A menor \\
\hline F\# & G maior & E menor \\
\hline F\#, C\# & D maior & B menor \\
\hline F\#, C\#, G\# & A maior & F\# menor \\
\hline F\#, C\#, G\#, D\# & E maior & C\# menor \\
\hline F\#, C\#, G\#, D\#, A\# & B maior & G\# menor \\
\hline F\#, C\#, G\#, D\#, A\#, E\# & F\# maior & D\# menor \\
\hline F\#, C\#, G\#, D\#, A\#, E\#, B\# & C\# maior & A\# menor \\
\hline & &
\end{tabular}

Tabela 5.2: Armadura chave.

\begin{tabular}{|c|c|c|c|}
\hline Acorde Maior & \multicolumn{3}{|c|}{ Tríade } \\
\hline C & C & E & G \\
\hline C\# & C\# & F & G\# \\
\hline D & D & F\# & A \\
\hline D\# & D\# & G & A\# \\
\hline E & E & G\# & B \\
\hline F & F & A & C \\
\hline F\# & F\# & A\# & C\# \\
\hline G & G & B & D \\
\hline G\# & G\# & C & D\# \\
\hline A & A & C\# & E \\
\hline A\# & A\# & D & F \\
\hline B & B & D\# & F\# \\
\hline
\end{tabular}

Tabela 5.3: Tríades de um acorde maior

\begin{tabular}{|c|c|c|c|}
\hline Acorde Menor & \multicolumn{3}{|c|}{ Tríade } \\
\hline $\mathrm{Cm}$ & $\mathrm{C}$ & $\overline{D \#}$ & $\mathrm{G}$ \\
\hline $\mathrm{C \# m}$ & $\mathrm{C \#}$ & $\mathrm{E}$ & $\mathrm{G \#}$ \\
\hline$\overline{\mathrm{Dm}}$ & $\mathrm{D}$ & $\bar{F}$ & $\bar{A}$ \\
\hline D\#m & D\# & F\# & A\# \\
\hline Em & $E$ & $\mathrm{G}$ & $\bar{B}$ \\
\hline Fm & $\overline{\mathrm{F}}$ & $\mathrm{G \#}$ & $\mathrm{C}$ \\
\hline F\#m & F\# & $\mathrm{A}$ & $\mathrm{C \#}$ \\
\hline $\mathrm{Gm}$ & $\mathrm{G}$ & $\mathrm{A \#}$ & $\mathrm{D}$ \\
\hline G\#m & $\mathrm{G \#}$ & $\bar{B}$ & $\overline{D \#}$ \\
\hline $\mathrm{Am}$ & $\mathrm{A}$ & $\mathrm{C}$ & $\mathrm{E}$ \\
\hline A\#m & $\mathrm{A \#}$ & $\mathrm{C \#}$ & $\mathrm{F}$ \\
\hline $\mathrm{Bm}$ & $\mathrm{B}$ & $\mathrm{D}$ & F\# \\
\hline
\end{tabular}

Tabela 5.4: Tríades de um acorde menor

- Campo harmônico O campo harmônico está relacionado com algo que nós percebemos por instinto, a harmônia. Por exemplo ao compôr uma música tentamos achar uma sequencia de notas que combinem entre si. Assim, o campo harmônico de uma tonalidade é o conjunto de acordes que dão harmônia básica a uma melodia. A Tabela 5.5 apresenta os campos harmônicos para cada tonalidade maior e a 
a Tabela 5.6 para cada tonalidade menor.

\begin{tabular}{|c|c|c|c|c|c|c|c|}
\hline Tonalidade Maior & \multicolumn{7}{|c|}{ Campo harmônico } \\
\hline & I & II & III & IV & V & VI & VII \\
\hline & Maior & Menor & Menor & Maior & Maior & Menor & Dim \\
\hline C & C & Dm & Em & F & G & Am & Bdim \\
\hline C\# & C\# & D\#m & Fm & F\# & G\# & A\#m & Cdim \\
\hline D & D & Em & F\#m & G & A & Bm & C\#dim \\
\hline D\# & D\# & Fm & Gm & G\# & A\# & Cm & Ddim \\
\hline E & E & F\#m & G\#m & A & B & C\#m & D\#dim \\
\hline F & F & Gm & Am & A\# & C & Dm & Edim \\
\hline F\# & F\# & G\#m & A\#m & B & C\# & D\#m & Fdim \\
\hline G & G & Am & Bm & C & D & Em & F\#dim \\
\hline G\# & G\# & A\#m & Cm & C\# & D\# & Fm & Gdim \\
\hline A & A & Bm & C\#m & D & E & F\#m & G\#dim \\
\hline A\# & A\# & Cm & Dm & D\# & F & Gm & Adim \\
\hline B & B & C\#m & D\#m & E & F\# & G\#m & A\#dim \\
\hline
\end{tabular}

Tabela 5.5: Campos harmônicos para cada tonalidade maior

\begin{tabular}{|c|c|c|c|c|c|c|c|}
\hline Tonalidade Menor & \multicolumn{7}{|c|}{ Campo harmônico } \\
\hline & I & II & III & IV & V & VI & VII \\
\hline & Menor & Dim & Maior & Menor & Menor & Maior & Maior \\
\hline Cm & Cm & Ddim & D\# & Fm & Gm & G\# & A\# \\
\hline C\#m & C\#m & D\#m & E & F\#m & G\#m & A & B \\
\hline Dm & Dm & Edim & F & Gm & Am & A\# & C \\
\hline D\#m & D\#m & Fdim & F\# & G\#m & A\#m & B & C\# \\
\hline Em & Em & F\#dim & G & Am & Bm & C & D \\
\hline Fm & Fm & Gdim & G\# & A\#m & Cm & C\# & D\# \\
\hline F\#m & F\#m & G\#dim & A & Bm & C\#m & D & E \\
\hline Gm & Gm & Adim & A\# & Cm & Dm & D\# & F \\
\hline G\#m & G\#m & A\#dim & B & C\#m & D\#m & E & F\# \\
\hline Am & Am & Bdim & C & Dm & Em & F & G \\
\hline A\#m & A\#m & Cdim & C\# & D\#m & Fm & F\# & G\# \\
\hline Bm & Bm & C\#dim & D & Em & F\#m & G & A \\
\hline
\end{tabular}

Tabela 5.6: Campos harmônicos para cada tonalidade menor

\subsection{Musical Instrument Digital Interface (MIDI)}

MIDI pertence a um grupo de formatos chamados simbólicos, que representam a informação de uma forma diferente dos arquivos de áudio, que armazenam sinais. Os arquivos simbólicos, em contraste, armazenam características de alto nível, ou seja, abstrações musicais que são significativas para pessoas treinadas musicalmente, como os instrumentos usados, contornos melódicos, frequências de acordes, densidade rítmica, entre outros. Existem outros formatos simbólicos como NIFF (Notation Interchange File Format), RIFF (Resource Interchange File Format), MusicXML e outros. Mas MIDI é, de longe, o formato de arquivo simbólico mais conhecido pelo público em geral . Como consequência, existe uma grande quantidade de músicas de vários tipos que foram codificadas nesse formato. Ironicamente, o MIDI foi originalmente concebido como um protocolo em 
tempo real para a comunicação entre os controladores de instrumentos e sintetizadores, e não como especificação de formato de música. No entanto, foi adotado pela indústria musical, o que resultou em ampla popularidade como um formato para armazenar dados simbólicos musicais (McKay, 2010).

Os arquivos MIDI armazenam essencialmente sequências de instruções chamadas mensagens MIDI. Cada uma destas mensagens corresponde a um evento ou alteração de um parâmetro de controle. O MIDI permite a utilização de até 16 canais de forma independente, nos quais diferentes tipos mensagens podem ser enviadas, representando diferentes instrumentos ou vozes. Há duas importantes classes de mensagens: mensagens de canal e mensagens de sistema. Um dos tipos mais relevantes é a mensagem de canal de voz. As mensagens de canal de voz podem ser: Note On, Note Off, Channel Pressure, Polyphonic Key Pressure, Program Change, Control Change e Pitch Bend. Para este trabalho foram usadas as mensagens Note On e Note Off, já que fornecem as notas que são reproduzidas ao longo da música. A mensagem Note On indica que temos que começar a tocar uma nota. Essa nota vai continuar tocando até que seja recebida uma mensagem de Note Off.

A sincronização do MIDI é controlada por um relógio que emite ticks a intervalos regulares. A taxa do relógio está usualmente relacionada à duração das notas, em um quarto de nota (Parts per quarter note (PPQN)). A maior PPQN corresponde a uma maior resolução rítmica, que permite acelerar ou retardar o ritmo. Além disso, o MIDI permite incluir outras informações como o número de bemóis $(s f)$ ou sustenidos $(m i)$. Por exemplo, $C$ maior e $A$ menor são representados pelo número 0 (sem sustenidos e bemóis), o número 3 representa 3 sustenidos ( $A$ maior ou $F \#$ menor) e o número -2 representa dois bemóis ( $B b$ maior ou $G$ menor). $m i$ indica se a peça é maior (0) ou menor (1). Ressalta-se que nem todos os MIDIs possuem esta informação.

Além das mensagens, os MIDIs também contêm meta-eventos de armadura de tempo, os quais podem ser: $n n, d d, c c$ e $b b$. $n n$ e $d d$ são o numerador e o denominador da armadura de tempo. $c c$ é o número de ticks em um metrônomo e $b b$ é o número de 32 notas em um quarto de nota MIDI.

\subsection{Extração de características}

Nesta seção, é descrita detalhadamente a forma de extrair a estrutura das músicas, além de apresentar outros tipos de características utilizados para comparar os resultados. 


\subsubsection{Estrutura musical}

O primeiro passo para extrair a estrutura musical é segmentar a música em compassos, usando os metadados de armadura de tempo do MIDI. Uma vez segmentada a música, o passo seguinte é identificar a tonalidade da música, na qual giram as progressões musicais. Algumas músicas no formato MIDI já contém metadados para a identificação da tonalidade musical, mas outras não. Neste caso, é necessário verificar como está composta a armadura de chave. Dentro do conjunto de notas, realiza-se uma verificação das alterações que aparecem e segundo isso, pode-se estabelecer o nome da tonalidade.

Após definir a tonalidade, é procurado seu campo harmônico. A partir do campo harmônico, é possível obter os acordes, nos quais gira a música. Resta apenas identificar, nas notas do MIDI, o conjunto delas que conformam um acorde. A Figura 5.3 apresenta uma visão geral dos passos necessários para a extração da estrutura musical.

(2)

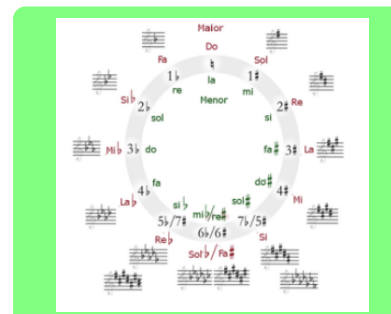

(1)

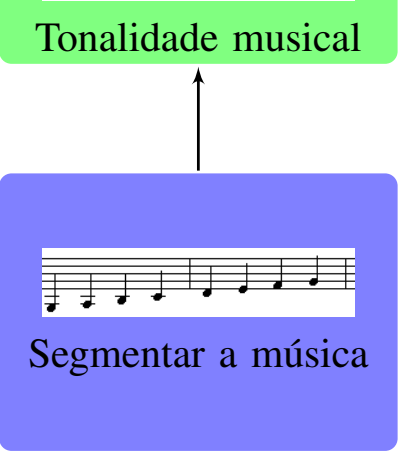

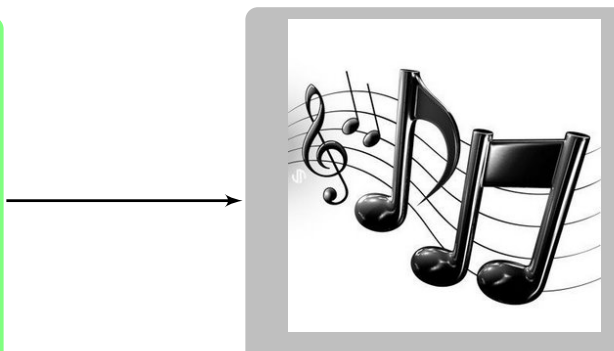

Possíveis acordes

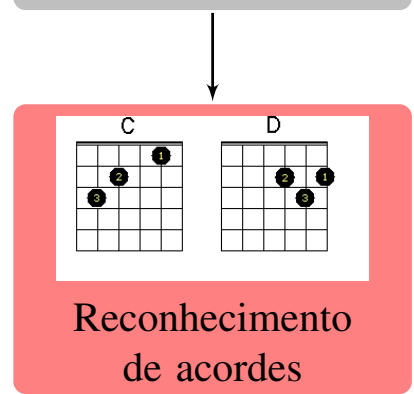

(3)

Figura 5.3: Processo de reconhecimento de acordes

\subsubsection{Momentos estatísticos}

Alternativamente, técnicas estatísticas simples podem ser úteis para capturar características globais de uma música (Lartillot et al., 2007). Uma abordagem para a descrição de músicas é quantificar seu conteúdo de velocidade e de notas musicais. Esta abordagem fornece uma aproximação à percepção humana, que para diferenciar duas músicas faz uso do ritmo e da melodia intuitivamente. Para este objetivo, foram usadas a média, o desvio padrão, a uniformidade e a entropia. 
Seja $z$ uma variável aleatória que denota uma nota musical de 0 a 128 ou a velocidade com a qual é pressionada uma nota que vai de 0 a 127. $p\left(z_{i}\right)$ é a probabilidade no histograma de $z_{i}$, na qual $i=0,1,2, \ldots, L-1$, sendo $L$ o número de níveis distintos (129 no caso de notas musicais e 128 no caso da velocidade).

O primeiro momento usado é a média $(m)$, calculada para obter o valor médio das notas musicais e da velocidade. A Equação 5.1 é aplicada sobre o histograma de notas e sobre o histograma de velocidades.

$$
m=\sum_{i=0}^{L-1} z_{i} p\left(z_{i}\right)
$$

O segundo momento, o desvio padrão $(\sigma(z))$ é usado frequentemente como uma medida porque os valores tendem a ser mais intuitivos. É uma medida do grau de centralização ou dispersão, que mostra a variação em relação à média. Assim, um valor baixo para o desvio padrão indica que os dados estão próximos da média e um desvio padrão alto indica que os dados estão espalhados. O desvio padrão é definido como a raiz quadrada da variância $\left(\sigma^{2}(z)\right)$, a qual é definida pela Equação 5.2.

$$
\sigma^{2}(z)=\sum_{i=0}^{L-1}\left(z_{i}-m\right)^{n} p\left(z_{i}\right)
$$

em que $m$ é o valor médio de $z$. A Equação 5.3 define o desvio padrão, sendo aplicado tanto ao histograma de notas como ao histograma das velocidades.

$$
\sigma(z)=\sqrt{\sigma^{2}(z)}
$$

O terceiro momento usado é a uniformidade $(U(z))$ obtida por meio da Equação 5.4.

$$
U(z)=\sum_{i=0}^{L-1} p^{2}\left(z_{i}\right)
$$

A uniformidade será alta para uma música em que todas as notas musicais sejam iguais ou constantes, no caso de ser aplicado na melodia, e será alta para uma música em que todas as velocidades sejam iguais ou constantes, no caso do ritmo. Finalmente, o quarto momento utilizado é a entropia $(e(z))$, o qual pode ser definido como a medida de desordem ou de incerteza, dada pela Equação 5.5.

$$
e(z)=-\sum_{i=0}^{L-1} p\left(z_{i}\right) \log _{2} p\left(z_{i}\right)
$$




\subsubsection{Histograma de notas}

Outra alternativa para a extração de características a partir de músicas é o histograma de notas (Tzanetakis et al., 2002). Este histograma contém a quantidade das 12 notas possíveis que aparecem em uma música. Assim, duas músicas similares geram histogramas similares. O MIDI proporciona as notas de 0 a 127 o qual diferencia duas notas iguais em diferentes oitavas. Para obter a nota correspondente da escala de 0 a 12, precisa-se fazer módulo \%12 do número da nota. A Figura 5.4 apresenta um exemplo da distribuição da quantidade de notas de um histograma, e seus respectivos nomes.

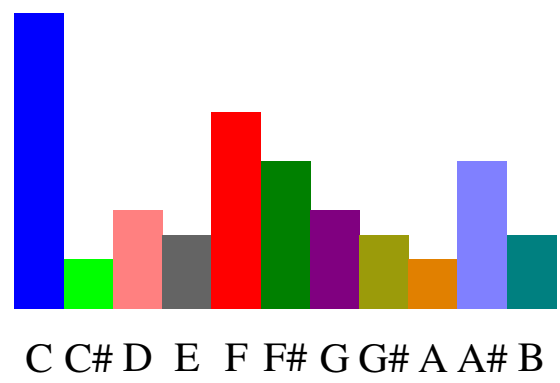

Figura 5.4: Exemplo de um histograma de notas.

\subsubsection{Características extraídas usando JSymbolic}

JSymbolic é uma ferramenta de extração de características de alto nível a partir de uma música em formato MIDI. Foi proposta por McKay (2010) e permite extrair 111 características que se encontram identificadas em 7 propriedades: instrumentos, textura, ritmo, dinamismo, estatísticas da tonalidade, melodia e acordes. A Figura 5.5 apresenta uma imagem da interface do JSymbolic.

\subsection{Representação icônica da música}

Um ícone consiste em uma imagem criada a partir do vetor de características obtido da música em formato MIDI. Neste trabalho, foram criados ícones sobre o vetor que descreve a estrutura musical. Cada instância de dados é representada por um ícone que exibe padrões de acordes repetidos, identificados por sua cor.

Sobre a estrutura musical obtida (Seção 5.4) é aplicado o algoritmo de casamento de strings Horspool (Levitin, 2003) para identificar padrões. A partir da sequência de acordes da estrutura musical são extraídos subconjuntos de tamanho inicial $\frac{N}{2}$, em que $N$ é o número total de acordes. Estes subconjuntos de acordes são os padrões a serem procurados na sequência por meio do algoritmo Horspool, o qual desloca o padrão sobre a sequência 


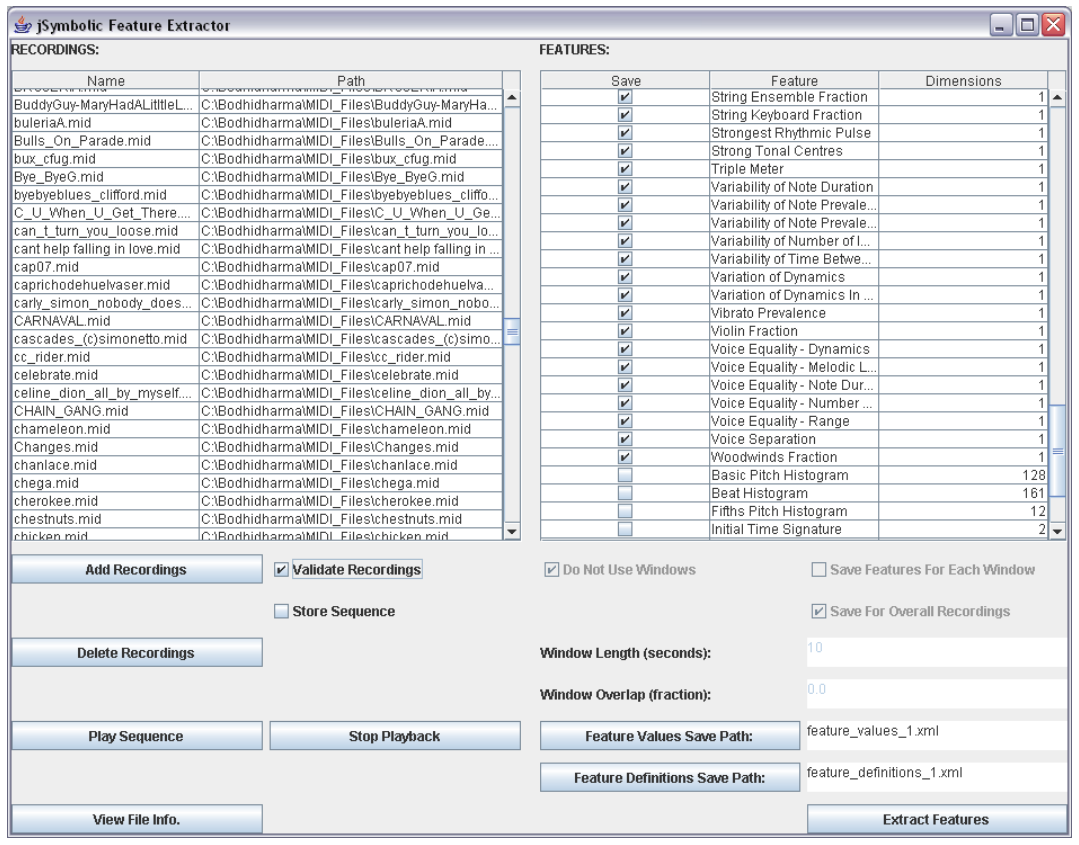

Figura 5.5: Imagem da interface do JSymbolic. Fonte: McKay (2010).

até encontrar uma ou mais ocorrências. Este processo é realizado iterativamente, diminuindo a cada passo em 1 o tamanho dos padrões a serem procurados. Finalmente, os padrões encontrados na sequência de acordes são representados no ícone mediante uma cor diferente para cada padrão. Este processo é sumarizado no Algoritmo 1.

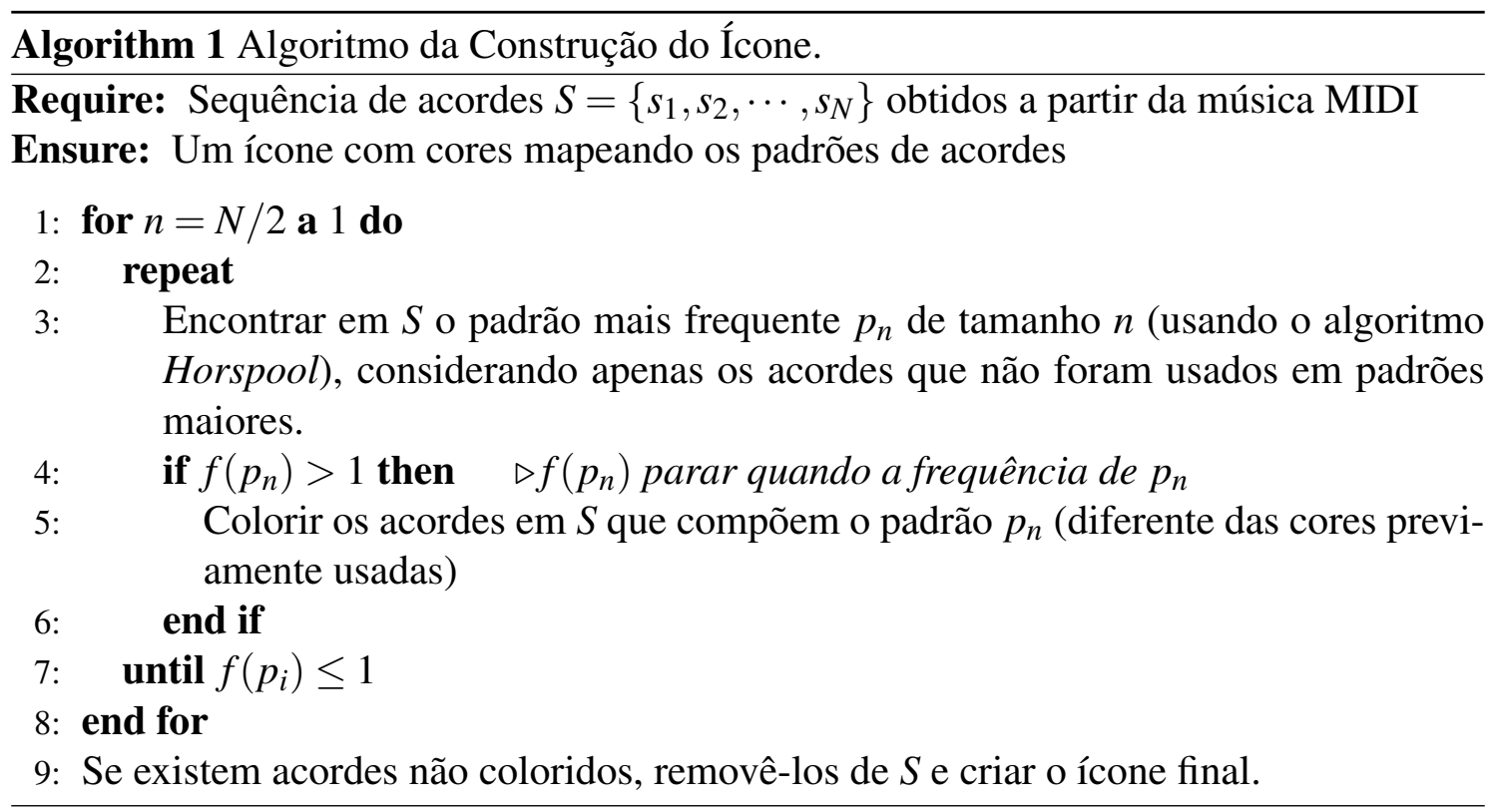

A Figura 5.6 mostra um exemplo simples da aplicação do Algoritmo 1 sobre uma sequência de acordes hipotética de tamanho $N=8$. Dada uma sequência de acordes $S$, como ilustrado na Figura 5.6.a, o ícone da música é obtido aplicando os seguintes passos. 


\begin{tabular}{|l|l|l|l|l|l|l|l|l|}
\hline $\mathrm{A}$ & $\mathrm{B}$ & $\mathrm{C}$ & $\mathrm{D}$ & $\mathrm{A}$ & $\mathrm{B}$ & $\mathrm{C}$ & $\mathrm{E}$ & $\mathrm{D}$ \\
\hline
\end{tabular}

(a) Sequência hipotética de acordes $S$.

\begin{tabular}{|c|c|c|c|c|c|}
\hline ABCD & BCDA & CDAB & DABC & ABCE & BCED \\
\hline 1 & 1 & 1 & 1 & 1 & 1 \\
\hline
\end{tabular}

(b) Padrões a serem procurados de tamanho 4 e o número de ocorrências.

\begin{tabular}{|c|c|c|c|c|c|}
\hline ABC & BCD & CDA & DAB & BCE & CED \\
\hline 2 & 1 & 1 & 1 & 1 & 1 \\
\hline
\end{tabular}

(c) Padrões a serem procurados de tamanho 3 e o número de ocorrências.

\begin{tabular}{|l|l|l|l|l|l|l|l|l|}
\hline $\mathrm{A}$ & $\mathrm{B}$ & $\mathrm{C}$ & $\mathrm{D}$ & $\mathrm{A}$ & $\mathrm{B}$ & $\mathrm{C}$ & $\mathrm{E}$ & $\mathrm{D}$ \\
\hline
\end{tabular}

(d) Sequência de acordes $S$ colorida, passo (ii).

\begin{tabular}{|c|c|c|c|c|c|}
\hline $\mathrm{AB}$ & $\mathrm{BC}$ & $\mathrm{CD}$ & $\mathrm{DA}$ & $\mathrm{CE}$ & $\mathrm{ED}$ \\
\hline 2 & 2 & 1 & 1 & 1 & 1 \\
\hline
\end{tabular}

(e) Padrões a serem procurados de tamanho $2 \mathrm{e}$ o número de ocorrências.

\begin{tabular}{|c|c|c|c|c|}
\hline $\mathrm{A}$ & $\mathrm{B}$ & $\mathrm{C}$ & $\mathrm{D}$ & $\mathrm{E}$ \\
\hline 2 & 2 & 2 & 2 & 1 \\
\hline
\end{tabular}

(f) Padrões a serem procurados de tamanho 1 e o número de ocorrências.

\section{\begin{tabular}{|l|l|l|l|l|l|l|l|l|}
\hline $\mathrm{A}$ & $\mathrm{B}$ & $\mathrm{C}$ & $\mathrm{D}$ & $\mathrm{A}$ & $\mathrm{B}$ & $\mathrm{C}$ & $\mathrm{E}$ & $\mathrm{D}$ \\
\hline
\end{tabular}}

(g) Sequência de acordes $S$ colorida, passo (iv).
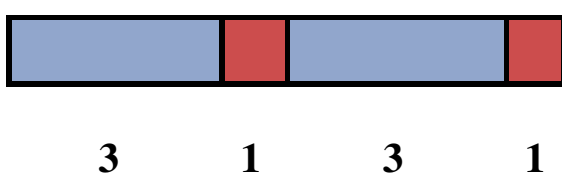

(h) Estrutura de padrões de acordes extraída de uma música. Os padrões que aparecem apenas uma vez não são significativos e podem ser removidos. Neste exemplo é removido o padrão $E$.

Figura 5.6: Etapas do processo de criação de um ícone da música. 
i) Define o tamanho dos padrões iniciais $n=\frac{N}{2}$. Neste exemplo, $n=4$. Os padrões e o número de ocorrências obtidas com o algoritmo Horspool são mostrados na Figura 5.6.b. Dado que todos os padrões apresentam apenas uma ocorrência, nenhum deles é selecionado.

ii) Define o tamanho dos padrões $n=3$. Os padrões e o número de ocorrências são mostrados na Figura 5.6.c. Notar que o padrão $A B C$ (segmento amarelo) aparece 2 vezes na sequência, por isso após verificar se o padrão não pertence a padrões maiores já rotulados, pode ser escolhido atribuindo-lhe uma cor, (Figura 5.6.d, cor azul).

iii) A Figura 5.6.e mostra os padrões de tamanho $n=2$ e o número de ocorrências. Neste caso, os padrões com mais de uma ocorrência $(A B$ e $B C)$ pertencem a padrões maiores já rotulados (passo (ii)), por isso estes são descartados.

iv) A Figura 5.6.f mostra os padrões de tamanho $n=1$ e o número de ocorrências. Apenas o padrão $D$ apresenta mais de uma ocorrência e não faz parte de padrões maiores já rotulados, assim é selecionado e rotulado com uma cor diferente (Figura 5.6.g, cor vermelha).

v) Os padrões que aparecem apenas uma vez não são significativos e podem ser removidos. Neste exemplo, é removido o padrão E. A Figura 5.6.h apresenta o resultado final do procedimento, para este exemplo.

\subsection{Mapas de similaridade}

O ícone que simboliza uma peça musical oferece uma representação gráfica do vetor de características que representa uma determinada música. Mais precisamente, cada vetor de características corresponde a um array no qual as entradas armazenam os segmentos das músicas detetados durante a construção do ícone. Por exemplo, o vetor de características correspondente à música simbolizada pelo ícone na Figura 5.6.h é [3,1,3,1]. Esses vetores de características podem ser interpretados como um sinal regular ou uma série temporal, com amplitudes dadas pelas entradas do vetor, como ilustrado na Figura 5.7. A Figura 5.7.a mostra o ícone calculado para uma música em particular (Wind of change, dos Scorpions) e a Figura 5.7.b descreve a representação do seu vetor de características correspondente como um sinal.

Dado um conjunto de músicas descritas por suas estruturas, é gerado um mapa de similaridade em um espaço bidimensional, projetando os vetores de características com a técnica Least Square Projection (LSP) (Paulovich et al., 2008). Para este trabalho, foi considerado produzir resultados melhores que os trabalhos existentes na literatura. Por tanto, foram estudadas várias técnicas de projeção multidimensional, e foram analisados seus resultados visuais, os quais mostraram que a técnica Least Square Projection (LSP) é adequada para as representações propostas. As Figuras 5.8, 5.9 e 5.10 mostram os 


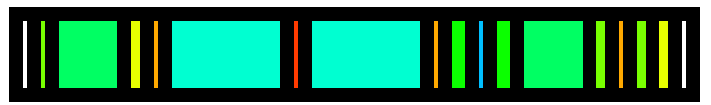

(a) Ícone

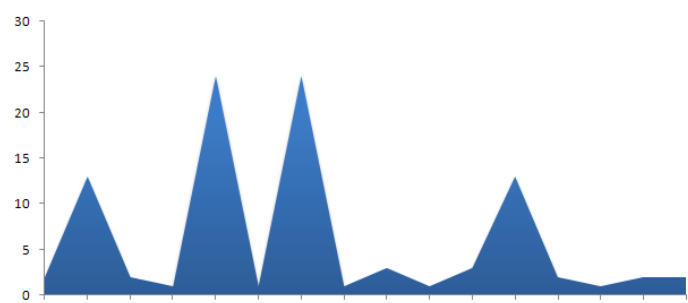

(b) Sinal

Figura 5.7: (a) Ícone da estrutura musical da música Wind of change, dos Scorpions, e (b) seu vetor de características correspondente, visto como uma série temporal.

resultados visuais das diferentes técnicas de projeção multidimensional estudadas, para um conjunto de 1.300 músicas distribuídas em três gêneros musicais. A cor de cada círculo indica o agrupamento: azul para música clássica, vermelho para rock e verde para sertanejo. Notar que as diferentes técnicas, exceto a técnica $L S P$, não conseguiram agrupar claramente os diferentes gêneros musicais.

A similaridade é avaliada usando a função de distância Dynamic Time Warping (DTW) (Berndt e Clifford, 1994). Esta distância é adequada uma vez que pode-se calcular a similaridade entre series temporais permitindo deslocamentos temporais para comparar as estruturas, encontrando assim uma correspondência ótima entre duas sequências dadas.

Por outro lado, é importante notar que os vetores de características e seus correspondentes sinais têm tamanhos diferentes, uma vez que cada música é representada por um número arbitrário de sequências de acordes relevantes. Apesar da DTW ser capaz de tratar sequências de tamanhos diferentes, obtivemos melhores resultados aplicando na menor sequência a interpolação pelo vizinho mais próximo, de modo que ambas as sequências tenham o mesmo tamanho ao realizar a comparação.

A Figura 6.1 ilustra um resultado obtido com o processo descrito. Inicialmente, cada música é representada por um círculo colorido de acordo com seu gênero. Esses layouts fornecem informações úteis sobre as relações entre as músicas, mas eles são difíceis de interpretar quando exibidos como nuvens de pontos, uma vez que pouca informação semântica é exibida sobre as músicas individuais, além de apresentar sobreposição e desordem. Buscando minimizar esse problema, propomos a combinação dos layouts que refletem a similaridade com os ícones que refletem a estrutura. Isto é conseguido associando aos layouts como nuvem de pontos, novas janelas que permitem visualizar uma lista de ícones musicais relativos a uma seleção do usuário. Exemplos são apresentados no Capítulo 6. 


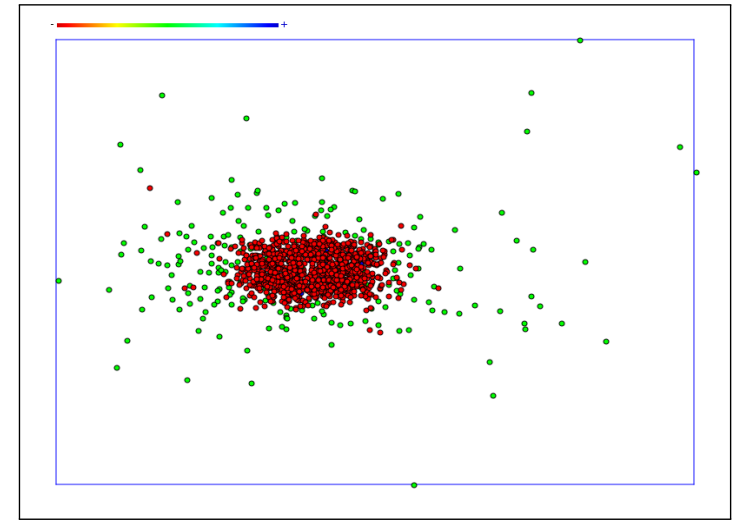

(a) Chalmers (Chalmers, 1996)

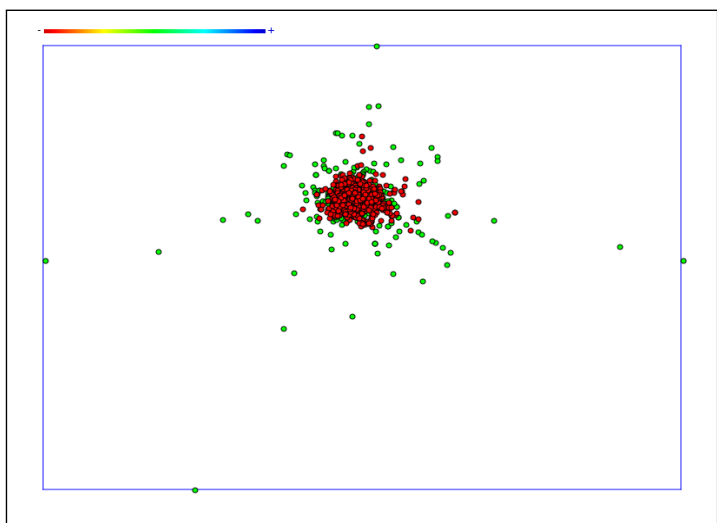

(c) Fastmap (Faloutsos e Lin, 1995)

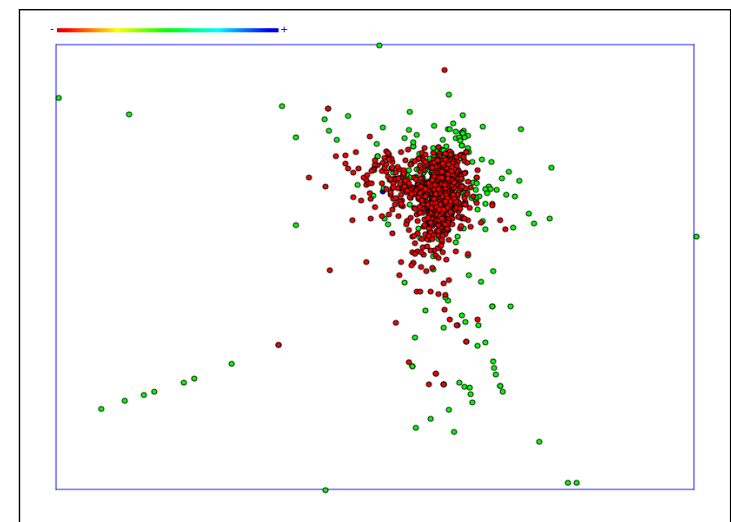

(e) Isomap (Tenenbaum et al., 2000)

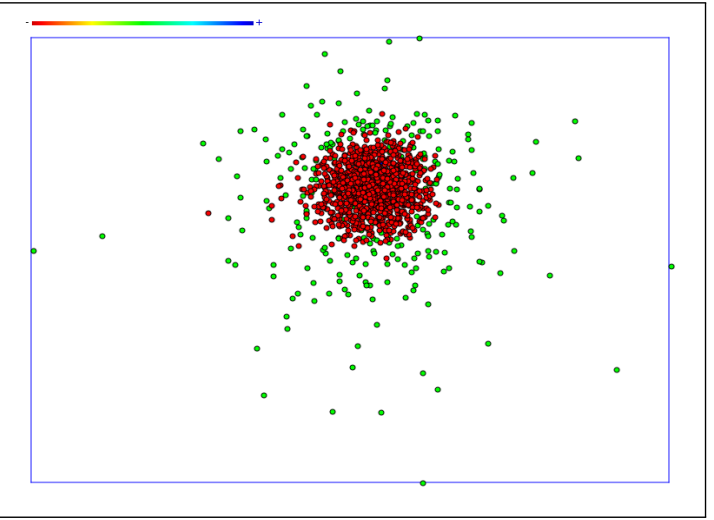

(b) Force Scheme (Tejada et al., 2003)

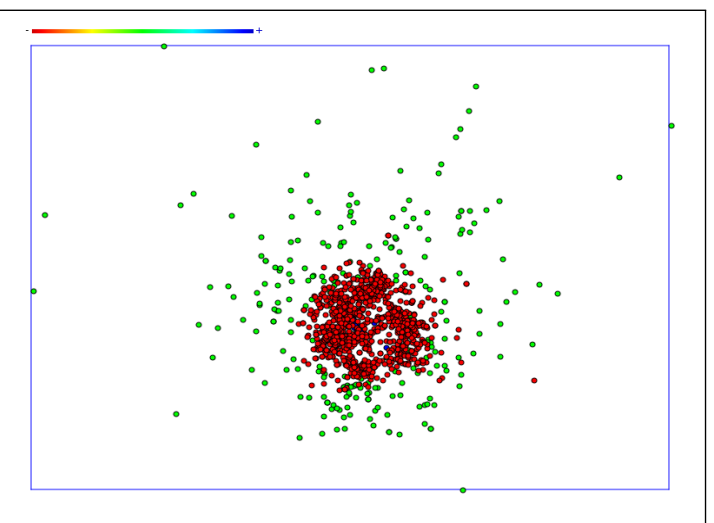

(d) Idmap (Minghim et al., 2006)

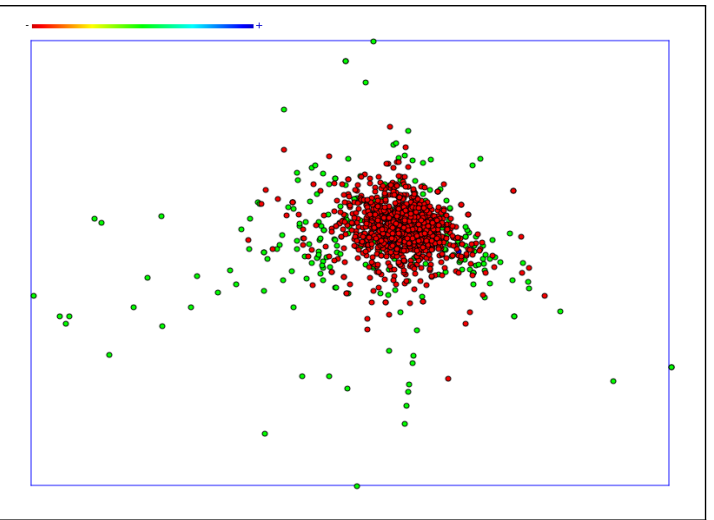

(f) $\operatorname{LAMP}$ (Joia et al., 2011)

Figura 5.8: Resultados visuais das diversas técnicas estudadas de projeção multidimensional, para um conjunto de 1.300 músicas distribuídas em três gêneros musicais. A cor de cada círculo indica o agrupamento: azul para música clássica, vermelho para rock e verde para sertanejo. 


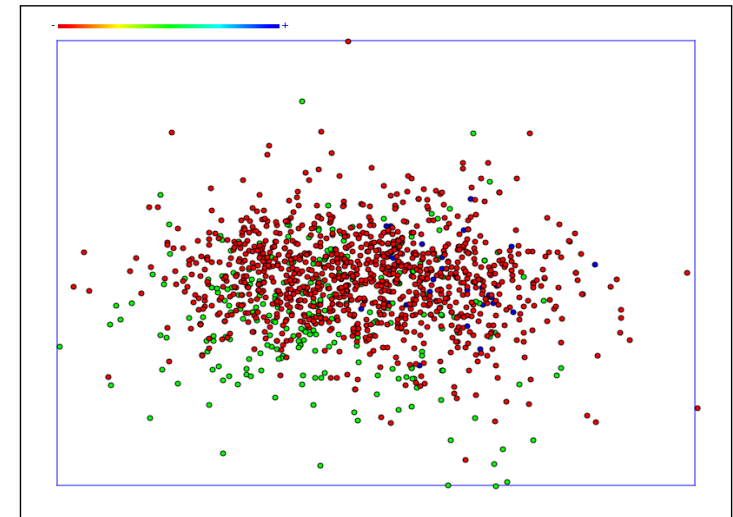

(a) Landmark Isomap (de Silva e Tenenbaum, 2003)

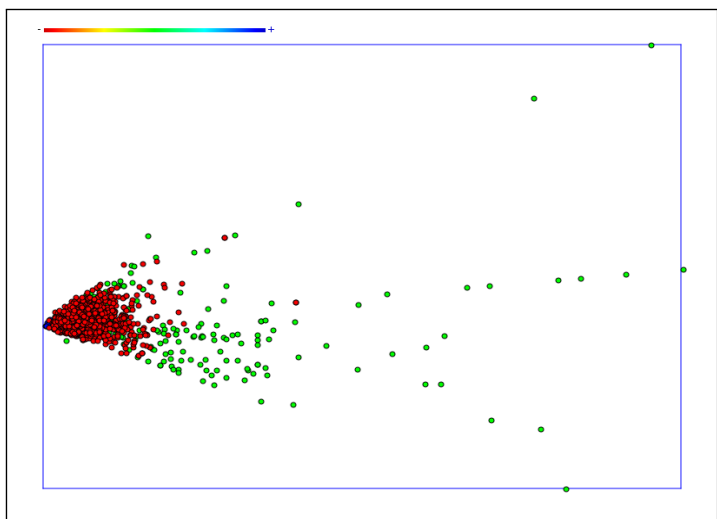

(c) $\operatorname{MDS}(\mathrm{Cox}$ e Cox, 2000)

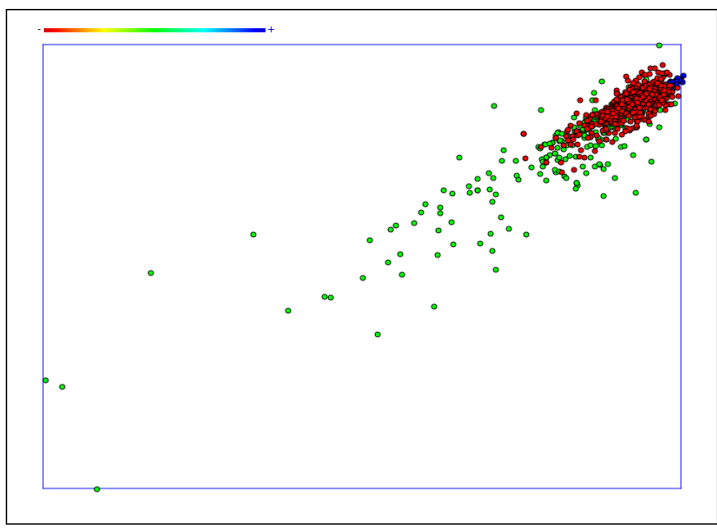

(e) PLS (Wold, 1985)

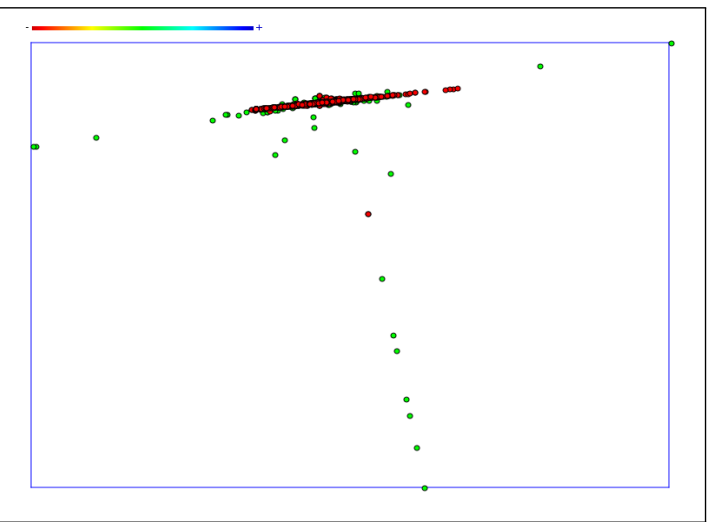

(b) LLE (Roweis e Saul, 2000)

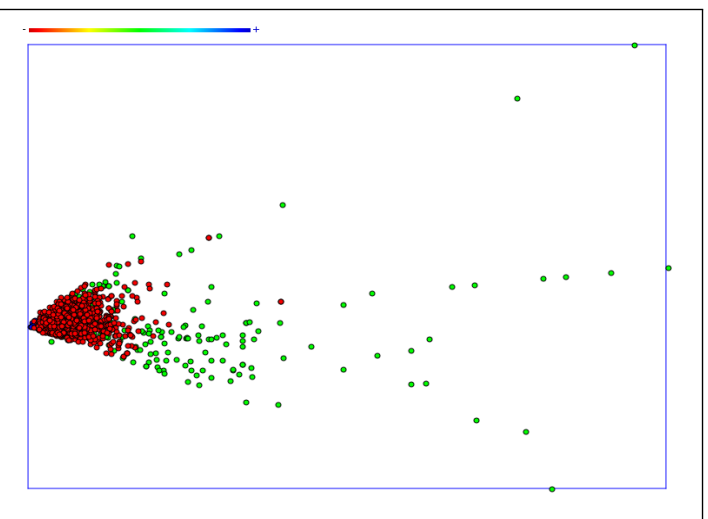

(d) PCA (Jolliffe, 1986)

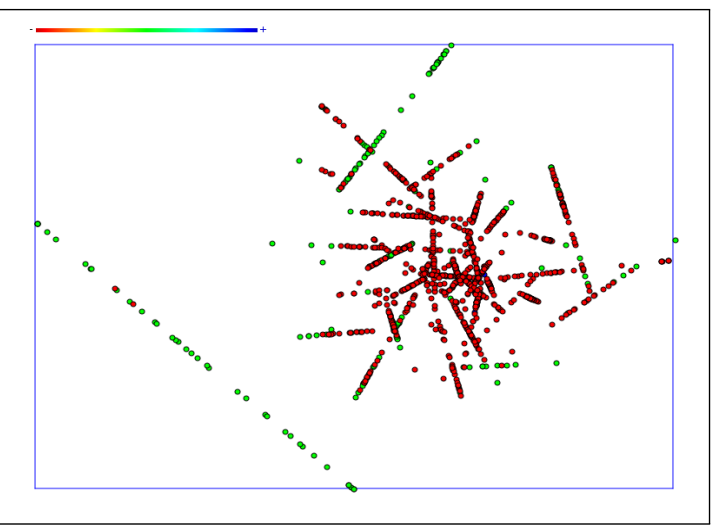

(f) PLSP (Paulovich et al., 2010)

Figura 5.9: Resultados visuais das diversas técnicas estudadas de projeção multidimensional, para um conjunto de 1.300 músicas distribuídas em três gêneros musicais. A cor de cada círculo indica o agrupamento: azul para música clássica, vermelho para rock e verde para sertanejo. 


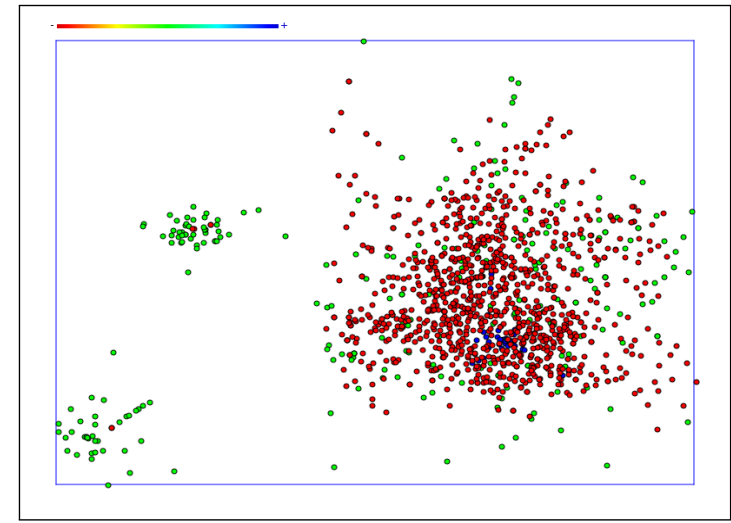

(a) ProjClus (Paulovich e Minghim, 2006)

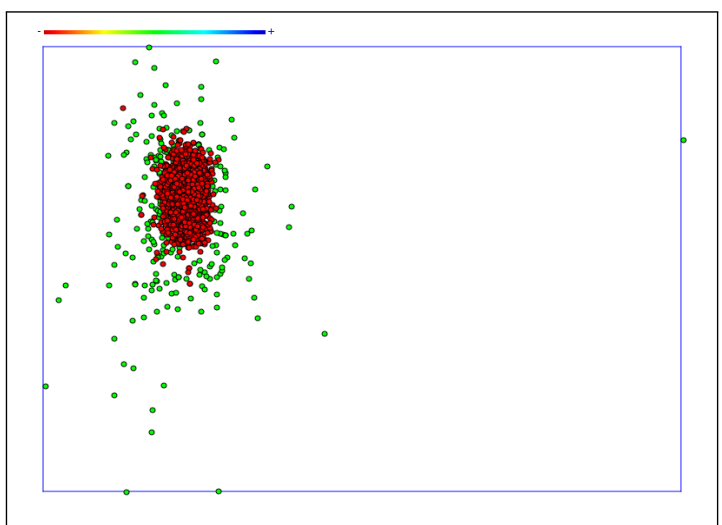

(c) Sammon Mapping (Sammon, 1969)

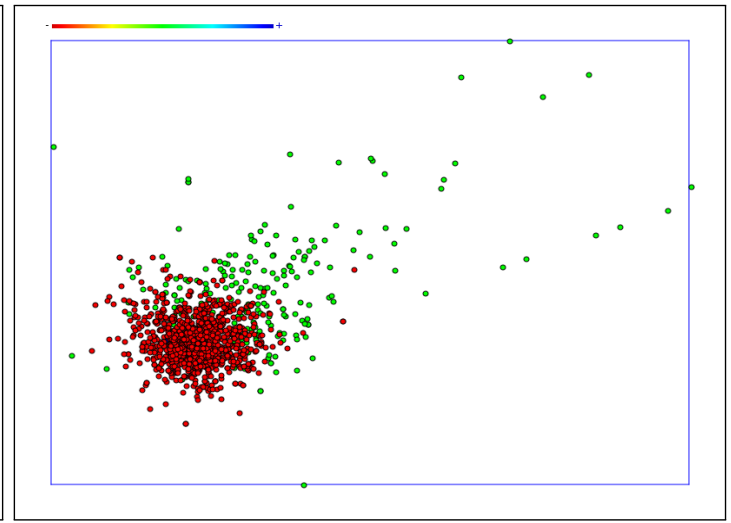

(b) Rapid Sammom (Pekalska, 2005)

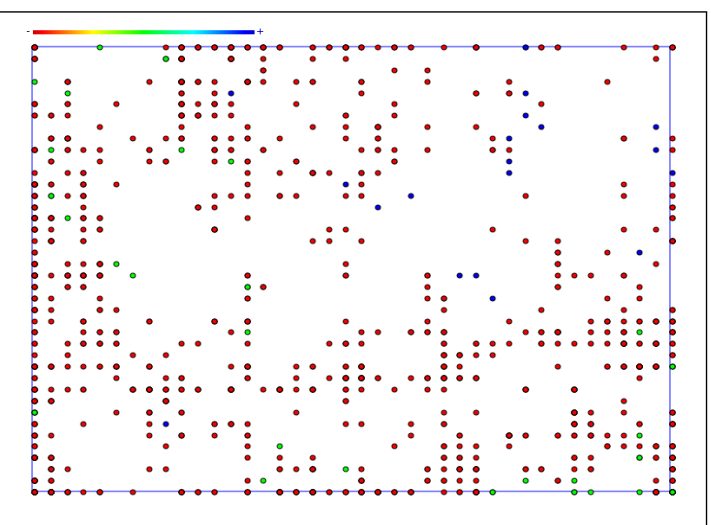

(d) SOM (Kohonen, 1990)

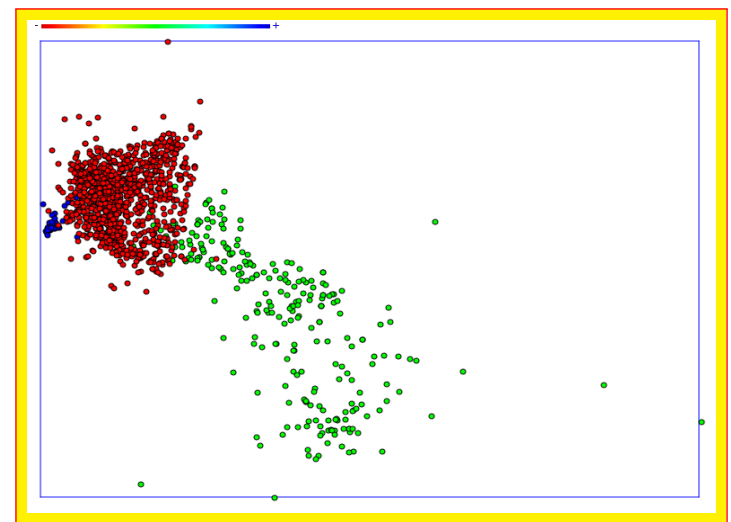

(e) LSP (Paulovich et al., 2008)

Figura 5.10: Resultados visuais das diversas técnicas estudadas de projeção multidimensional, para um conjunto de 1.300 músicas distribuídas em três gêneros musicais. A cor de cada círculo indica o agrupamento: azul para música clássica, vermelho para rock e verde para sertanejo. 


\subsection{Representações por densidade}

Foi implementada a técnica GraphSplatting discutida no Capítulo 3. Testes preliminares mostraram que esta técnica apresenta um alto custo computacional, por isso neste trabalho foram propostas aproximações alternativas, visando reduzir o tempo de processamento sem perder a qualidade da representação, uma vez que estas representações serão usadas em visualizações em tempo real. Para atingir este objetivo foram desenvolvidas 5 aproximações baseadas na técnica GraphSplatting, apresentadas a seguir.

A primeira aproximação, chamada Triangular Splatting é baseada em uma função triangular definida na Equação 5.6.

$$
T^{\sigma}(x, y)=\left\{\begin{array}{cc}
1.0-u & \text { if } u<0 \\
0.0 & \text { if } u \geq 0
\end{array}\right.
$$

na qual a variável $u$ é dada pela Equação 5.7.

$$
u=\frac{|x|+|y|}{\sigma}
$$

Assim a máscara Gaussiana usada na técnica original (Equação 5.8) é substituída por uma máscara Triangular (Equação 5.6). Esta aproximação usa menor tempo de processamento do que a técnica original pela simplicidade da função, mas sacrificando a qualidade da representação.

$$
G^{\sigma}(x, y)=\frac{1}{2 \pi \sigma^{2}} e^{-\frac{\left|x^{2}+y^{2}\right|}{2 \sigma^{2}}}
$$

Outra aproximação deste algoritmo foi feita baseada em uma Desfocagem Gaussiana, que consiste na aplicação da máscara gaussiana (Equação 5.8) em cada ponto. Matematicamente, aplicar uma desfocagem gaussiana a um ponto é equivalente a aplicar uma convolução do ponto com uma matriz da função gaussiana discretizada.

Nearest Neighbors Splatting (NNS) é outra aproximação proposta. Também é baseada na ideia original do GraphSplatting, mas a soma das contribuições é limitada a uma área de busca circular (Figura 5.11). Primeiro, é criada uma matriz esparsa contendo todos os pontos, devido a que geralmente a distribuição dos pontos no espaço é também esparsa. Assim, o raio $r$ é definido pelo usuário, o valor por omissão é $10 \%$ da distância dos pontos mais afastados.

Para o cálculo da suma das contribuições apenas são considerados os pontos dentro do raio, mas devido a que o cálculo da distância ponto a ponto é custosa em tempo computacional, foram aplicados os seguintes passos para diminuir este tempo:

1. Verifica se o ponto a contribuir encontra-se nos limites da área de busca do eixo $y$, assim o limite menor será a subtração da coordenada $y$ do ponto com o raio e o 


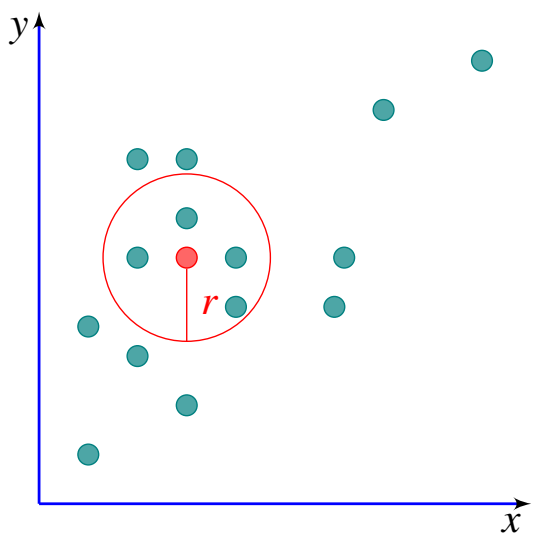

Figura 5.11: Splatting com vizinhos mais próximos.

limite maior será a coordenada y mais o valor do raio (Figura 5.12.a).

2. Verifica se o ponto a contribuir encontra-se nos limites da área de busca do eixo $x$, assim o limite será a soma da coordenada $x$ do ponto mais o valor do raio (Figura 5.12.b).

3. Verifica se o ponto a contribuir encontra-se na área de busca dada pelo raio (Figura 5.12.c).

O campo resultante é apenas afetado pela soma das contribuições dos pontos dentro da circunferência dada pelo raio.

A quarta aproximação proposta considera apenas a sobreposição existente em cada ponto. Assim, cada valor (número de sobreposições) é multiplicado pela máscara Gaussiana, por meio de uma convolução.

Finalmente, é proposta uma aproximação por retângulo, similar à Nearest Neighbors Splatting, em que o centro do retângulo é dado pelas coordenadas do ponto tratado. $\mathrm{O}$ resultado é dado pela soma de todos os pontos encontrados dentro deste retângulo, cujo tamanho é definido pelo usuário. Assim, o resultado também é multiplicado pela máscara Gaussiana.

Todas as representações por densidade foram implementadas usando programação paralela para aproveitar os recursos do computador, e reduzir o tempo de processamento. Resultados são apresentados no Capítulo 6.

\subsection{Representação por distribuição espacial}

Em um mapa de similaridade é exibida pouca informação sobre as peças musicais e sobre os grupos que estão se formando, além de apresentar sobreposição considerável dos 


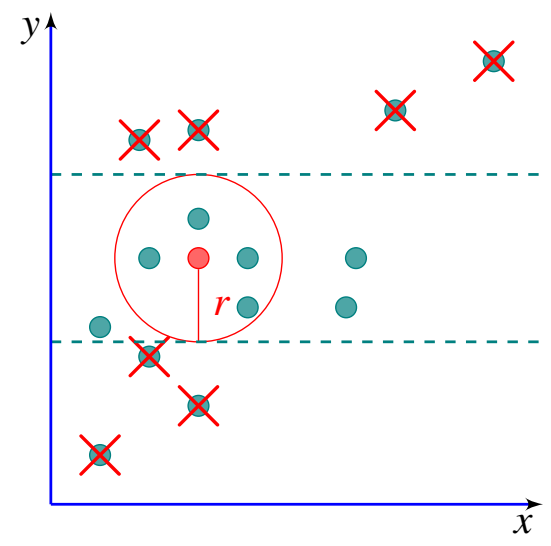

(a) Passo 1

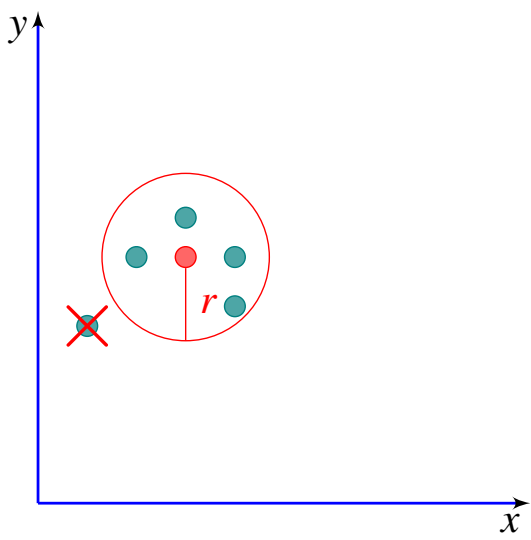

(c) Passo 3

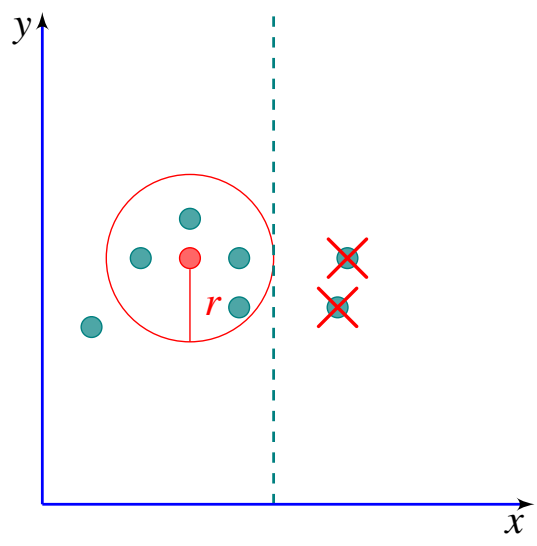

(b) Passo 2

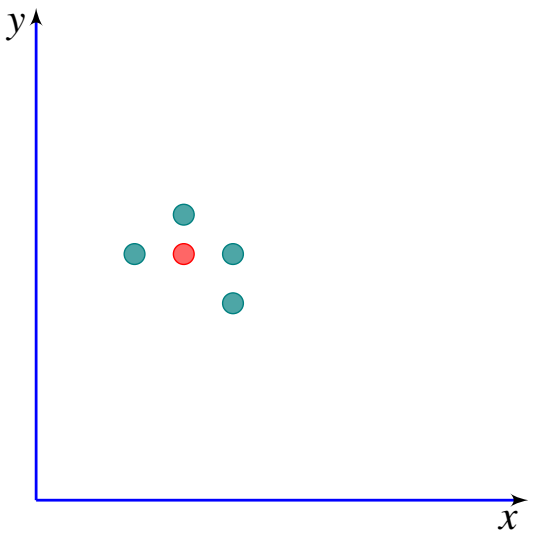

(d) Resultado

Figura 5.12: Pontos a contribuir no Nearest Neighbors Splatting. (Passo a passo). 
pontos. Substituir os círculos pelos ícones da música, anteriormente explicados, minimiza a primeira limitação mas agrava a sobreposição, o que consequentemente reduz a interpretabilidade.

Em vista dessas limitações, foi proposta uma visualização que combina os layouts de similaridade e os ícones da estrutura musical para oferecer um meio termo entre os layouts de nuvens de pontos, que carecem de informação semântica e sofrem de sobreposição, e as listas simples de ícones, que carecem de informações sobre as relações de similaridade.

Nesta visualização, ícones musicais representativos são posicionados em uma grade, de acordo com a sua disposição espacial dada pelo mapa de similaridade. Uma grade é definida pelo usuário a qual é sobreposta no mapa gerado com a LSP, de modo que cada célula da grade contém um certo número de músicas. O usuário pode definir o número máximo de ícones a serem exibidos na célula, assim pode exibir vários ícones por célula ou apenas um. A Figura 5.13 mostra um exemplo desta representação.

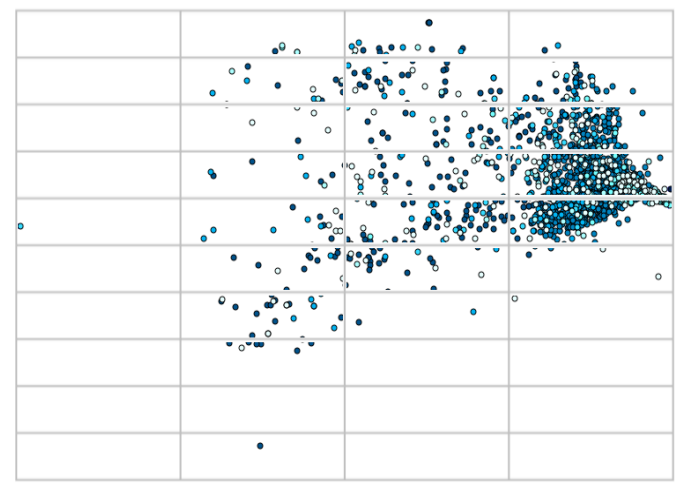

(a) Pontos originais

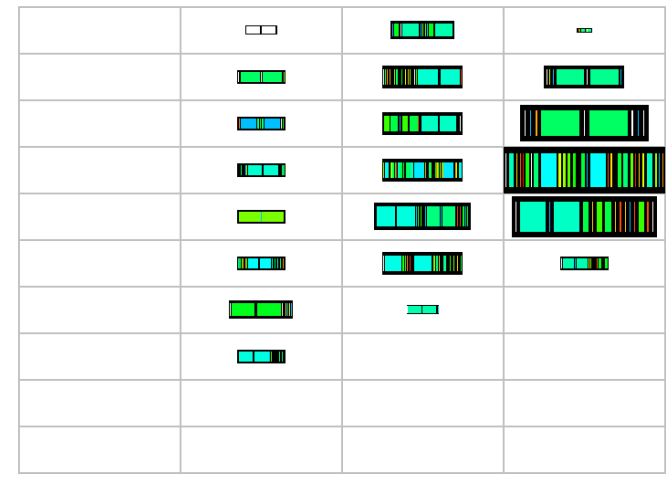

(b) Apenas um ícone por célula

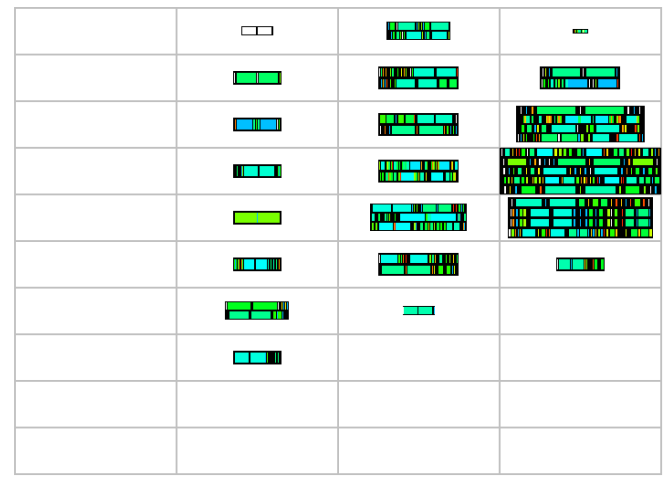

(c) Múltiplos ícones por célula

Figura 5.13: Representação de distribuição espacial de uma coleção de 1.970 músicas.

Os ícones exibidos são selecionados como os mais representativos do conjunto de músicas dentro de uma célula em particular, se o usuário escolheu representar apenas um ícone por célula será exibido o elemento centróide do grupo nela contido, caso contrário 
serão exibidos o centróide e os seus $k-1$ vizinhos mais próximos. A ordem na qual os ícones são empilhados dentro de uma célula, bem como o seu tamanho, transmite informação sobre os dados. Os ícones são empilhados de acordo a sua similaridade, calculada em relação ao centróide, em que os ícones superiores tem maior similaridade que os ícones da parte inferior. O tamanho do ícone é ajustado de acordo com o número de elementos na célula: tamanhos maiores do ícone refletem células densas e tamanhos menores refletem células mais esparsas. Notar que os layouts densos possuem células densamente ocupadas, nas quais apenas um subconjunto das músicas é apresentado na exibição da grade global. De fato, esta representação sumariza as informações de modo a ajudar os usuários a contextualizar o conteúdo de uma célula em relação à sua vizinhança. O conteúdo das células pode ser melhor explorado utilizando funções de interação de detalhe sob demanda.

A fim de assegurar a interatividade, mesmo quando são utilizadas coleções relativamente grandes com células densamente ocupadas, é fundamental a identificação em tempo real das instâncias que se encontram em uma célula. Para resolver este problema, foi proposta uma versão $2 D$ da estrutura de dados Axis Aligned Bounding Box (AABB) (Van Den Bergen, 1997), denominada neste trabalho Axis Aligned Bounding Square (AABS). Esta estrutura adota a estratégia dividir e conquistar e permite determinar os elementos contidos em cada célula em tempo $O(\log m)$, em que $m$ é o número de células. A Figura 5.14 ilustra a estrutura AABS. O nó raiz contém a área de visualização inteira, que é recursivamente subdividida em duas partes iguais, alternando a divisão nas direções vertical e horizontal. Em alguns casos, não é possível subdividir a área na direção correspondente. Estes casos acontecem quando o tamanho do lado da área a subdividir é igual ao tamanho do lado correspondente da célula. Portanto nestes casos, se repete o critério de divisão do nó pai. A iteração é realizada até que as folhas da estrutura contenham apenas uma célula.

O processo de busca de um elemento na estrutura AABS inicia no nó raiz, determinando se o elemento encontra-se dentro da área delimitada pelo nó raiz. Se o elemento está neste nó, então é verificado iterativamente se ele encontra-se no nó filho direito ou esquerdo, até chegar a um nó folha. O Algoritmo 2 define a função para determinar se um elemento encontra-se em um nó. 


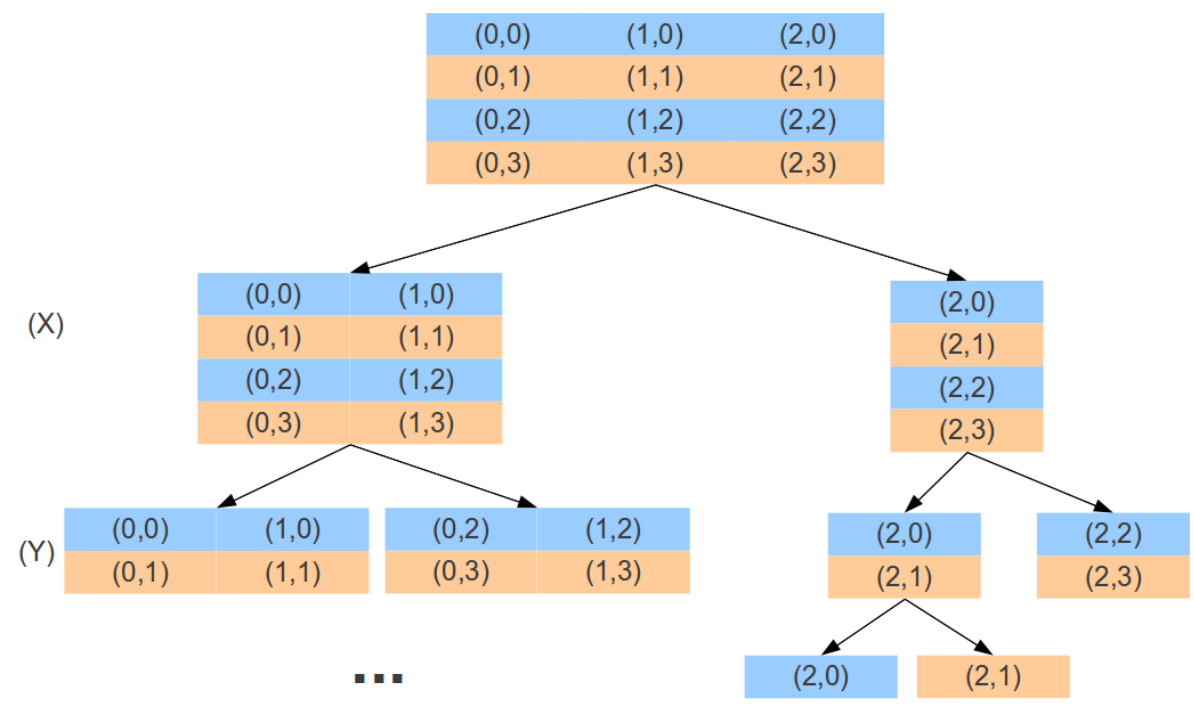

Figura 5.14: Estrutura Axis Aligned Bounding Square (AABS).

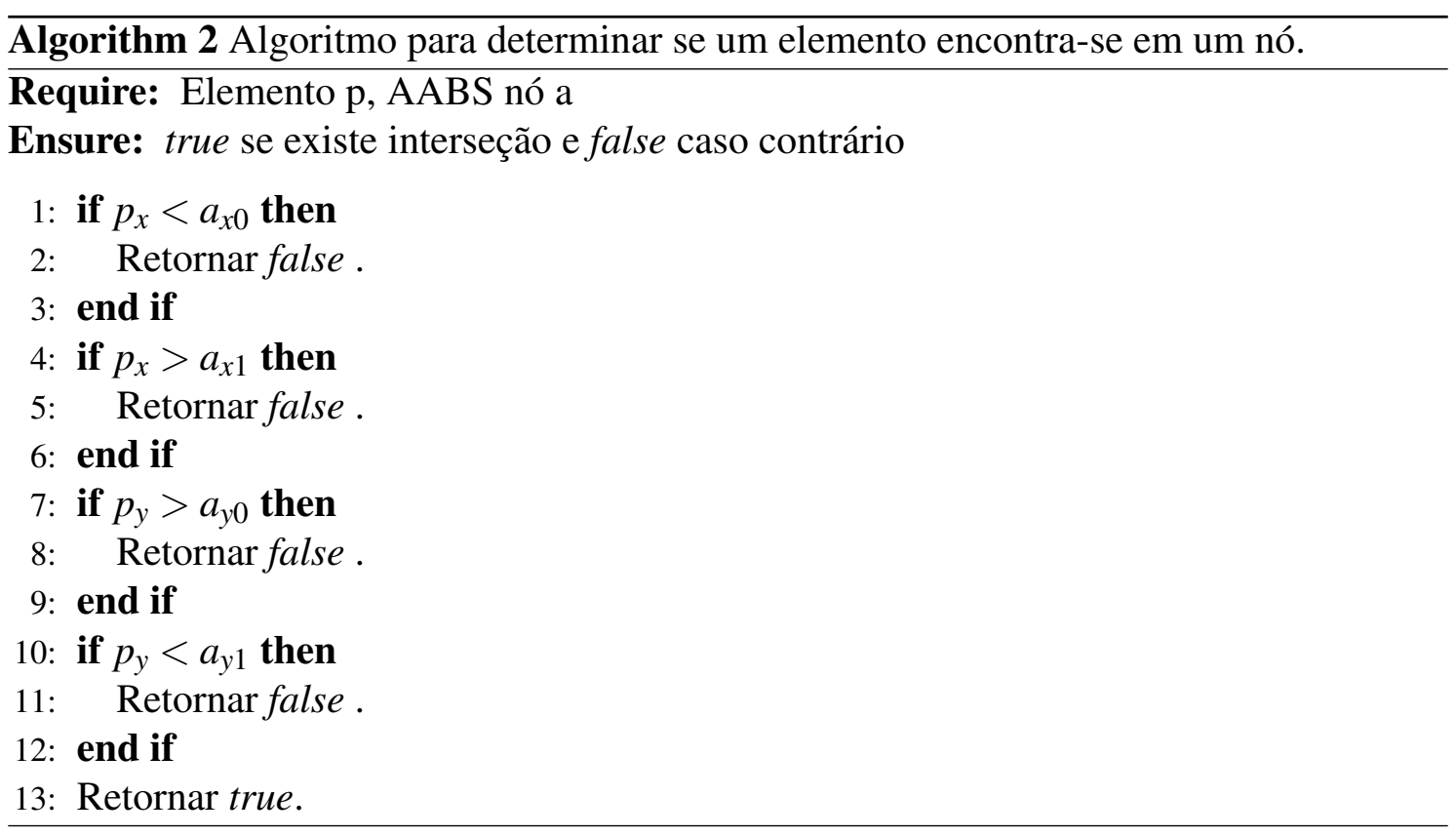

No Algoritmo 2, $\left(p_{x}, p_{y}\right)$ são as coordenadas do ponto $p$ e cada nó na estrutura possui quatro constantes $\left(a_{x 0}, a_{y 0}\right)$ e $\left(a_{x 1}, a_{y 1}\right)$ para delimitar a área que representa. Notar que o tempo computacional deste algoritmo é $O(C)$, em que $C$ é uma constante. 



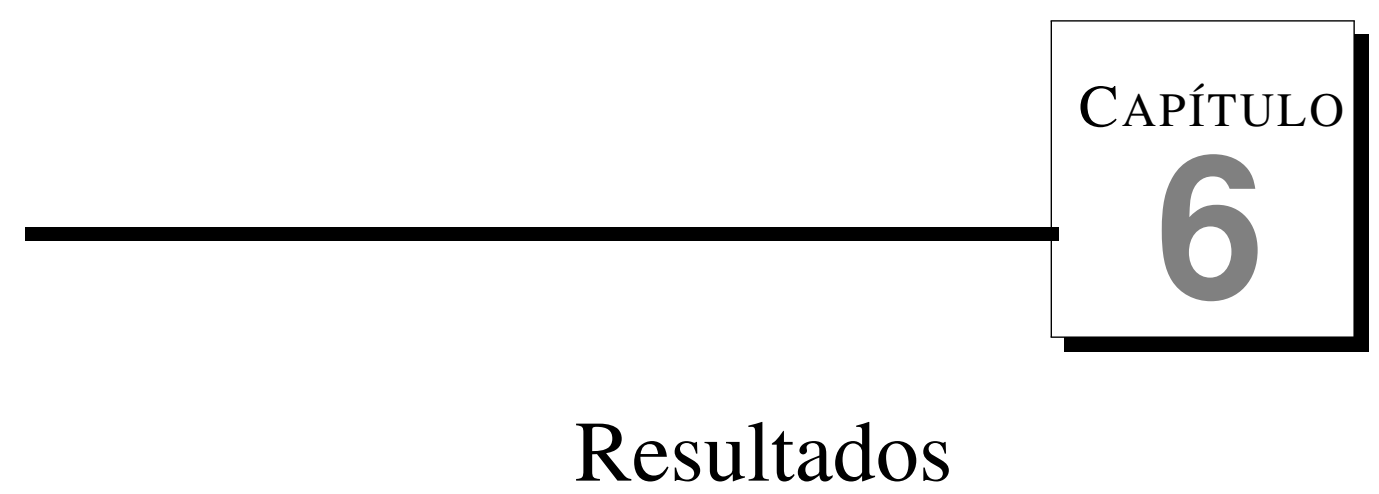

A qualidade nunca se obtém por acaso; ela é sempre o resultado do esforço inteligente (John Ruskin).

\subsection{Considerações Iniciais}

Esse capítulo descreve os experimentos realizados com a finalidade de testar as metáforas gráficas propostas, a fim de ilustrar cenários em que estas metáforas podem-se mostrar úteis e interessantes, bem como comparar a estrutura musical com outros tipos de características, como histogramas de notas, momentos estatísticos, características extraídas com a ferramenta JSymbolic e com a ferramenta JAudio das sinais das músicas convertidas a MP3. Na Seção 6.2 é apresentada uma descrição do sistema de visualização e das principais funcionalidades implementadas. A Seção 6.3 apresenta uma comparação dos tempos computacionais e dos resultados visuais entre a técnica original GraphSplatting e as técnicas propostas para gerar mapas de densidade reduzindo o tempo computacional. Na Seção 6.4, é apresentada uma comparação das representações visuais obtidas a partir dos vetores de características baseados na estrutura das músicas, frente a outros vetores de características mais usuais. A Seção 6.5 mostra resultados para músicas de vários gêneros musicais. A Seção 6.6 ilustra um exemplo de exploração de nossa representação icônica, mostrando similaridades e diferenças de versões distintas das mesmas músicas. E, finalmente a Seção 6.7 apresenta outro exemplo de exploração das músicas, ilustrando a variação temporal de músicas dos Beatles. Os resultados apresentados neste 
capítulo foram produzidos em uma máquina Intel Core i3 CPU M $3502.27 \mathrm{GHz} \times 4$ e 8GB de RAM.

Neste trabalho, foi gerado um conjunto de músicas formado por cerca de 2.000 músicas em formato MIDI, de diversos gêneros musicais, coletados a partir de fontes na Internet. Na Tabela 6.1 detalha-se a distribuição da coleção de músicas por gênero. Apesar de existirem conjuntos de dados de referência que poderiam ser considerados para testar os efeitos visuais, ver Neumayer et al. (2005), por exemplo estes tipicamente consistem de arquivos de áudio em formato Mp3. Entretanto, o formato MIDI é o mais adequado para o nosso objetivo de mapear visualmente uma representação mais abstrata que reflita a estrutura musical, e não foram encontradas coleções de referência de arquivos MIDI.

\begin{tabular}{|c|c|}
\hline \multicolumn{2}{|c|}{ Gêneros } \\
\hline rock_pop & 1.015 \\
\hline música clássica & 33 \\
\hline sertanejo & 252 \\
\hline salsa & 146 \\
\hline rap & 68 \\
\hline country & 73 \\
\hline jazz & 96 \\
\hline samba & 185 \\
\hline Total & 1.868 \\
\hline
\end{tabular}

Tabela 6.1: Conteúdo da coleção de música em formato MIDI.

Para os experimentos discutidos nas seções 6.3, 6.4 e 6.5, foi usado um subconjunto de 1.300 músicas de três gêneros: 1.015 músicas do gênero rock , 33 músicas clássicas e 252 músicas do gênero sertanejo. Os vetores de características das músicas foram projetados com a técnica $L S P$, a partir das matrizes de distância obtidas com a métrica $D T W$.

\subsection{Sistema de Visualização}

Foi desenvolvido um sistema de visualização que visa transmitir informações sobre a natureza de apenas uma música e também de como músicas individuais estão relacionadas com outras, permitindo a exploração de uma coleção de músicas. Ele combina uma representação de ícone com informações dadas por um mapa de similaridade da coleção, fornecendo a possibilidade de visualizar intuitivamente relações, bem como navegar na coleção com uma transição entre os diferentes níveis de detalhe, até o desejado.

Este sistema foi adicionado à plataforma de visualização desenvolvida pelo grupo de pesquisa de Visualização, Imagens e Computação Gráfica (VICG-ICMC), chamada VisPipeline, que é uma ferramenta visual e modular. A Figura 6.1 mostra uma imagem 
da interface do sistema desenvolvido neste trabalho. A região 1 da interface mostra um mapa interativo da coleção de músicas, que é o resultado do mapeamento pela projeção multidimensional LSP. Por meio das ferramentas da região 2, os usuários podem interagir com a representação, explorando o mapa, por exemplo: fazer zooming, selecionar áreas de interesse e criar representações por densidade. A região 3 permite reproduzir e criar uma lista de reprodução. O ícone da música reproduzida no momento é exibido na região 4.

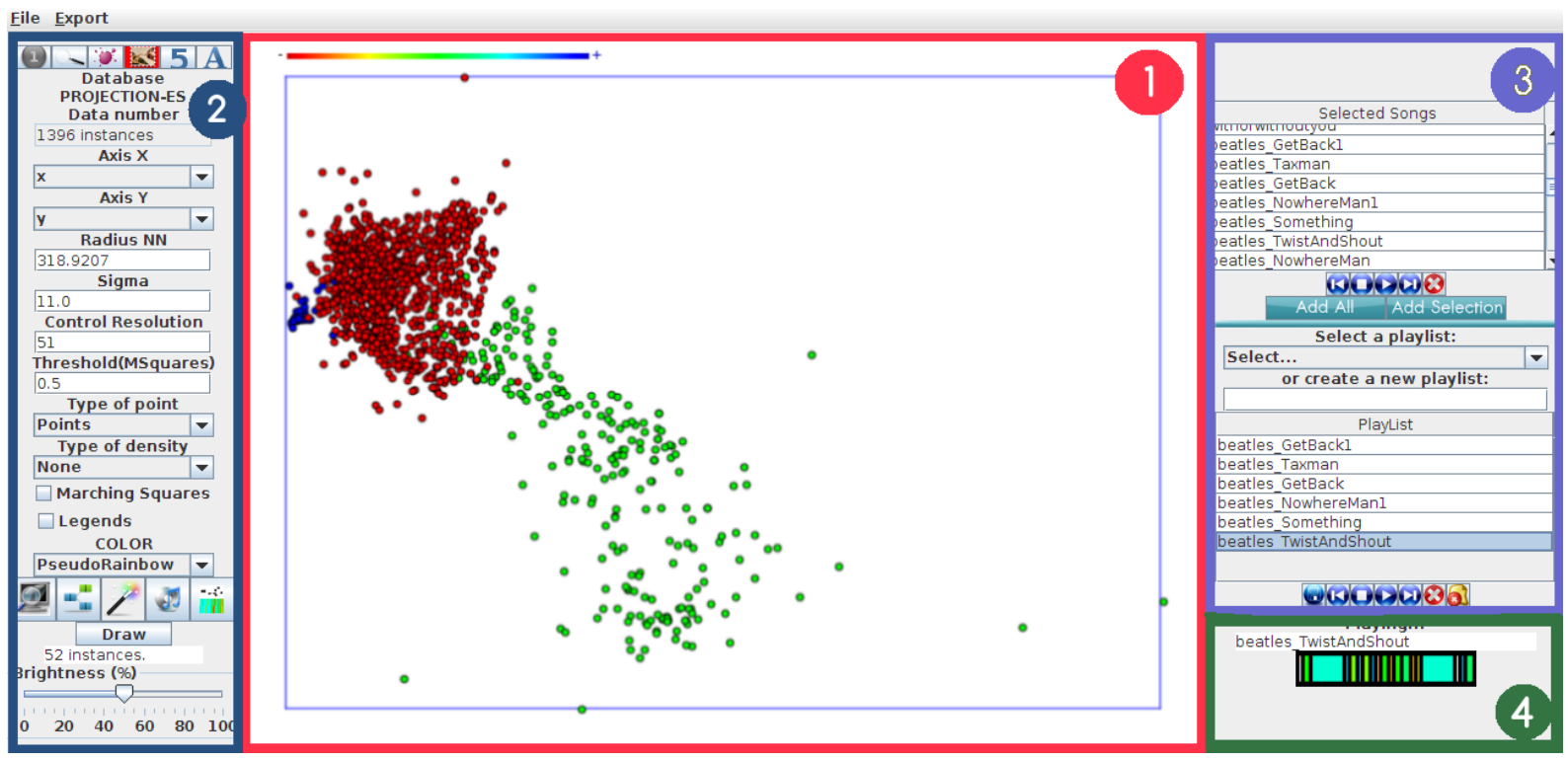

Figura 6.1: Interface do sistema de visualização de músicas desenvolvido neste trabalho.

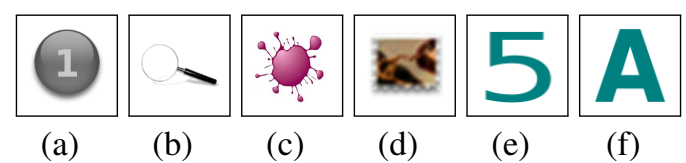

Figura 6.2: Botões na parte superior da região 2 do sistema de visualização.

A Figura 6.2 exibe os botões que se encontram na parte superior da região 2 do sistema de visualização. O sistema permite ao usuário realizar operações de zoom in ou zoom out, utilizando o mouse. Com o botão exibido na Figura 6.2.a, o usuário pode retornar à vista original do layout. Outra maneira de fazer zoom é de forma local, usando uma lente, a qual é ativada clicando no botão exibido na Figura 6.2.b. Os resultados destas duas maneiras de fazer zooming podem ser vistos na Figura 6.3.

O botão da Figura 6.2.c permite exibir uma lente que visualiza a densidade do conjunto de dados, para ativar esta funcionalidade deve ser selecionado um método de splatting e uma escala de cor. O botão da Figura 6.2.d é essencial, já que permite selecionar un subconjunto de dados para ser reusado em outras funcionalidades. Os botões das Figuras 


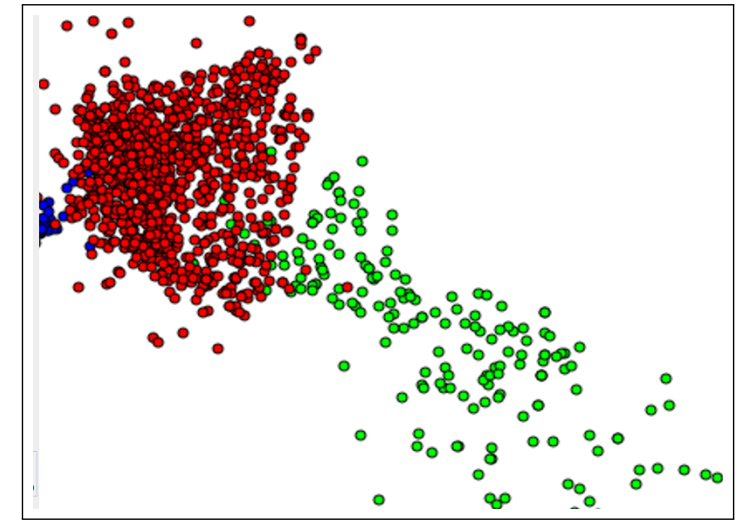

(a)

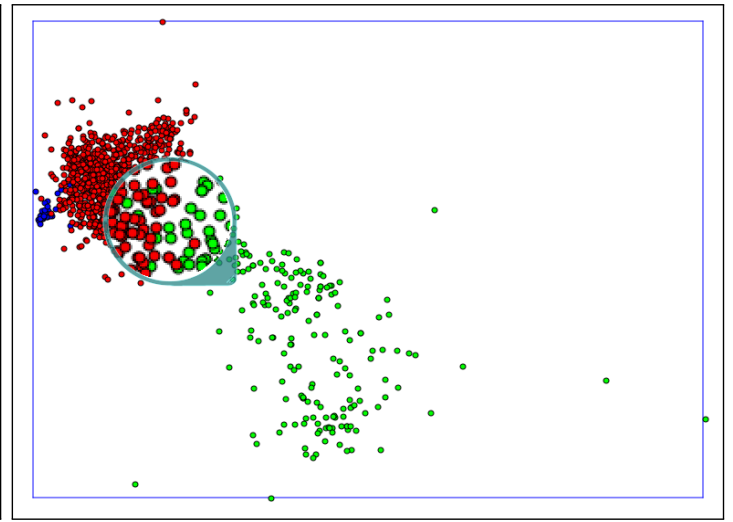

(b)

Figura 6.3: Duas maneiras de fazer zoom: (a) Interagindo com o mouse e (b) Usando uma lente.

6.2.e e 6.2.f permitem visualizar os identificadores ou os nomes, respectivamente, interagindo com o mouse. Os resultados visuais relativos às funcionalidades dos botões das Figuras 6.2.c, 6.2.e e 6.2.f são exibidos nas Figuras 6.4.a, 6.4.b e 6.4.c respectivamente.

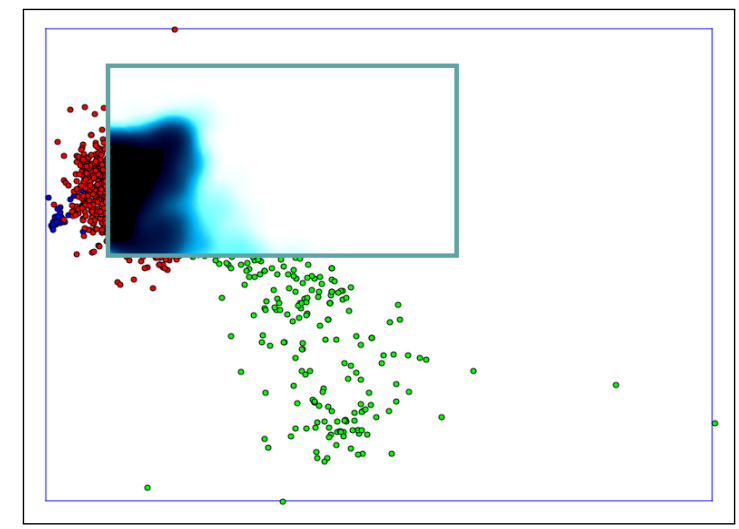

(a)

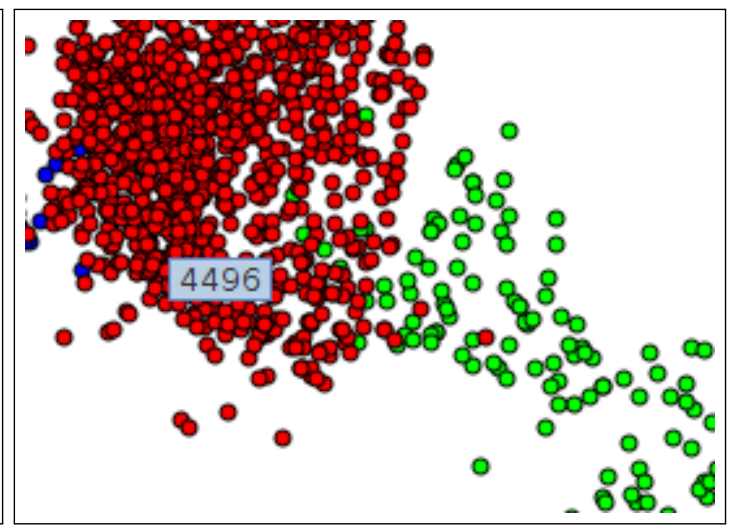

(b)

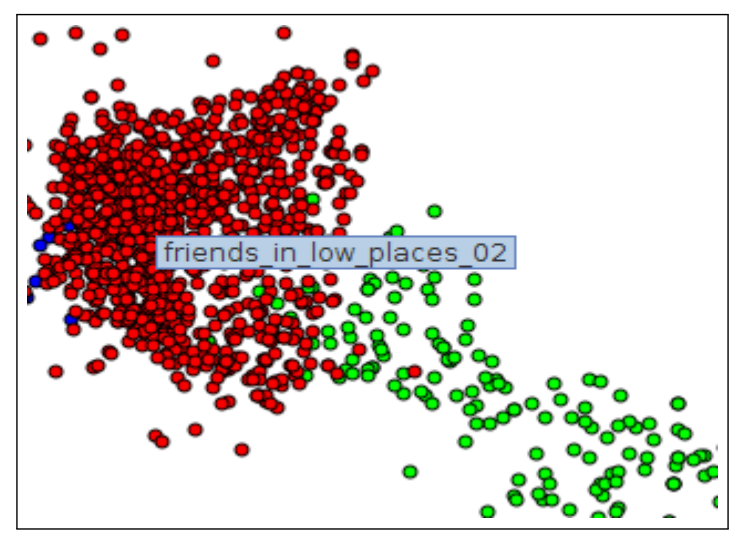

(c)

Figura 6.4: Resultados visuais para os botões das Figuras 6.2.c, 6.2.e e 6.2.f, respectivamente. 
Existem 5 maneiras de exibir cada elemento do conjunto de dados: exibi-las como círculos cuja cor reflete a classe, exibir apenas as bordas coloridas dos círculos, exibi-las usando transparência, exibir os ícones de cada elemento do conjunto de dados e exibi-las por densidade. A escala de cor pode ser alterada e para a densidade pode ser escolhido qualquer técnica descrita anteriormente, cujos parâmetros podem ser alterados. Os resultados visuais para as 5 formas de exibir as instâncias são apresentados na Figura 6.5. Notar que a Figura 6.5.d confirma que o uso dos ícones como alternativa às nuvens de pontos não pode ser considerado devido à alta sobreposição.

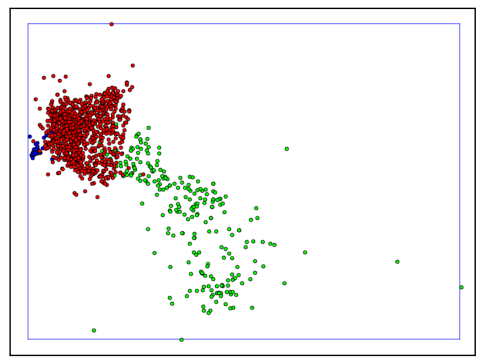

(a) Círculos

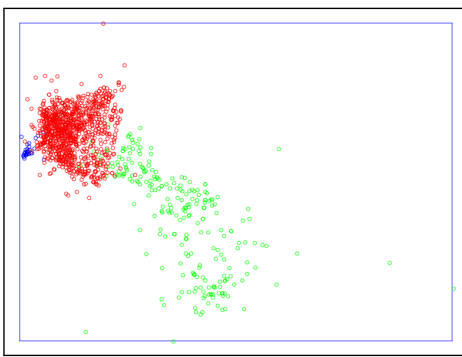

(b) Bordas

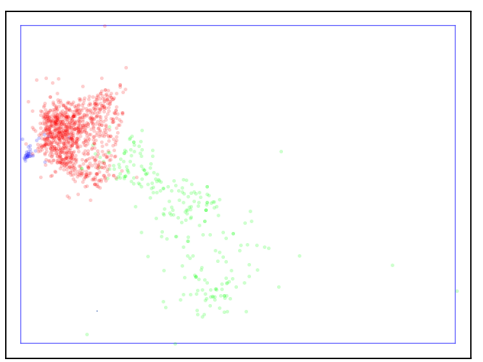

(c) Transparência

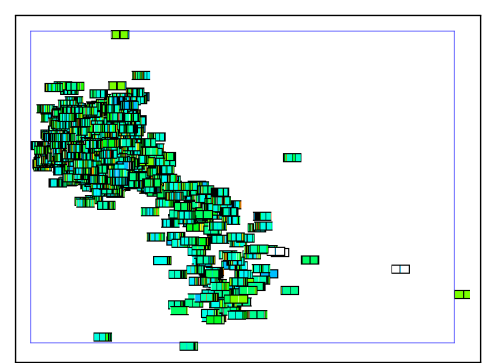

(d) Ícones

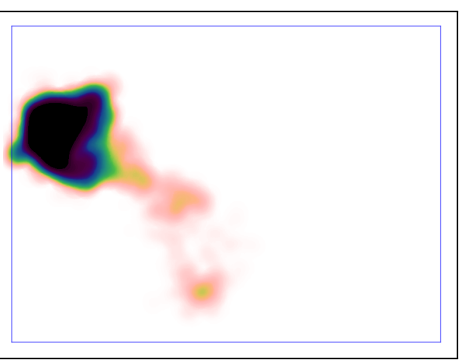

(e) Splatting

Figura 6.5: Resultados visuais para as 5 maneiras de exibir os elementos do conjunto de dados.

Por outro lado, foram implementadas dois tipos de feedback visual. Um deles é a técnica Marching Squares, que por meio do uso de um limiar, permite ressaltar as áreas de maior incidência que se encontram dentro deste limiar e o outro é a alteração do brilho da imagem do layout. Os resultados visuais relativos a essas funcionalidades são exibidos na Figura 6.6.

A Figura 6.7 exibe os botões na parte inferior da região 2 do sistema de visualização. O sistema permite realizar um zooming semântico, ou seja criar uma nova visualização apenas para uma seleção de dados feita pelo usuário, usando o botão da Figura 6.7.a. Esta seleção é manipulada como um conjunto novo e aparece em uma nova janela com todas as funcionalidades ativas. A Figura 6.8.a exibe um exemplo de um zooming semântico para uma seleção do usuário. Além disso, o usuário pode criar uma visualização de uma árvore filogenética a partir da mesma ou outra seleção, ativando o botão exibido na Figura 6.7.b. Um exemplo de uma árvore filogenética criada para uma seleção do usuário pode 


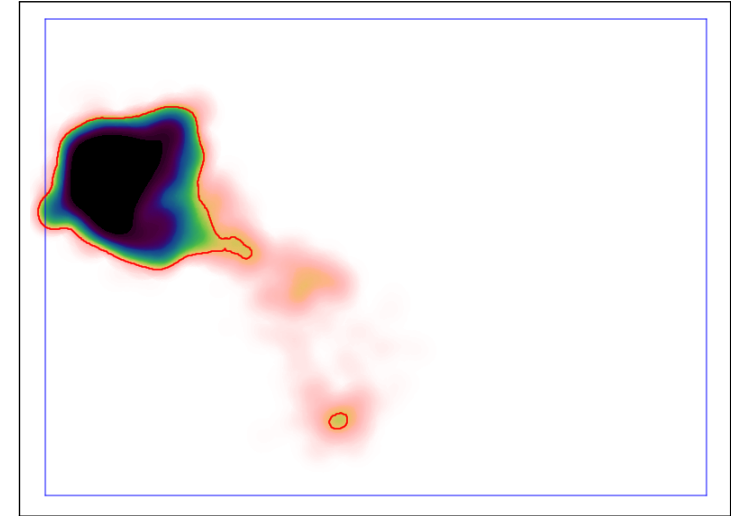

(a) Marching Squares

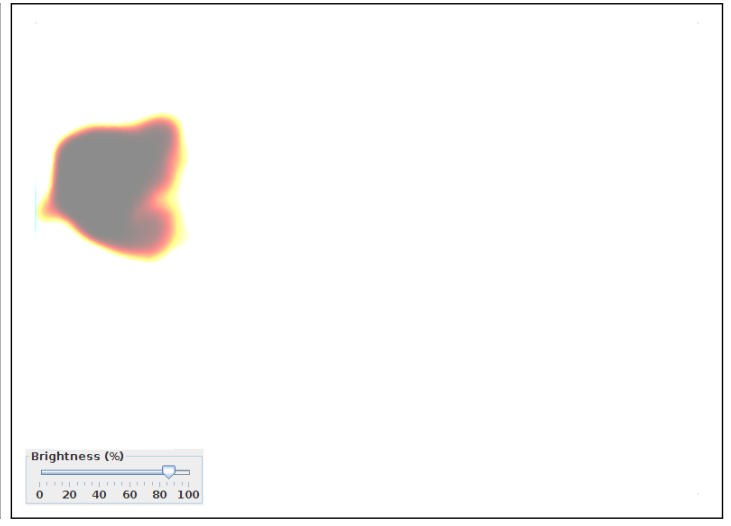

(b) Ajuste de Brilho

Figura 6.6: Resultados dos dois tipos de feedback visual implementados.

ser vista na Figura 6.8.b. Alias, ativando o botão da Figura 6.7.c o usuário pode criar uma representação de distribuição espacial dos ícones, fornecendo o número de retângulos da altura, o número de retângulos da largura e escolher entre a opção de representar cada célula por um ícone ou por múltiplos ícones. A Figura 6.7.c exibe um exemplo da saída da visualização por distribuição espacial para uma grade de $4 \times 4$ e com a opção de apenas um ícone por célula. O botão da Figura 6.7.d permite a seleção de músicas a serem reproduzidas na lista da região 3 ou para salvar uma lista de reprodução. Assim, esta lista de reprodução pode ser preenchida por meio de uma seleção do usuário ou por selecionar uma célula da representação por distribuição espacial, como é exibido nas Figuras 6.8.d e 6.8.e, respectivamente. Estas músicas selecionadas podem ser reproduzidas, filtradas ou salvadas em um arquivo como uma lista de reprodução, a qual pode ser reproduzida ou alterada em qualquer momento. E finalmente, o botão da Figura 6.7.e cria uma nova janela com a lista de ícones, que pode ser reproduzida, de uma seleção do usuário ou de uma célula da representação por distribuição espacial, um exemplo é exibido nas Figuras 6.7.f e 6.7.g, respectivamente.

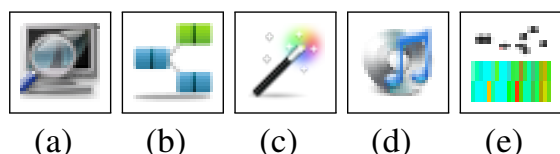

Figura 6.7: Botões na parte inferior da região 2 do sistema de visualização. 


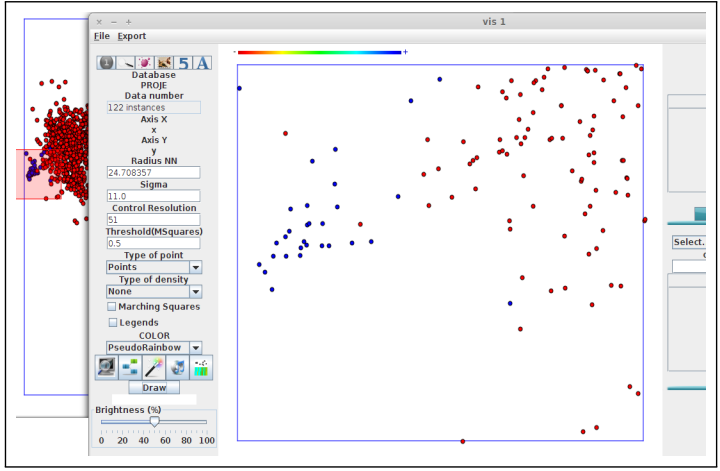

(a) Zooming semântico

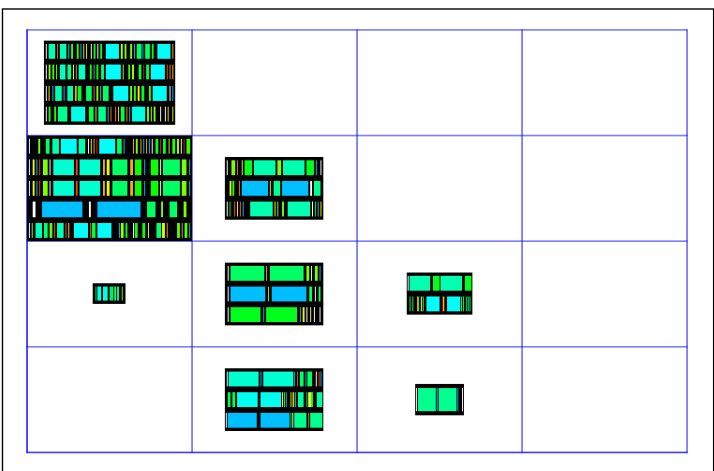

(c) Representação por distribuição espacial

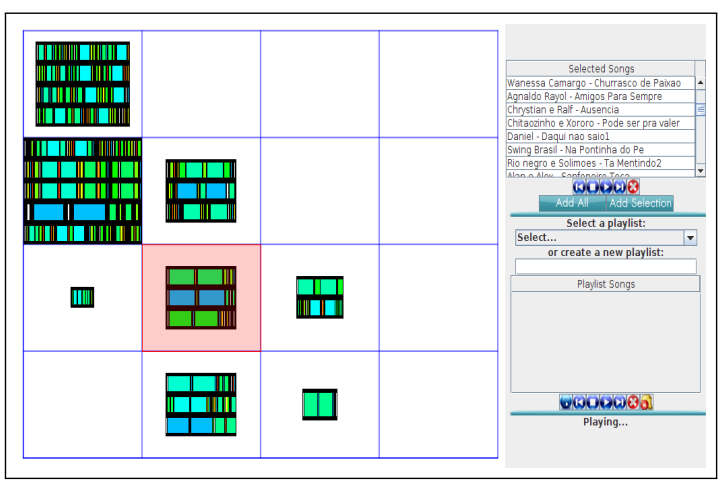

(e) Lista de Reprodução - Célula selecionada

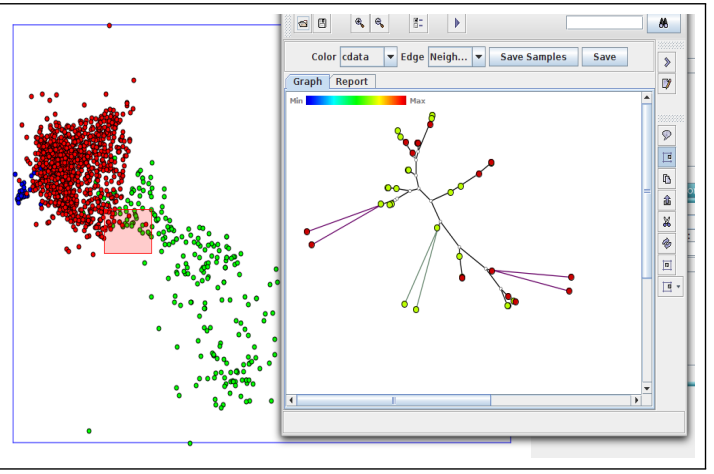

(b) Árvore filogenética

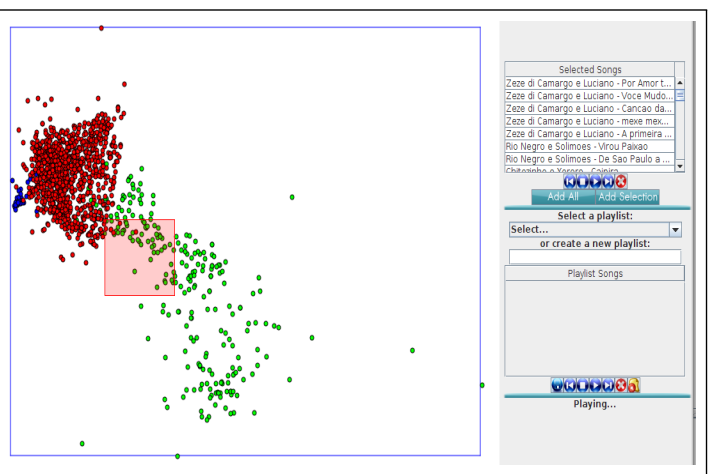

(d) Lista de Reprodução - Seleção do usuário

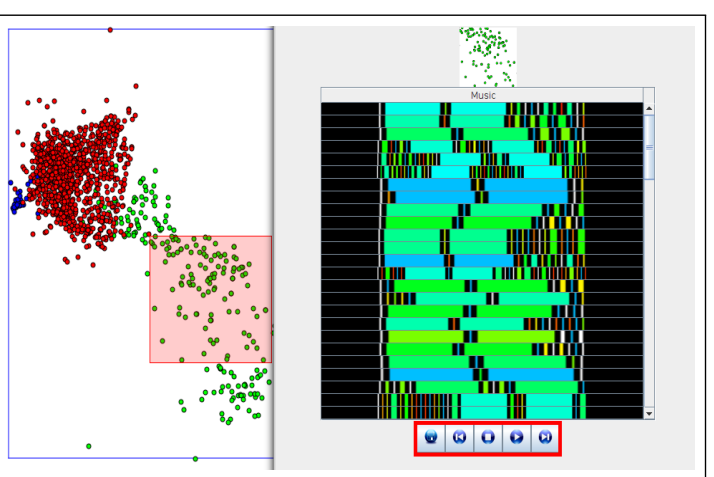

(f) Lista de Ícones - Seleção do usuário

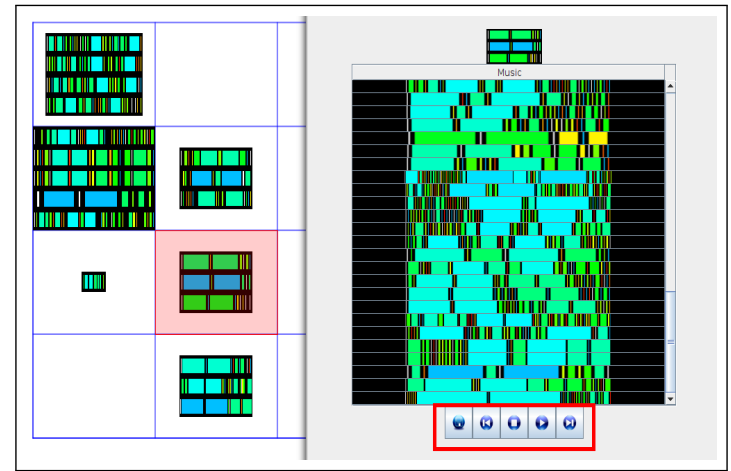

(g) Lista de Ícones - Célula selecionada

Figura 6.8: Resultados visuais relativos às funcionalidades dos botões das Figuras 6.7.a, 6.7.b, 6.7.c, 6.7.d e 6.7.e. 


\subsection{Experimento 1: Comparação das técnicas de re- presentação por densidade}

Este experimento tem por objetivo comparar o tempo de processamento das técnicas de representação por densidade: GraphSplatting e as aproximações: Triangular Splatting, Nearest Neighbors Splatting, Desfocagem Gaussiana, Aproximação por sobreposição e Aproximação por retângulo. A Tabela 6.2 apresenta os tempos de processamento destas técnicas e a Figura 6.9.a mostra os gráficos dos tempos médios de processamento das diferentes estratégias de representação por densidade. Como pode-se observar na Tabela 6.2, a diferença entre os tempos de processamento é muito grande, o que dificulta a análise do resultado quando é plotado em um único gráfico. Por isso, foi aplicada uma escala logarítmica sobre os resultados a fim de facilitar a análise comparativa do comportamento das técnicas. O gráfico obtido é mostrado na Figura 6.9.b. Observa-se que a GraphSplatting usou mais tempo de processamento do que as outras técnicas. Os melhores desempenhos, em termos de tempo, foram obtidos com as aproximações Nearest Neighbors Splatting, Desfocagem Gaussiana, Aproximação por sobreposição e Aproximação por retângulo.

\begin{tabular}{|c|c|c|c|c|c|c|c|}
\hline Conj. de dados & \# elem. & GS & TS & NNS & GB & AS & AR \\
\hline Iris & 150 & 0,19 & 0,025 & 0,17 & 0,13 & 0,05 & 0,12 \\
\hline cancer mama & 699 & 0,37 & 0,11 & 0,15 & 0,28 & 0,18 & 0,37 \\
\hline Cbrilpirivson & 945 & 0,33 & 0,14 & 0,08 & 0,15 & 0,09 & 0,23 \\
\hline Kdviz & 1.624 & 0,58 & 0,26 & 0,11 & 0,22 & 0,08 & 0,25 \\
\hline Coleção de músicas(MIDI) & 1.868 & 0.98 & 0.55 & 0.61 & 0,25 & 0,34 & 0.73 \\
\hline Segmentation-normcols & 2.100 & 0,92 & 0,34 & 0,48 & 0,31 & 0,46 & 1,2 \\
\hline swissroll & 3.000 & 1,43 & 0,62 & 0,55 & 0,24 & 0,28 & 1,57 \\
\hline winequality-white-std & 4.898 & 3,48 & 1,05 & 0,18 & 0,44 & 0,15 & 0,76 \\
\hline Letter recognition & 20.000 & 47,57 & 12,23 & 0,14 & 1,68 & 0,07 & 0,18 \\
\hline shuttle trn corr normcols & 43.500 & 221,92 & 21,32 & 0,28 & 4,46 & 0,13 & 0,18 \\
\hline
\end{tabular}

Tabela 6.2: Tempos de processamento, em segundos, das técnicas de representação por densidade. $(\mathrm{GS}=$ GraphSplatting, TS = Triangular Splatting, NNS = Nearest Neighbors Splatting, GB = Desfocagem Gaussiana, AS = Aproximação baseada na sobreposição e $\mathrm{AR}=$ Aproximação considerando um retângulo)

A Figura 6.10 exibe os resultados visuais das técnicas de representação por densidade: GraphSplatting, Triangular Splatting, Nearest Neighbors Splatting, Desfocagem Gaussiana, Aproximação por sobreposição e Aproximação por retângulo. Os testes foram gerados com uma resolução de $60 \times 60$ pixels e para o parâmetro $\sigma$ da função gaussiana foram aplicados os valores 5,10 e 15 .

Note-se que as técnicas alternativas propostas neste trabalho: Nearest Neighbors Splatting, Aproximação por sobreposição e Aproximação por retângulo geram representações 


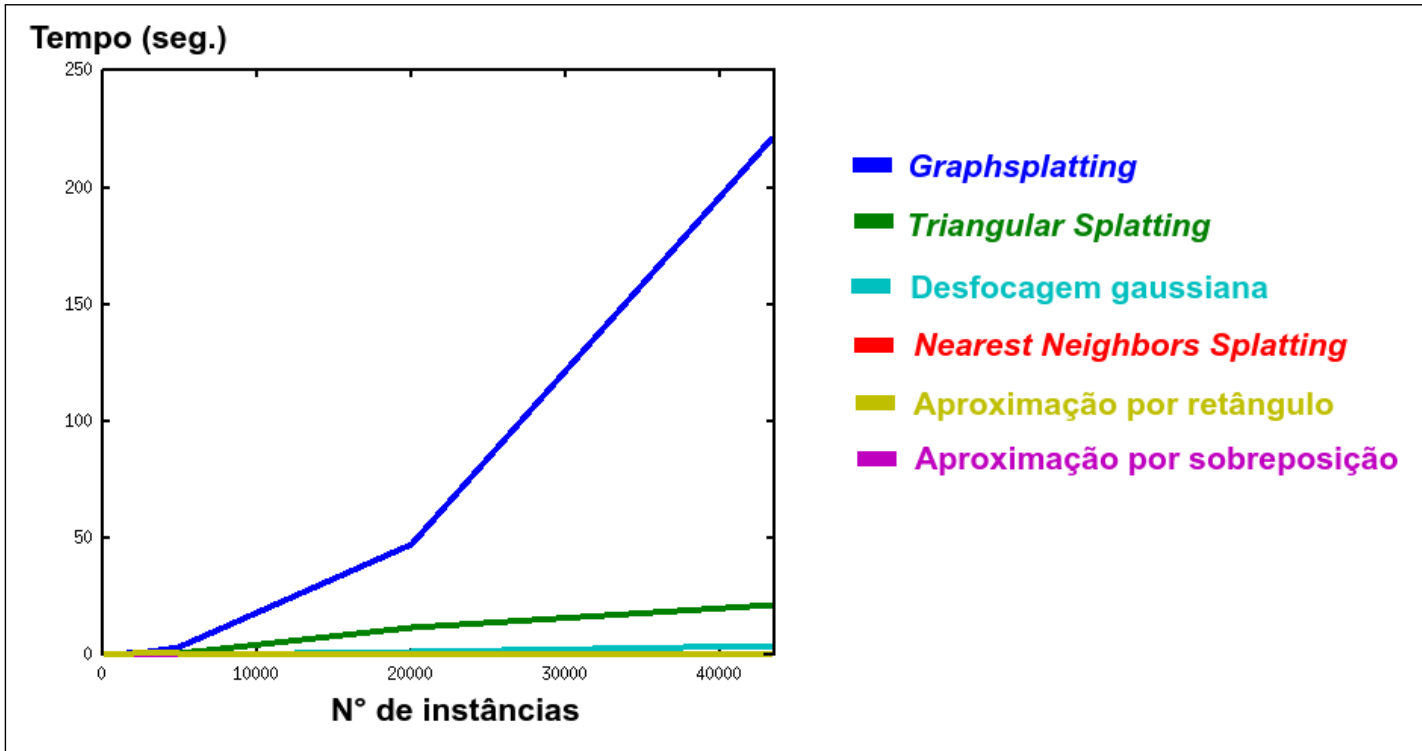

(a) Gráfico Original

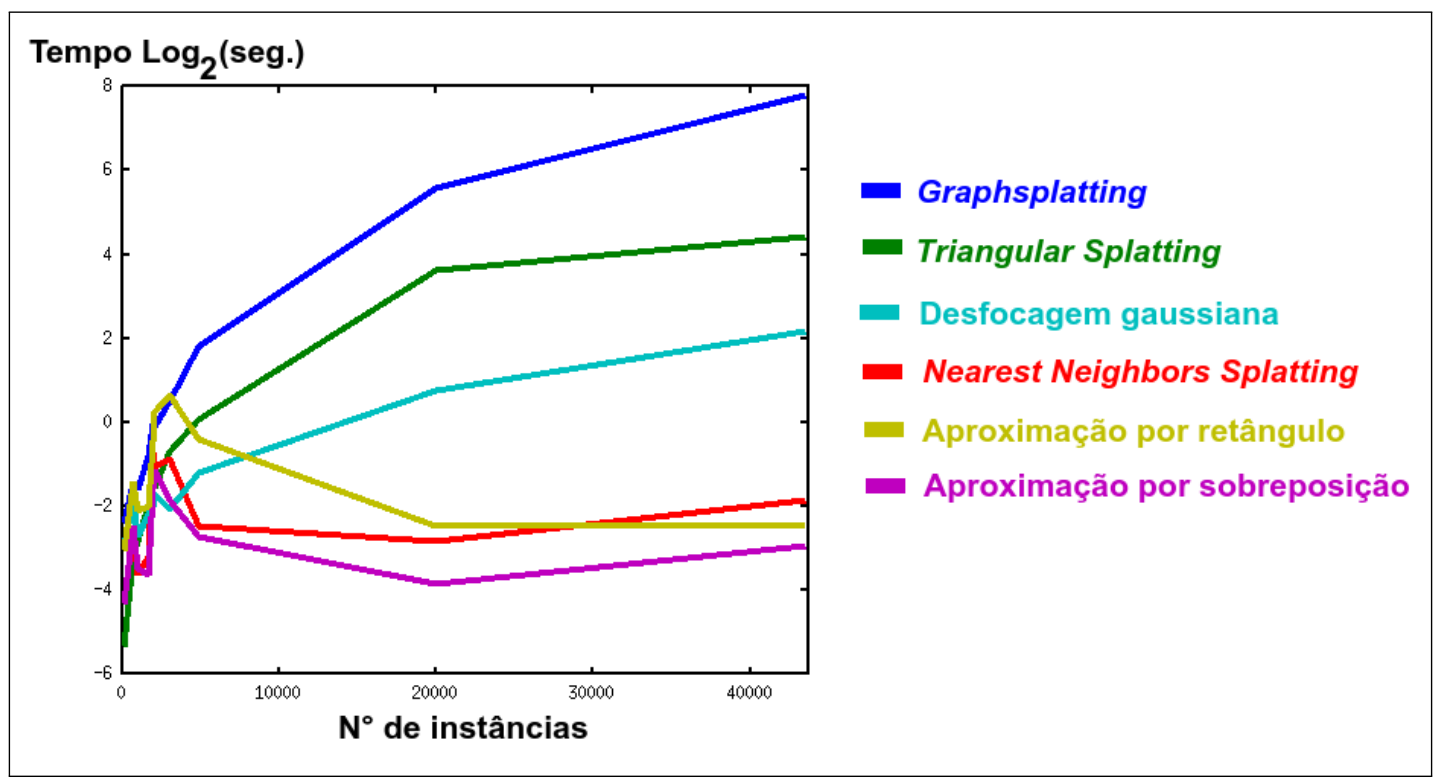

(b) Gráfico em escala Log2

Figura 6.9: Gráficos gerados para os tempos de processamento das técnicas de representação por densidade.

visuais muito parecidas à técnica GraphSplatting, como ilustra a Figura 6.10, mas com uma redução drástica no tempo de processamento. 


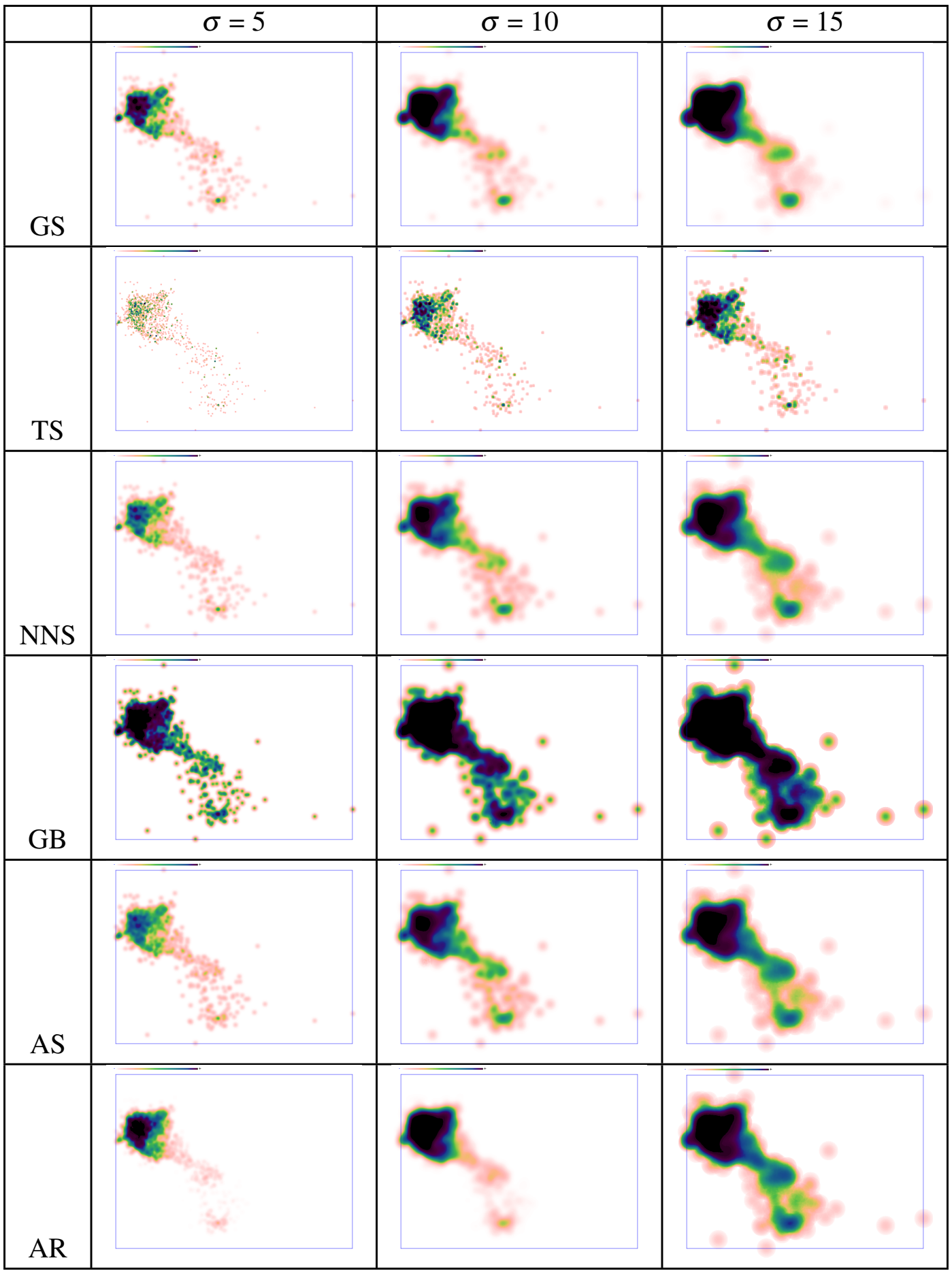

Figura 6.10: Resultados visuais das técnicas de representação por densidade do conjunto de 1.300 músicas. $(\mathrm{GS}=$ GraphSplatting, $\mathrm{TS}=$ Triangular Splatting, $\mathrm{NNS}=$ Nearest Neighbors Splatting, GB = Desfocagem Gaussiana, AS = Aproximação baseada na sobreposição e $\mathrm{AR}=$ Aproximação considerando um retângulo) 


\subsection{Experimento 2: Comparação das técnicas de ex- tração de características}

A fim de testar a eficácia de agrupar as músicas semelhantes, foi feito um experimento comparando a qualidade dos layouts obtidos a partir de diferentes vetores de características frequentemente usados (Lartillot et al., 2007). Esta qualidade refere-se ao agrupamento das músicas segundo seu gênero. Os descritores de características consideradas são: Histogramas de Notas, Momentos Estatísticos, características obtidas com o JSymbolic, características com o JAudio a partir das sinais das músicas em formato MIDI, as quais foram convertidas em Mp3; e finalmente as características estruturais introduzidas neste trabalho.

Neste experimento, foi utilizado o conjunto de músicas previamente descrito. A Figura 6.12 ilustra os layouts obtidos usando os diferentes vetores de características, na qual as músicas do gênero rock estão representadas por círculos vermelhos, as músicas clássicas por círculos azuis e as músicas do gênero sertanejo por círculos verdes.

O layout na Figura 6.12.a foi obtido considerando como vetores de características, os histogramas das notas obtidas das músicas em formato MIDI. Uma vez que o histograma é uma representação da distribuição das notas, pode acontecer que duas músicas semelhantes nas suas melodias, mas com diferentes escalas, gerem histogramas com distribuição semelhante mas em diferentes intervalos no eixo horizontal. Portanto, é necessário usar uma medida de similaridade que compare as distribuições, apesar destas se encontrem em diferentes intervalos. Para este fim, foi usada a medida de similaridade DTW que permite encontrar uma correspondência ideal entre duas sequências dadas.

A Figura 6.12.b apresenta a projeção resultante a partir das propriedades estatísticas das notas das músicas e das velocidades, tais como a média, a desvio padrão, a uniformidade e a entropia. Estas medidas estatísticas permitem quantificar as propriedades globais da música da melodia e do ritmo, para esse caso foi utilizada a distância Euclidiana.

O layout das músicas por meio das características extraídas com a ferramenta JSymbolic (McKay, 2010) é mostrado na Figura 6.12.c. Foram extraídas 111 características, com base nos instrumentos, na textura musical, ritmo, estatísticas, melodia e acordes. A Figura 6.12.d mostra a projeção das características padrão obtidas a partir de arquivos de áudio em formato MP3, usando JAudio (McKay, 2010). Pela natureza dos vetores obtidos com JSymbolic e dos vetores obtidos com JAudio, também foram comparados utilizando a distância Euclidiana.

A Figura 6.12.e mostra o layout das músicas usando o vetor de características estruturais introduzidas neste trabalho, que é claramente a alternativa mais eficaz para agrupar as músicas que pertencem ao mesmo gênero, o que neste caso, também corresponde a 
músicas com estruturas semelhantes.

Ressalta-se que a projeção gerada a partir da extração de estruturas musicais posicionou como vizinhas versões diferentes da mesma música. A Figura 6.11 apresenta a representação iconográfica de uma seleção de músicas do layout, na qual pode-se apreciar que foram posicionadas como vizinhas duas versões distintas da música Friends in low places de Garth Brooks. Esse layout representa uma pequena região do layout original, obtida por meio da opção de zooming semântico do sistema.
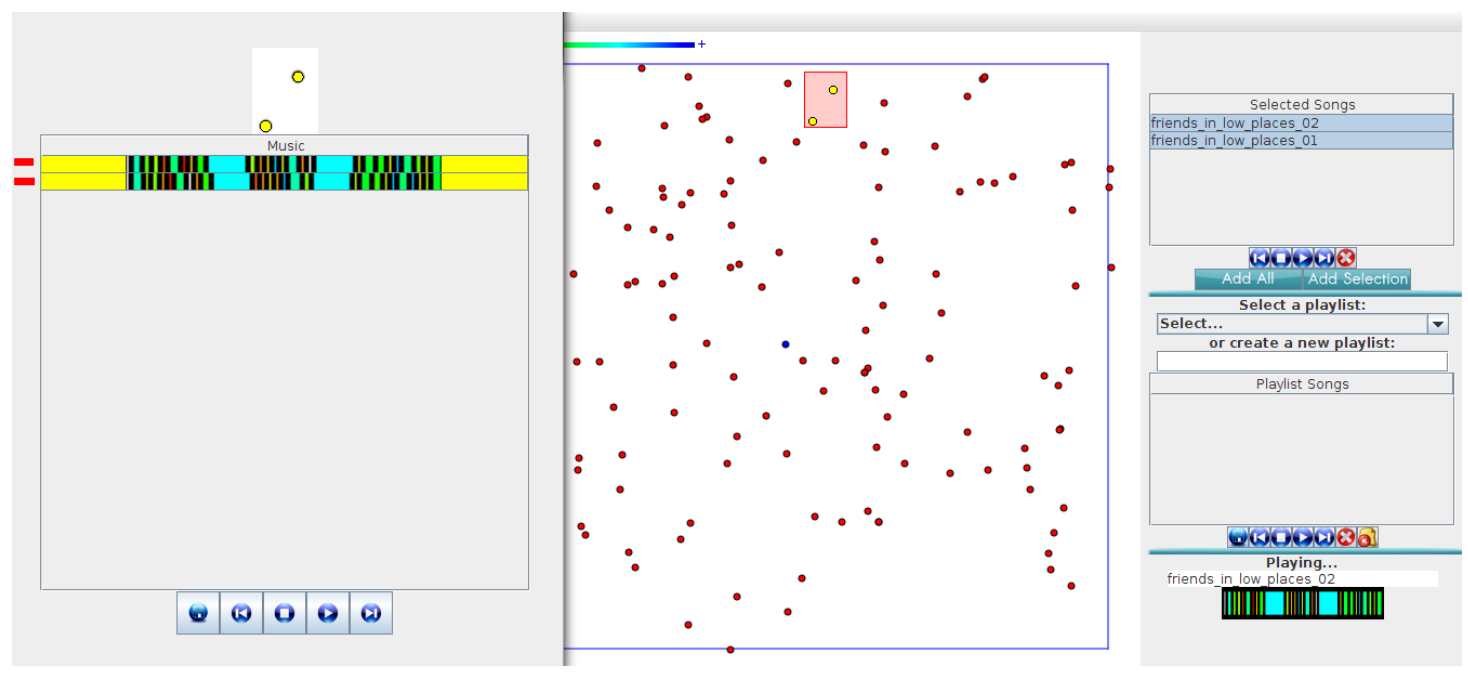

Figura 6.11: Representação iconográfica de uma seleção de músicas do mapa de similaridade, na qual nota-se que foram posicionadas como vizinhas duas versões distintas da música Friends in low places de Garth Brooks.

\subsection{Experimento 3: Estrutura versus gênero}

Este experimento visa mostrar a efetividade da representação icônica para destacar as semelhanças subjacentes em vários gêneros musicais. A Figura 6.13 mostra o layout obtido com a LSP, da coleção previamente descrita, na qual as músicas clássicas estão representadas por círculos azuis, as músicas do gênero rock representadas por círculos vermelhos e as músicas do gênero sertanejo representadas por círculos verdes.

O layout LSP separa claramente as músicas de diferentes gêneros, e mostra que as características propostas podem discriminar estas classes distintas de músicas. As representações icônicas dos grupos selecionados ilustram as estruturas subjacentes da cada música selecionada. Note a similaridade das estruturas das músicas que pertencem ao mesmo gênero, o que confirma a efetividade da representação icônica, a qual permite uma comparação visual das músicas.

Uma análise semelhante pode ser feita a partir da Figura 6.14, que exibe um mapa da 


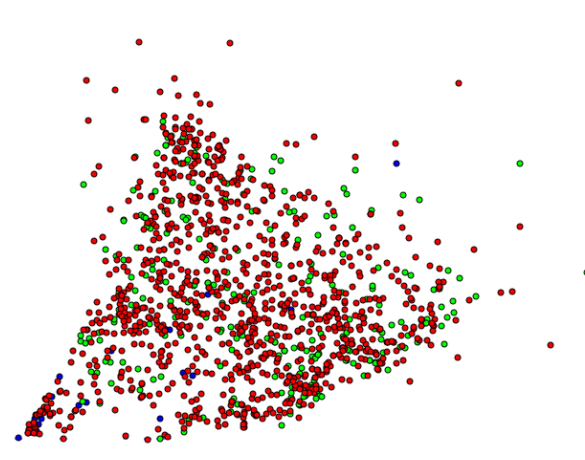

(a) Histogramas

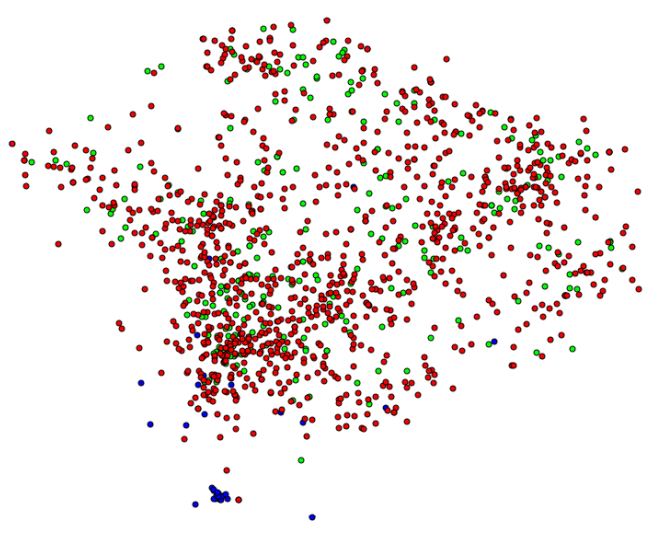

(c) JSymbolic

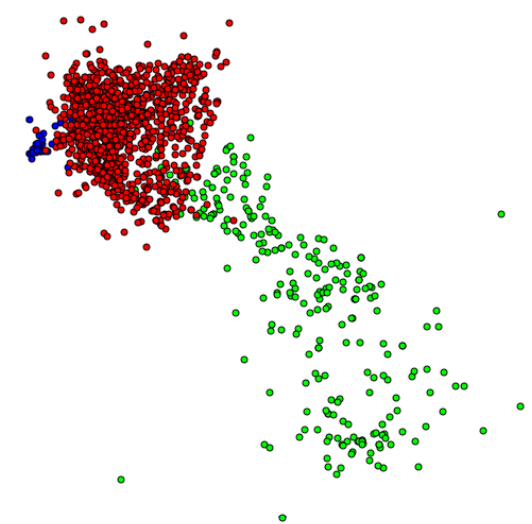

(e) Estruturas Musicais

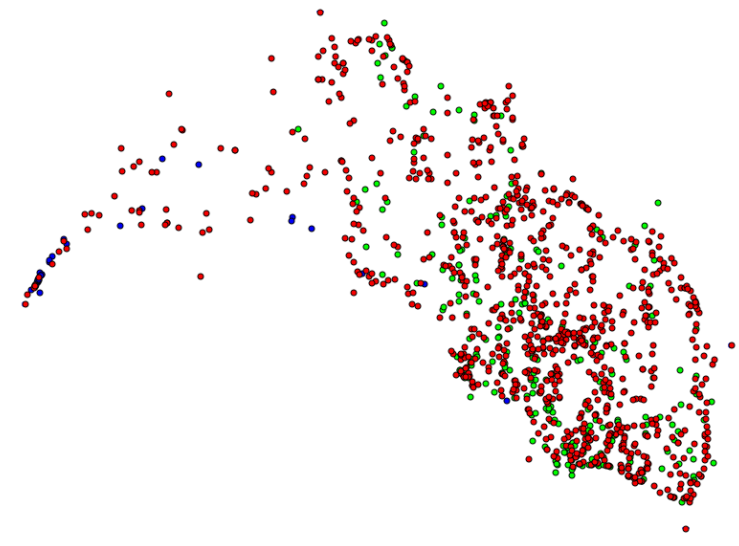

(d) Mp3

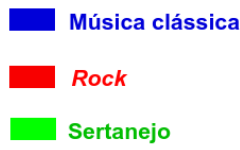

Figura 6.12: Projeções do conjunto de 1.300 músicas geradas com a $L S P$ a partir dos vetores de características obtidos por meio das técnicas de extração. As cores dos círculos indicam o gênero musical, azul para música clássica, vermelho para rock e verde para sertanejo. 
coleção anterior, à qual foram incluídas 96 músicas do gênero jazz mostradas em cinza. A visualização sugere que a estrutura subjacente da música clássica e do jazz são similares, pois elas são significativamente sobrepostas no layout. Isto pode ser confirmado na Figura 6.15, que mostra exemplos dos ícones da estrutura, para uma seleção de músicas em um desses dois gêneros.

Ressalta-se que esses resultados foram discutidos com um maestro, que confirmou que uma característica distintiva das composições clássicas e de jazz é a ausência de uma estrutura homogênea, no que se diferenciam consideravelmente da música pop-rock. Os ícones dessas músicas têm tipicamente poucos blocos bem definidos, que se repetem 2 ou 3 vezes ao longo da música.
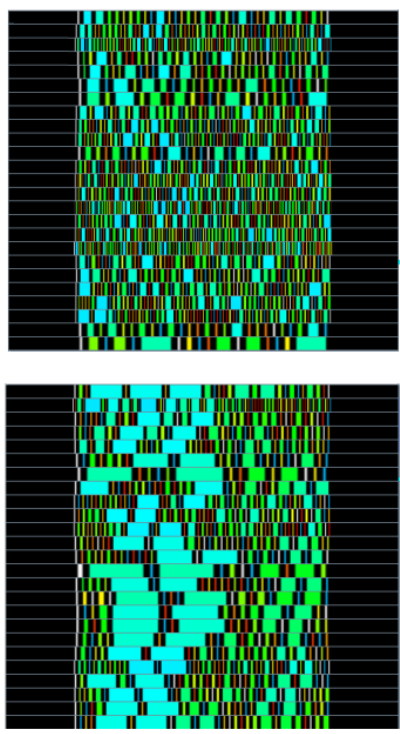
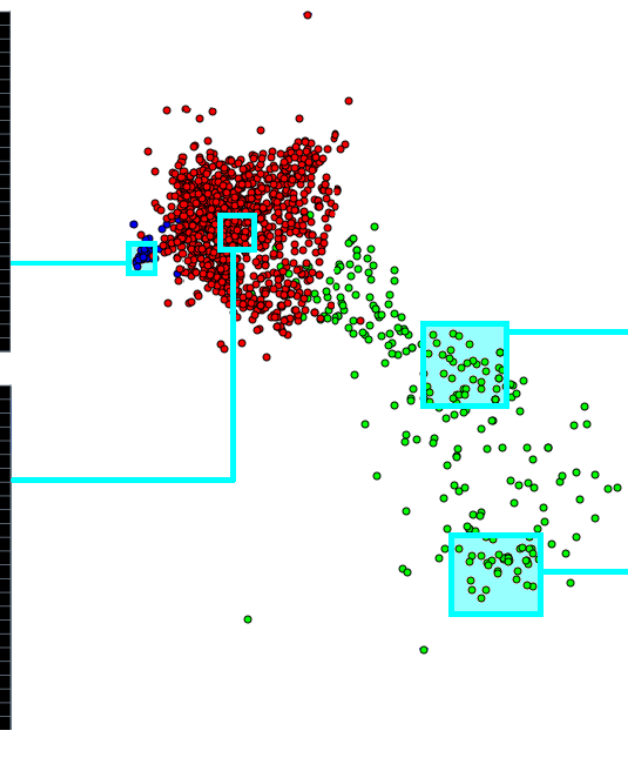
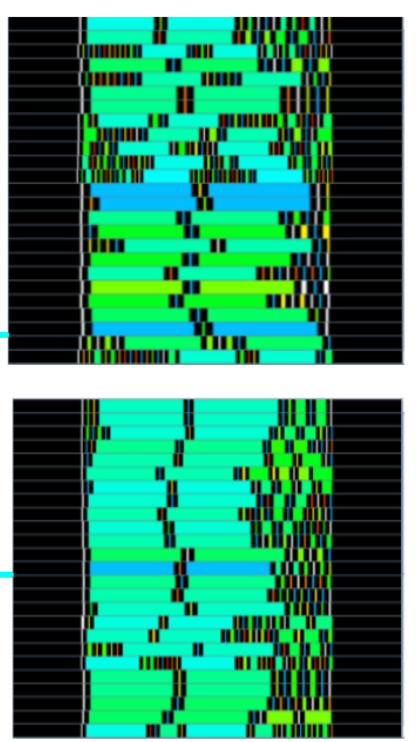

Figura 6.13: Mapa de similaridades de 1.300 músicas, com mostras de música clássica (azul), rock (vermelho) e sertanejo (verde), e seus ícones musicais relativos ás seleções.

Os ícones nas visões detalhadas são empilhados de acordo com as suas similaridades calculadas no layout. O primeiro ícone é o centroide da seleção, e os seguintes são listados em ordem crescente de dissimilaridade em relação ao primeiro. Além disso, todos os ícones selecionados são apresentados com tamanhos iguais, embora as músicas sejam representadas por vetores de características, de diferentes comprimentos. Os sinais (como foi discutido no Capítulo 5) são interpolados de modo que tenham o mesmo tamanho do maior sinal, o que produz uma representação visualmente mais agradável.

Esta representação icônica é a base da representação de distribuição espacial. Por meio da representação por distribuição espacial pode-se obter uma visão global da distribuição das músicas, gerando uma visualização resumo das estruturas das músicas localizadas em diferentes regiões do mapa. Foi aplicada a representação por distribuição espacial, ao conjunto anteriormente descrito. Assim, a Figura 6.16 exibe o resultado desta 

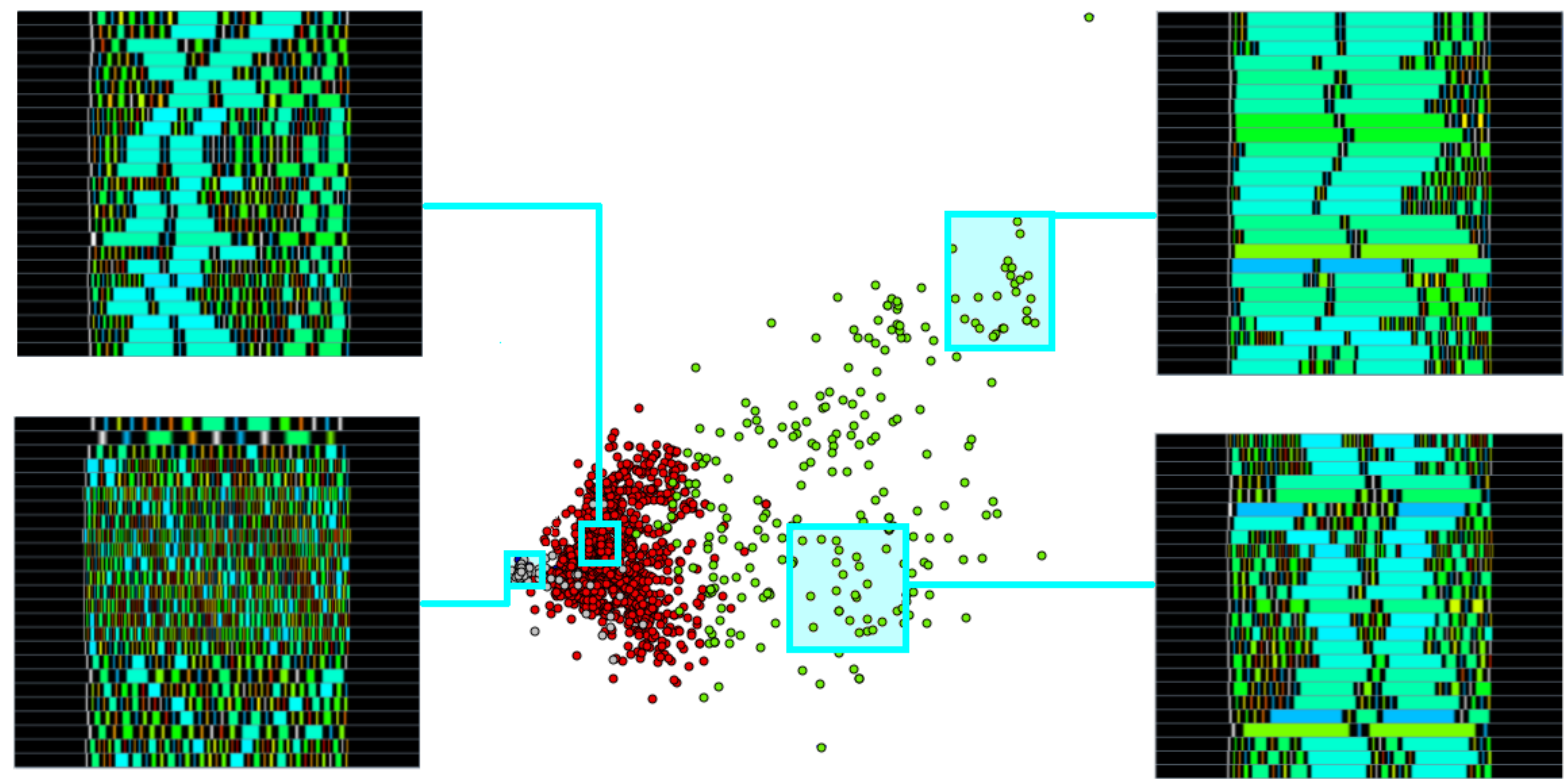

Figura 6.14: Mapa de similaridades de 1.396 músicas, com mostras de música clássica (azul), jazz (cinza), rock (vermelho) e sertanejo (verde), e seus ícones musicais relativos ás seleções.

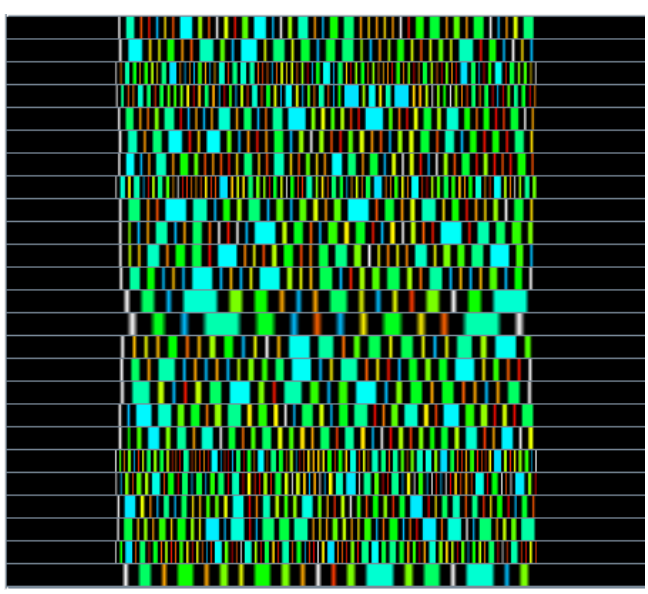

(a) jazz

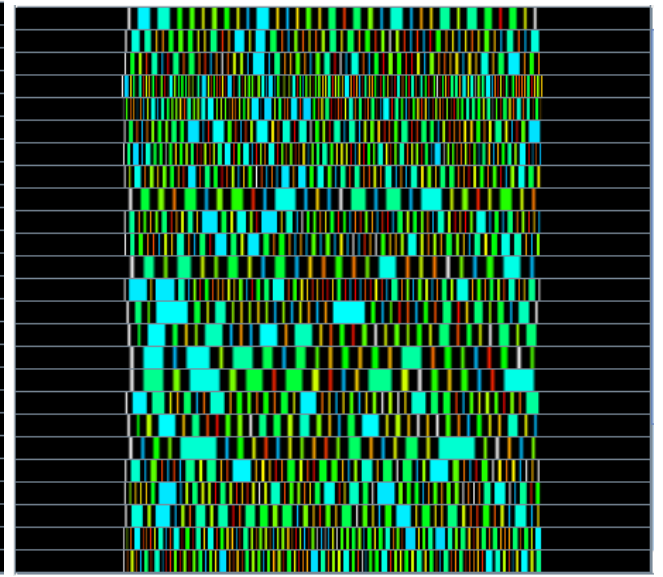

(b) música clássica

Figura 6.15: Ícones das estruturas para exemplos de jazz e música clássica na coleção.

metáfora para o conjunto de músicas. Para este exemplo, para a representação de distribuição espacial, foi definida uma grade regular de tamanho $3 \times 10$. Para a representação de distribuição espacial de vários ícones por célula, foi definido como máximo 5 ícones, note-se que as células com menor quantidade de pontos possuem menor quantidade de ícones. Note-se que a seção $B$ concentra músicas do gênero sertanejo, que apresentam estruturas simples o qual pode ser observado pelo resumo dos ícones apresentados em cada célula. A seção $A$ inclui músicas clássicas e de rock, e os ícones do seu resumo revelam estruturas mais complexas. No entanto, esta representação precisa ser melhorada, 
pois apresenta muitas regiões vazias, decorrentes da distribuição das músicas no mapa de similaridade.

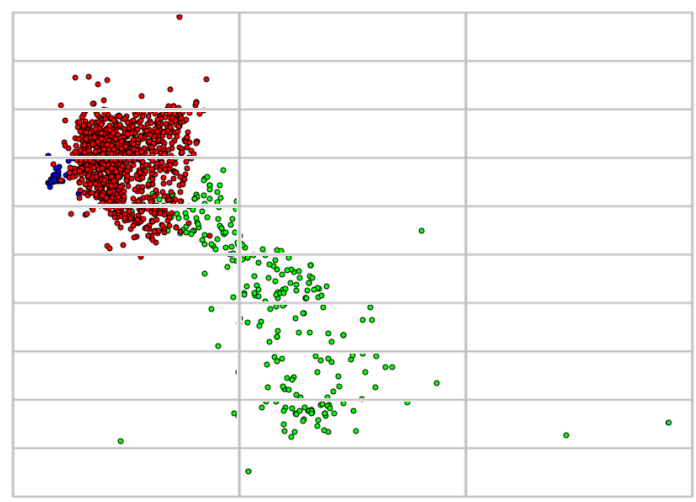

(a) Pontos originais

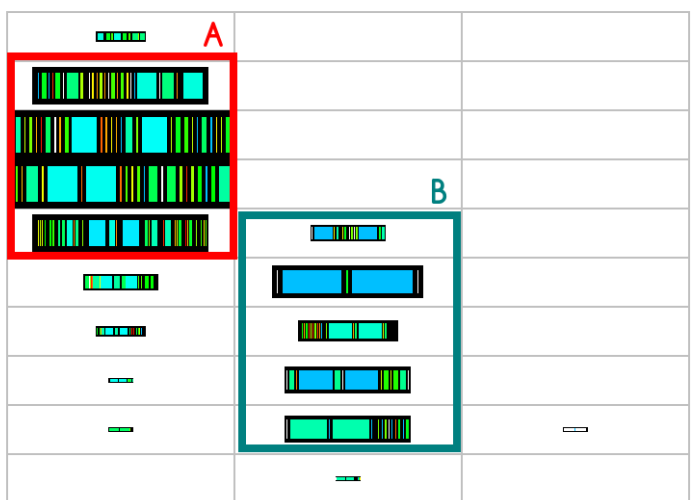

(b) Apenas um ícone representativo por célula

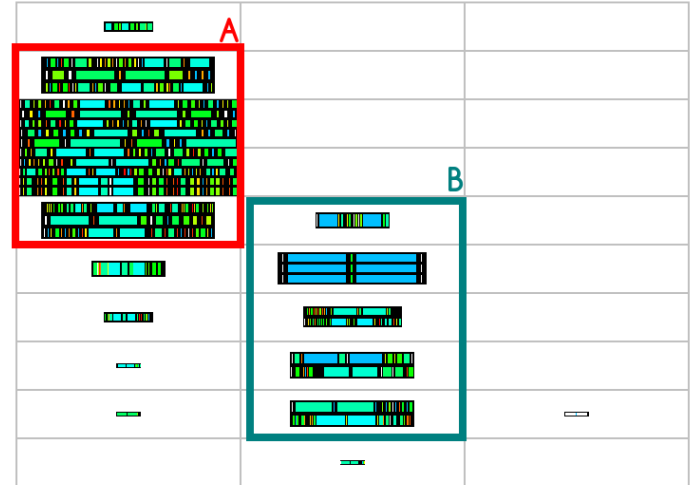

(c) Vários ícones representativos por célula

Figura 6.16: Metáfora de ícones representativos por célula da projeção do conjunto de 1.300 músicas.

\subsection{Experimento 4: Identificando versões das músicas}

Este experimento tem por objetivo ilustrar que a representação icônica permite identificar as mesmas músicas, mas em diferentes versões, ou seja, cujos arquivos MIDI foram codificados com diferentes recursos, por exemplo, em termos de instrumentos, tempo, entre outros. A Figura 6.17 apresenta os ícones criados relativos a diversas versões de músicas do grupo musical $A B B A$ e dos Beatles contidas na coleção. Os arquivos MIDI das músicas populares, como rock ou sertanejo, são muitas vezes criados por voluntários e para diferentes fins, e não necessariamente aderem a um padrão de qualidade estabelecido. A qualidade dos resultados é possivelmente afetada pelos diversos níveis de motivação, capacidade e objetivos do usuário, ao contrário das codificações de alta qualidade forne- 
cidas por gravadoras ou por usuários especialistas. É interessante comparar versões da mesma música codificadas em arquivos MIDI criados por diferentes usuários. Os ícones revelam claramente similaridades e diferenças, devido à qualidade variável das codificações, ao uso de diferentes instrumentos musicais, ou diferentes execuções das músicas.

As variações são claramente perceptíveis quando os MIDIs são reproduzidos e ao examinar as partituras correspondentes, as quais foram obtidas com a ferramenta Tuxguitar $^{1}$. Podem-se inspecionar alguns casos específicos em nossa coleção. Por exemplo, temos dois arquivos MIDI distintos que codificam a música Dancing Queen. A versão 1 inclui 89 compassos, enquanto a versão 2 tem 99 compassos. Isto introduz variações nos ícones, pois na extração das características é extraído um acorde por compasso. Na versão 2 a música é tocada um pouco mais rápido, e a partitura correspondente do MIDI revelou que é um pouco mais complexa do que a versão 1. Inspecionando os ícones correspondentes, observa-se as diferenças que são também perceptíveis ao ouvir as músicas. Uma análise semelhante aplica-se as duas codificações da música Fernando. Ao ouvir as duas versões, observa-se que uma é claramente de melhor qualidade. Por outro lado, existem algumas variações sutis nas codificações das outras músicas do ABBA, como Knowing you knowing me, Mamma Mia e Money, money, money. Por exemplo, a versão 1 do MIDI Knowing you knowing me é um pouco mais acelerada, e a versão 2 possui uma partitura mais complexa. Mais uma vez, as variações são perceptíveis nas representações dos ícones.

Alguns outros exemplos de músicas dos Beatles são apresentados. A versão 2 da música Can't buy me love novamente tem um ritmo um pouco mais rápido e os finais das duas versões são bastante diferentes. A versão 1 acaba abruptamente, enquanto que a versão 2 termina com uma melodia suave. Uma situação similar ocorre com a música I'll cry instead. As versões da música Tell me why são bastante semelhantes, mas os ícones não são idênticos. Ao ouvir as músicas notou-se que a codificação 1 utiliza mais instrumentos e é de melhor qualidade. No caso da música Help, a versão 2 tem uma introdução mais longa e um ritmo mais rápido em comparação com a versão 1. A música I need you tem ícones muito semelhantes, mas a diferença principal encontra-se na introdução. Aparentemente, a codificação da versão 2 é de melhor qualidade.

\subsection{Experimento 5: Variações temporais de uma banda}

O objetivo deste experimento é ilustrar a efetividade das representações icônicas na exploração da produções de uma banda ou artista ao longo do tempo. A Figura 6.18 mos-

\footnotetext{
${ }^{1}$ http://tuxguitar.herac.com.ar/ - 05/2013
} 


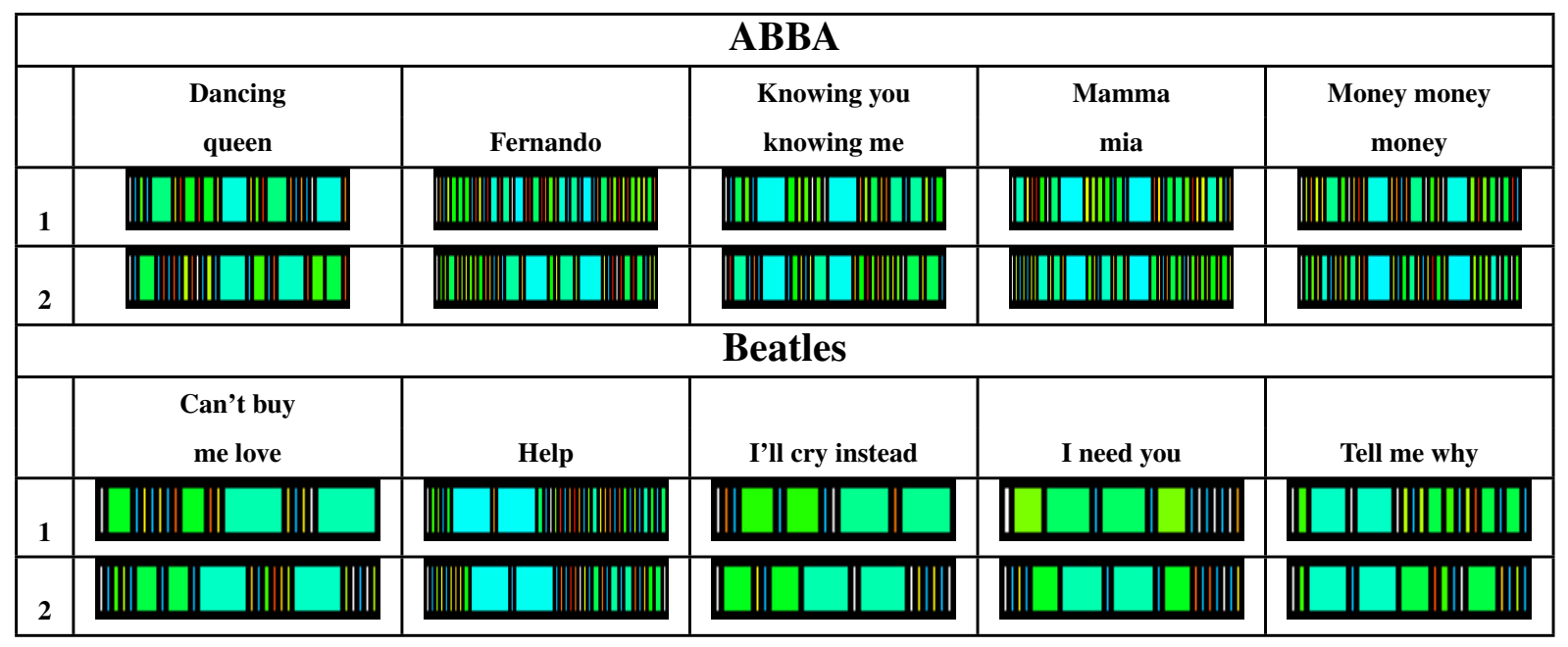

Figura 6.17: Os ícones musicais revelam diferencias em múltiplas versões (arquivos MIDI) de uma música.

tra uma projeção de 370 músicas dos Beatles que foram agrupadas em duas janelas de tempo, uma referente a músicas de suas primeiras produções, de 1963 a 1965 (círculos azuis), e outra relativas a música lançadas de 1966 a 1988 (círculos vermelhos). A Figura 6.18 também detalha as estruturas musicais relativas a ambos períodos, mostrando os ícones para duas seleções das músicas de cada período temporal. Seus padrões estruturais são claramente bastante distintos, confirmando a segmentação temporal observada na distribuição espacial das músicas no mapa de similaridade, com a concentração das músicas antigas na região esquerda. Esse experimento ilustra como as representações visuais podem suportar investigações exploratórias da produção de um artista ou banda ao longo do tempo. Vale destacar que não temos conhecimento de alguma outra ferramenta visual capaz de apoiar tal tarefa.

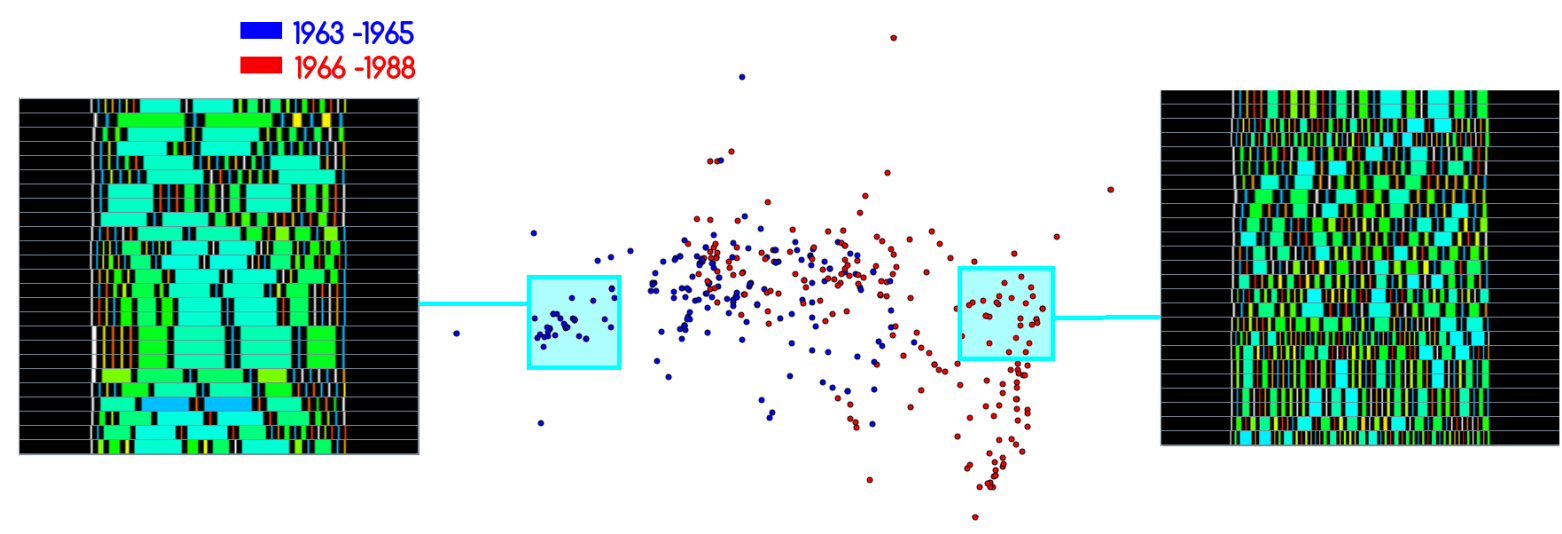

Figura 6.18: Visão geral das músicas do Beatles, em diferentes épocas da sua produção, e as vistas detalhadas das estruturas das músicas de cada período considerado. 


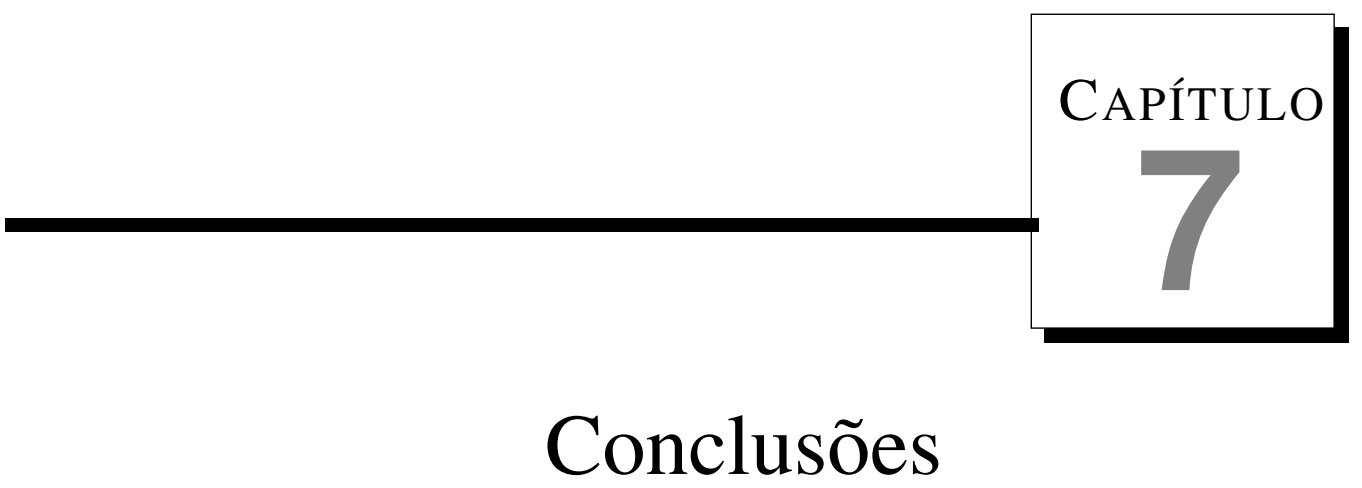

Se um homem não tem o seus conhecimentos em ordem, quanto mais tiver, maior será a confusão (Spencer).

Este trabalho explorou o problema de representar visualmente os layouts gerados por técnicas de projeção multidimensional, dando uma representação alternativa às comumente usadas nuvens de pontos no espaço bidimensional, em que círculos ou pontos representam cada instância do conjunto de dados.

O foco desta dissertação foi centrado no tratamento de conjuntos de músicas em formato MIDI. Assim, descrevemos uma interface visual baseada em uma metáfora gráfica visando transmitir as estruturas musicais presentes em cada música, denominada representação icônica. Esta representação é baseada na extração de sequências de acordes significativos, o que permite a criação de um vetor de características que serve tanto para codificar uma representação visual para a música quanto para calcular a similaridade entre pares de músicas. Esta representação icônica foi integrada ao layout, o qual fornece um posicionamento espacial das músicas que reflete as suas semelhanças estruturais. Os posicionamentos espaciais baseados na similaridade foram obtidos com a técnica LSP e usando a distância DTW para avaliar as similaridades. Além disso, foi proposta a representação por distribuição espacial, que também integra os layouts com a representação icônica, mas fornecendo um resumo visual das músicas em uma grade.

Foram apresentados vários exemplos que ilustram como as visualizações propostas podem apoiar algumas tarefas de exploração da música, que não são suportadas por so- 
luções existentes. Os resultados ilustram cenários de uso interessantes, em comparação com o que pode ser inferido a partir de visualizações obtidas com o uso de outros tipos de características. Como mostram os resultados apresentados, a abordagem proposta é bastante flexível e permite identificar visualmente agrupamentos, versões diferentes das mesmas músicas e mudanças temporais no estilo musical de um determinado artista ou banda.

Em resumo, as principais contribuições deste trabalho são:

- Uma representação por densidade para representar conjuntos de dados alternativa à representação por nuvem de pontos dos layouts, gerados por projeções multidimensionais.

- Uma nova metodologia para extrair características estruturais de músicas em formato MIDI que permite a identificação de peças musicais similares, assim como visualizar apenas uma música ou um conjunto delas ou uma coleção inteira.

- Uma representação icônica da estrutura das composições musicais. Tal representação icônica permite uma análise unificada de um conjunto de músicas, tornando possível identificar as semelhanças em músicas de distintos gêneros, arranjos harmônicos e ritmos.

- Um mecanismo interativo que combina a representação icônica com as projeções multidimensionais, o qual torna a análise de coleções de músicas uma tarefa mais natural.

\subsection{Discussões, limitações e trabalhos futuros}

O uso de uma mesma representação subjacente para gerar uma visualização das músicas de forma individual e para avaliar as similaridades entre elas permite a criação de uma visualização flexível que suporta varias tarefas exploratórias em uma coleção de músicas. Estas tarefas incluem a identificação de diferentes versões da mesma música, identificação de gravações de características e qualidades distintas, o que permite observar as variações através de vários gêneros musicais e variações estruturais no tempo nas produções de uma banda ou artista.

As comparações das features utilizadas com outros tipos de características extraídas das músicas ilustram claramente o potencial da representação proposta para distinguir músicas com tipos de estruturas diferentes e ressaltar similaridades e dissimilaridades entre elas. 
Confirmou-se que a estrutura musical, expressa em termos de repetições de acordes identificados ao longo da música, fornece as características que permitem identificar gêneros musicais distintos, além de adicionar a vantagem de produzir uma visualização sucinta que é simples e facilmente interpretável.

A escalabilidade é uma das principais limitações da versão atual das representações. Os layouts resultantes de projetar conjuntos de dados com técnicas de projeção multidimensionais tendem à sobreposição, dificultando a navegação e interação. Isso inviabiliza a integração direta dos ícones na representação do mapa de similaridade. Assim, apresentamos os ícones em uma lista, quando ocorre uma seleção do usuário, mas outras soluções podem ser investigadas. A representação baseada em densidades foi pouco explorada nesse contexto. Outras tentativas foram abordadas com algumas funcionalidades de detalhe e com a representação da distribuição espacial, em uma grade. Esta representação tinha por objetivo integrar as duas formas da representação, mas o resultado deixa a desejar. A visualização tem muitos espaços vazios, e apenas um subconjunto reduzido das músicas é exibido. Os espaços vazios poderiam ser tratados com algum operador Seam carving (Yingcai Wu e Ma, 2011), mas outras estratégias seriam necessárias para tornar a visualização de mapa de similaridade mais informativa. 



\section{Referências Bibliográficas}

AndrienKo, G.; Andrienko, N. Blending aggregation and selection: Adapting parallel coordinates for the visualization of large datasets. The Cartographic Journal, v. 42, n. 1, p. 49-60, 2005.

Berndt, D.; Clifford, J. Using dynamic time warping to find patterns in time series. In: Workshop on Knowledge Discovery in Databases (KDD), 1994, p. 359-370.

Burkhard, R.; Meier, M. Tube map: Evaluation of a visual metaphor for interfunctional communication of complex projects. In: 4th International Conference on Knowledge Management (I-Know), 2004, p. 449-456.

CARrizo, S. Phylogenetic trees: an information visualisation perspective. In: 2nd Conference on Asia-Pacific bioinformatics, 2004, p. 315-320.

Chalmers, M. A linear iteration time layout algorithm for visualising highdimensional data. 1996, p. 127.

Cox, T. F.; Cox, M. A. A. Multidimensional scaling. Chapman and Hall - CRC, second edition, 2000.

Dalhuijsen, L.; Velthoven, L. Musicalnodes: the visual music library. In: International conference on Electronic Visualisation and the Arts, 2010, p. 232-236.

ELER, D.; Minghim, R. Múltiplas visões coordenadas para exploração de mapas de similaridade. Tese de Doutoramento, Instituto de Ciências Matemáticas e de Computação, Universidade de São Paulo, 2010.

ElmQvist, N.; FeKete, J. Hierarchical aggregation for information visualization: Overview, techniques, and design guidelines. IEEE Transactions on Visualization and Computer Graphics, v. 16, n. 3, p. 439-454, 2010. 
Faloutsos, C.; Lin, K. Fastmap: A fast algorithm for indexing, data mining and visualization of traditional and multimedia databases. International Conference on Management of Data (SIGMOD), p. 163-174, 1995.

Finkel, R.; Bentley, J. Quad trees a data structure for retrieval on composite keys. Acta informatica, v. 4, n. 1, p. 1-9, 1974.

Foote, J. Visualizing music and audio using self-similarity. In: 7th Association for Computing Machinery (ACM) International conference on Multimedia, 1999, p. 77-80.

Gershon, N. D. From perception to visualization. Computer graphics, v. 26, n. 2, p. 414-415, 1992.

InselberG, A.; Dimsdale, B. Parallel coordinates: A tool for visualizing multidimensional geometry. In: 1st IEEE Conference on Visualization, 1990, p. 361-378.

Joia, P.; Coimbra, D.; Cuminato, J.; Paulovich, F.; Nonato, L. Local affine multidimensional projection. IEEE Transactions on Visualization and Computer Graphics, v. 17, n. 12, p. 2563-2571, 2011.

Jolliffe, I. T. Principal component analysis. Springer-Verlag, 1986.

KoHonen, T. The self-organizing map. IEEE, v. 78, n. 9, p. 1464-1480, 1990.

Lartillot, O.; Toiviainen, P.; Eerola, T. A matlab toolbox for music information retrieval. In: 31st Conference of the German Classification Society (GfKl), 2007, p. 261-268.

LEVITIN, A. Introduction to the design \& analysis of algorithms. Addison-Wesley Reading, MA, 2003.

LILliE, A. Musicbox: Navigating the space of your music. Tese de Doutoramento, Massachusetts Institute of Technology, 2008.

MACHADO, B. Exploração visual do espaço de características: uma abordagem para análise de imagens via projeção de dados multidimensionais. Dissertação de Mestrado, Instituto de Ciências Matemáticas e de Computação, Universidade de São Paulo, 2010 .

MacQueEn, J. B. Some methods for classification and analysis of multivariate observations. In: 5th Berkeley Symposium on Mathematical Statistics and Probability, 1967, p. 281-297. 
McKay, C. Automatic music classification with jmir. Tese de Doutoramento, McGill University, Montreal, Canada, 2010.

Minghim, R.; Paulovich, F. V.; Lopes, A. A. Content-based text mapping using multidimensional projections for exploration of document collections. Symposium on Electronic Imaging - Visualization and Data Analysis, v. 6060, p. 60600S, 2006.

Muelder, C.; Provan, T.; MA, K. Content based graph visualization of audio data for music library navigation. In: IEEE International Symposium on Multimedia (ISM), 2010, p. 129-136.

MÜLLER, M.; JIANG, N. A scape plot representation for visualizing repetitive structures of music recordings. In: 13th International Society for Music Information Retrieval Conference, 2012, p. 97-102.

Neumayer, R.; Lidy, T.; RAuber, A. Content-based organization of digital audio collections. In: 5th Open Workshop of Musicnetwork, 2005.

Paiva, J.; Florian, L.; Pedrini, H.; Telles, G.; Minghim, R. Improved similarity trees and their application to visual data classification. IEEE Transactions on Visualization and Computer Graphics, v. 17, n. 12, p. 2459-2468, 2011.

PAMPALK, E. Islands of music: Analysis, organization, and visualization of music archives. Dissertação de Mestrado, University of Technology, Vienna, Austria, 2001.

PAulovich, F. Mapeamento de dados multi-dimensionais-integrando mineração e visualização. Tese de Doutoramento, Instituto de Ciências Matemáticas e de Computação, Universidade de São Paulo, 2008.

Paulovich, F.; Eler, D.; Poco, J.; Nonato, L.; Botha, C.; Minghim, R. A fast projection technique and its applications to visualization of large data sets. Relatório Técnico, 2010.

Paulovich, F.; Minghim, R. Hipp: A novel hierarchical point placement strategy and its application to the exploration of document collections. IEEE Transactions on Visualization and Computer Graphics, v. 14, n. 6, p. 1229-1236, 2008.

Paulovich, F.; Nonato, L.; Minghim, R.; LeVkowitz, H. Least square projection: A fast high-precision multidimensional projection technique and its application to document mapping. IEEE Transactions on Visualization and Computer Graphics, v. 14, n. 3, p. 564-575, 2008. 
Paulovich, F. V.; Minghim, R. Text map explorer: a tool to create and explore document maps. 10th International Conference on IEEE Information Visualisation, p. 245-251, 2006.

PEKALSKA, E. M. Dissimilarity representations in pattern recognition. concepts, theory and applications. Tese de Doutoramento, Wroclaw University, 2005.

PolAnCO, X.; ZARTL, A. Information visualization. EICSTES Project. Deliverable, v. 1, 2002.

RoweIS, S.; S AUL, L. Nonlinear dimensionality reduction by locally linear embedding. Science, v. 290, n. 5500, p. 2323-2326, 2000.

SAitou, N.; NeI, M. The neighbor-joining method: a new method for reconstructing phylogenetic trees. Molecular biology and evolution, v. 4, n. 4, p. 406-425, 1987.

SAMMON, J. A nonlinear mapping for data structure analysis. IEEE Transactions on Computers, v. 18, n. 5, p. 401-409, 1969.

Silva, V.; Tenenbaum, J. B. Global versus local methods in nonlinear dimensionality reduction. Advances in neural information processing systems, v. 15, p. 705-712, 2003.

Souza PaIVA, J. Técnicas computacionais de apoio para a classificação visual de imagens. Tese de Doutoramento, Instituto de Ciências Matemáticas e de Computação, Universidade de São Paulo, 2011.

Tejada, E.; Minghim, R.; Nonato, L. On improved projection techniques to support visual exploration of multi-dimensional data sets. Information Visualization, v. 2, n. 4, p. 218-231, 2003.

Tenenbaum, J. B.; Silva, V.; Langford, J. C. A global geometric framework for nonlinear dimensionality reduction. Science, v. 290, n. 5500, p. 2319-2323, 2000.

Torrens, M.; Hertzog, P.; Arcos, J. Visualizing and exploring personal music libraries. In: 5th International Conference on Music Information Retrieval (ISMIR), 2004, p. 421-424.

Tzanetakis, G.; ERmolinskyi, A.; CoOK, P. Pitch histograms in audio and symbolic music information retrieval. In: 3rd International Conference on Music Information Retrieval (ISMIR), 2002, p. 31-38. 
Valdivia, A.; Paulovich, F.; Minghim, R.; Telles, G. Point placement by phylogenetic trees and its application for visual analysis of document collections. In: IEEE Symposium on Visual Analytics Science and Technology (VAST), 2007, p. 99-106.

VAn Den Bergen, G. Efficient collision detection of complex deformable models using aabb trees. Journal of Graphics Tools, v. 2, n. 4, p. 1-13, 1997.

VAn GuliK, R.; Vignoli, F. Visual playlist generation on the artist map. In: 6th International Conference on Music Information Retrieval (ISMIR), 2005, p. 520-523.

VAN Liere, R.; De LeEuW, W. Graphsplatting: Visualizing graphs as continuous fields. IEEE Transactions on Visualization and Computer Graphics, v. 9, n. 2, p. 206212, 2003.

Wattenberg, M. Arc diagrams: Visualizing structure in strings. In: IEEE Symposium on Information Visualization (InfoVis), 2002, p. 110-116.

Westover, L. Splatting: a parallel, feed-forward volume rendering algorithm. Tese de Doutoramento, University of North Carolina at Chapel Hill, 1991.

Wold, H. Partial least squares. Encyclopedia of Statistical Sciences, v. 6, p. 581-591, 1985.

Wolkowicz, V.; Brooks, S.; Keselu, V. Midivis: Visualizing music pieces structure via similarity matrices. In: International Computer Music Conference (ICMC), 2009.

YANG, C. Music database retrieval based on spectral similarity. International Symposium on Music Information Retrieval, p. 349-352, 2001.

Yingcai Wu, Thomas Provan, F. W. S. L.; Ma, K.-L. Semantic-preserving word clouds by seam carving. Computer Graphics Forum, v. 30, n. 3, p. 741-750, 2011.

ZhANG, J.; OWEn, C. Octree-based animated geometry compression. In: Data Compression Conference, 2004, p. 508-517.

Zhou, H.; Cui, W.; Qu, H.; Wu, Y.; Yuan, X.; Zhuo, W. Splatting the lines in parallel coordinates. In: Computer Graphics Forum, 2009, p. 759-766. 